Aus der Abteilung Gastroenteropathologie (Prof. Dr. med. L. Füzesi)

im Zentrum Pathologie und Rechtsmedizin

der Medizinischen Fakultät der Universität Göttingen

\title{
Molekularzytogenetische Veränderungen bei \\ kolorektalen Karzinomen und Lebermetastasen \\ kolorektaler Karzinome
}

\author{
INAUGURAL-DISSERTATION \\ zur Erlangung des Doktorgrades \\ der Medizinischen Fakultät \\ der Georg-August-Universität zu Göttingen
}

\author{
vorgelegt von \\ Susanne Richter \\ aus \\ Bad Hersfeld
}

Göttingen 2012 
Dekan: Prof. Dr. med. C. Frömmel

I. Berichterstatter: Prof. Dr. med. L.Füzesi

II. Berichterstatter/in: Prof. Dr. rer. nat. P.Burfeind

III. Berichterstatter/in: Priv.-Doz. Dr. med. T.Liersch

Tag der mündlichen Prüfung: 26. November 2012 


\section{$\underline{\text { Inhaltsverzeichnis }}$}

$\begin{array}{ll}\text { 1.Einleitung } & \text { S.5 }\end{array}$

1.1 Kolorektale Karzinome $\quad S .5$

$\begin{array}{ll}1.2 \text { Therapiestrategie KRK } & \mathrm{S} .13\end{array}$

$\begin{array}{ll}1.3 \text { Metastasierung KRK } & \mathrm{S} .17\end{array}$

1.4 Molekulare Grundlagen KRK und der korrespondierenden Metastasen $\quad$ S.19

$\begin{array}{ll}1.5 \text { Fragestellung und Ziele der Arbeit } & \text { S.22 }\end{array}$

$\begin{array}{ll}\text { 2.Material und Methoden } & \text { S.23 }\end{array}$

2.1 Darstellung des Kollektivs $\quad$ S.23

$\begin{array}{ll}2.2 \text { Material } & \text { S.24 }\end{array}$

$\begin{array}{ll}2.3 \text { Methoden } & \text { S.27 }\end{array}$

$\begin{array}{ll}2.4 \text { Statistische Methoden } & \text { S.38 }\end{array}$

$\begin{array}{ll}2.5 \text { Ethische Aspekte } & \text { S.39 }\end{array}$

$\begin{array}{lr}\text { 3.Ergebnisse } & \text { S.40 }\end{array}$

3.1 Auswertung der 25 PT KRK und ihrer korrespondierenden 29 Met S.40

3.2 Auswertung der PT aller Patienten ( $n=93)$ des Kollektivs $\quad$ S.54

3.3 Auswertung aller untersuchten PT KRK $(n=34)$ und aller untersuchten Met $(n=102)$ 
$\begin{array}{ll}4.2 \text { Bewertung der Methode CGH } & \text { S. } 68\end{array}$

4.3 Diskussion der chromosomalen Aberrationen der 25 PT von 25 Patienten mit PT KRK $\begin{array}{lr}\text { und korrespondierenden Met } & \text { S. } 69\end{array}$

4.4 Diskussion der chromosomalen Aberrationen der korrespondierenden Met $(n=29)$ von 25 Patienten mit PT KRK

4.5 Diskussion der chromosomalen Aberrationen der 34 untersuchten PT KRK $\quad$ S. 72

4.6 Diskussion der chromosomalen Aberrationen aller Met $(n=102) \quad S .73$

4.7 Diskussion ausgewählter chromosomaler Aberrationen in Bezug der jeweiligen Gene $\begin{array}{lr}\text { und ihrer Funktion } & \text { S.75 }\end{array}$

$\begin{array}{lr}\text { 4.8 Ausblick } & \text { S.79 }\end{array}$

$\begin{array}{ll}\text { 5.Zusammenfassung } & \text { S.81 }\end{array}$

$\begin{array}{ll}\text { 6. Literaturverzeichnis } & \text { S.84 }\end{array}$

$\begin{array}{ll}\text { 7.Abbildungs- und Tabellenverzeichnis } & \text { S.96 }\end{array}$ 


\section{Einleitung}

\subsection{Kolorektale Karzinome}

\subsubsection{Epidemiologie}

Das kolorektale Karzinom (KRK) ist mit über 70000 Neuerkrankungen und ca. 30000 Todesfällen/ Jahr in Deutschland einer der häufigsten malignen Tumoren [Schmiegel et al. 2008]. Das KRK ist die zweithäufigste Krebstodesursache bei Männern und die dritthäufigste bei Frauen [Jemal et al. 2002]. Männer sind etwas häufiger betroffen als Frauen, außerdem nimmt die Inzidenz mit dem Alter zu.

\subsubsection{Ursachen und Prävention KRK}

Die Ursachen sind multifaktoriell und reichen über genetische Prädisposition und Ernährungseinflüssen bis hin zu Umwelteinflüssen [Schmiegel et al. 2008]. Zu den schädlichen Nahrungsmitteln gehören gesättigte tierische Fette, ein hoher Eiweißgehalt der Nahrung, wenig Ballaststoffe, Nitrit-Pökelsalz, Chenodesoxycholsäure und Alkohol.

a) Lebensgewohnheiten

- Zur Risikoreduktion eines KRK sollte regelmäßig Sport betrieben werden und der BMI (body mass index) nicht größer $25 \mathrm{~kg} / \mathrm{m}^{2}$ sein. Der BMI errechnet sich aus dem Körpergewicht in kg/ Körpergröße in $\mathrm{m}^{2}$. Studien konnten zeigen, dass bereits 30-60 min körperliche Aktivität/Tag das Karzinomrisiko senkt [Lubin et al. 1997, Giacosa et al. 1999, Friedenreich und Orenstein 2002, Terry MB et al. 2002, Lee 2003, Wei et al. 2004].

- Rauchen ist mit einem erhöhten Risiko für Kolonadenome und -karzinome verbunden [Terry MB et al. 2002, Terry MB und Neugut 1998, Almendingen et al. 2000, Chao et al. 2000, Giovannucci 2001, Reid et al. 2003].

b) Ernährungsempfehlungen

- Zur Prophylaxe KRK wird eine ausreichende Ballaststoffzufuhr (30 g/d) empfohlen [Schmiegel et al. 2008]. 
- Auch eine erhöhte Zufuhr an Obst und Gemüse ist mit einer Reduktion des Risikos für Kolonadenome und -karzinome assoziiert. [Bingham et al. 2003, Peters et al. 2003, Terry P et al. 2001, Almendingen et al. 2001, Deneo- Pellegrini et al. 2002, Evans et al. 2002, Ghadirian et al. 1997, Normen et al. 2001].

- Mehrere Studien zeigten ein moderat erhöhtes Kolonkarzinomrisiko beim täglichen Verzehr von rotem und verarbeitetem Fleisch [Ghadirian et al. 1997, Zhang et al. 2002, Yoon et al. 2000, Voskuil et al. 2002, Norat et al. 2002, Fung et al. 2003, Giovannucci 2003]. Es sollte auch auf eine vermehrte Alkoholzufuhr, insbesondere in Verbindung mit reduzierter Folsäurezufuhr verzichtet werden.

- Zusätzlich scheint ein negativ synergistischer Effekt zwischen Rauchen und Alkoholgenuss zu bestehen. Das Risiko korreliert hierbei nicht mit der Art des alkoholischen Getränkes, sondern mit der aufgenommenen Alkoholmenge [Almendingen et al. 2001, Giovannucci 2003, Tiemersma 2003].

- Auch eine folsäurereiche Ernährung ist mit einem verminderten Karzinomrisiko assoziiert [Konings et al. 2002].

- Eine kalziumreiche Ernährung scheint auch mit einer Reduktion des Risikos für KRK einherzugehen [Wu et al. 2002].

\section{a) Medikamente}

In einigen Kohorten- und Fall-Kontrollstudien wurde eine verminderte Inzidenz KRK bei Einnahme von Aspirin beobachtet [Schmiegel et al. 2008]. Diese Ergebnisse wurden jedoch in anderen Studien nicht bestätigt [Schmiegel et al. 2008]. Obwohl es Hinweise gibt, dass eine Hormonersatztherapie bei Frauen zu einer Risiko-Reduktion für KRK führt [Prihartono et al. 2000, Nanda et al. 1999, Franceschi und La Vecchia 1998], sollten diese auf Grund der Nebenwirkungen (Mammakarzinom, Thromboserisiko) und des damit verbundenen negativen Gesamtnutzens nicht empfohlen werden [Nelson et al. 2002].

\subsubsection{Risikogruppen}

a) Risikogruppen des KRK

Für Verwandte 1. Grades (Eltern, Geschwister, Kinder) von Patienten mit KRK ist das mittlere Risiko 2-3fach erhöht. Eine weitere 3-4fache Risikosteigerung besteht, wenn der Indexpatient vor dem 60. LJ am KRK erkrankt und/oder mehr als ein Verwandter 1.Grades betroffen ist [St John et al. 1993, Kune et al. 1989, Guillem et al. 1992, Guillem et al. 1996, 
Johns und Houlston 2001, Lichtenstein et al. 2000]. Das Risiko ist für das Kolonkarzinom höher als für das Rektumkarzinom (relatives Risiko 2,4 vs. 1,9) außerdem ist das Risiko für Geschwister etwa 2,5x höher als für Kinder betroffener Personen. Wenn der Patient jedoch nach dem 60. LJ erkrankt, so ist das KRK-Risiko für Verwandte 1.Grades nur noch geringfügig erhöht [Johns und Houlston 2001]. Verwandte 1.Grades sollten also 10 Jahre vor dem Zeitpunkt des Auftretens beim Indexpatienten, jedoch spätestens mit 50 Jahren komplett koloskopiert werden. Bei jungen Indexpatienten in der Verwandtschaft sollte ein hereditäres nicht-polypöses Kolonkarzinom (HNPCC) ausgeschlossen und eine Mikrosatellitenanalyse und/ oder eine immunhistochemische Untersuchung der MismatchReparatur-Proteine durchgeführt werden [Schmiegel et al. 2008].

\section{b) Patienten mit kolorektalen Adenomen}

Jedes histologisch nachgewiesene Adenom stellt ein erhöhtes Risiko für KRK dar. Insbesondere Patienten mit mehr als drei Adenomen und Patienten mit Adenomen mit einer Größe über $1 \mathrm{~cm}$ sind gefährdet. Adenome mit einer Größe über $1 \mathrm{~cm}$ sind mit einem 4x erhöhten Karzinomrisiko verbunden [Atkin et al. 1992]. Multiple Adenome erhöhen das Risiko für KRK um den Faktor 4-6 [Atkin et al. 1992]. Ob hyperplastische Polypen als Präkanzerose beurteilt werden sollten, ist zu diesem Zeitpunkt noch nicht abschließend geklärt [Schmiegel et al. 2008].

\subsubsection{Hereditäre Kolonkarzinome}

KRK können auch vererbt werden. Zu nennen sind in diesem Zusammenhang die familiäre adenomatöse Polyposis (FAP) und das HNPCC oder Lynch-Syndrom, welche autosomaldominant vererbt werden.

A) Patienten mit familiärer adenomatöser Polyposis (FAP)

Patienten mit unbehandelter FAP entwickeln fast ausnahmslos ein KRK [Schmiegel et al. 2008]. Die FAP ist durch über 100 Adenome gekennzeichnet, die Polypenbildung beginnt meist im 2. Lebensjahrzehnt. Meist weisen die Patienten weitere extrakolische intestinale Manifestationen auf: 75\% zeigen Duodenal- bzw. Papillenadenome, welche ebenfalls als Präkanzerose zu werten sind, $<10 \%$ der Patienten weisen Magenadenome auf. Drüsenkörperzysten des Magens, die wenigstens bei 1/3 der Patienten auftreten, werden nicht als Präkanzerose angesehen. Weitere extraintestinale Manifestationen sind 
Desmoidtumoren, papilläre Schilddrüsenkarzinome, maligne ZNS-Tumoren (meist Medulloblastome), Hepatoblastome, Osteome, Epidermoidzysten oder Pigmentanomalien der Retina [Foulkes 1995].

Bei Verwandten eines FAP-Patienten sollte ab dem 10. LJ eine humangenetische Beratung und eine genetische Diagnostik durchgeführt werden. Wird eine Mutation nicht ausgeschlossen, sollte spätestens ab dem 10. Lebensjahr jährlich eine Sigmoidoskopie durchgeführt werden [Schmiegel et al. 2008]. Patienten mit klassischer FAP sollten außerdem prophylaktisch, wenn möglich kontinenzerhaltend, proktokolektomiert werden. Nach einer Operation sollte jährlich eine Pouchoskopie, bei Patienten mit erhaltenem Rektumstumpf alle 4 Monate eine Rektoskopie, erfolgen [Schmiegel et al. 2008], da das Risiko der Entstehung eines Rektumstumpfkarzinoms nach 25 Jahren ca.13\% beträgt [De Cosse et al. 1992].

B) Patienten mit HNPCC (Lynch Syndrom)

Beim Lynch-I-Syndrom findet man vorwiegend in proximalen Abschnitten des Kolons lokalisierte flache Tumoren. Zusätzlich dazu findet man beim Lynch-II-Syndrom neben den Kolonkarzinomen häufig auch Magen- und Uteruskarzinome und weitere maligne Tumoren [Schmiegel et al. 2008].

Das HNPCC-Syndrom wird nach den Amsterdam-Kriterien definiert (Tab. 1.1.4/1); um keine Risikopersonen zu übersehen, werden zusätzlich die Bethesda-Kriterien herangezogen (Tab. 1.1.4/2):

Tabelle 1.1.4/1: Amsterdam-Kriterien [Vasen et al. 1999, Vasen et al. 1991]

1. mindestens 3 Familienmitglieder mit HNPCC-assoziierten Karzinomen (Kolon/Rektum, Endometrium, Dünndarm, Urothel)

2. mindestens 2 aufeinanderfolgende Generationen betroffen

3. ein Familienmitglied erstgradig verwandt mit den beiden anderen

4. ein Erkrankter zum Zeitpunkt der Diagnose jünger als 50 Jahre

5. Ausschluss einer familiären adenomatösen Polyposis 
Tabelle 1.1.4/2: Bethesda-Kriterien

1. Diagnose eines KRKs vor dem 50 . LJ

2. Diagnose von syn- oder metachronen KRK oder anderen HNPCC-assoz. Tumoren

3. Diagnose eines KRKs vor dem 60. LJ mit typischer Histologie eines MSI-H (hohe Mikrosatelliteninstabilität)-Tumors (Tumor-infiltrierende Lymphozyten, Crohn's like lesions, muzinöse oder siegelringzellige Differenzierung, medulläres Karzinom)

4. Diagnose eines KRKs bei mindestens einem erstgradig Verwandten mit einem HNPCCassoziierten Tumor, davon Diagnose von mindestens einem Tumors vor dem 50. LJ

5. Diagnose eines KRKs bei 2 oder mehr erstgradig Verwandten mit einem HNPCCassoziierten Tumor, unabhängig vom Alter

Eine Mikrosatelliteninstabilität lässt sich bei $80-90 \%$ der Patienten, welche die AmsterdamKriterien erfüllen, nachweisen. Die Ursache hierfür liegt in einem Defekt der DNSReparaturenzyme (MSH2, MLH1, MSH6 und PMS2). Die daraus resultierenden Basenfehlpaarungen treten besonders an Stellen kurzer repetitiver DNS-Fragmente (sogenannte Mikrosatelliten) auf. Das allgemeine Tumorrisiko der Anlageträger beträgt 8090\%, wobei meistens KRK auftreten. Diese treten im Mittel im 44. LJ auf, selten jedoch vor dem 25. LJ. 50\% dieser Karzinome befinden sich im rechtsseitigen Kolon [Aarnio et al. 1995]. Die zweithäufigste Tumorentität stellen Endometrium-, gefolgt von Ovarial- , Magen(häufig vom intestinalen Typ) und Dünndarmkarzinomen dar. Karzinome des Urothels treten häufig als Zweit- oder Drittkarzinome auf [Schmiegel et al. 2008]. Beim Muir-Torre-Syndrom handelt es sich um eine seltene Variante, bei der zusätzlich Talgdrüsenadenome und karzinome auftreten [Kruse et al. 1998].

Risikopersonen für HNPCC sollten ab dem 25. LJ koloskopiert und Oberbauch sonografiert werden, bei weiblichen Patientinnen sollte zusätzlich jährlich zur gynäkologischen Untersuchung ein transvaginaler Ultraschall zur Detektion von Ovarial- oder Endometriumkarzinomen erfolgen [Schmiegel et al. 2008].

C) Patienten mit hamartomatösen Polyposis-Syndromen

Zu den hamartomatösen Polyposis-Syndromen gehören das Peutz-Jeghers-Syndrom (PJS), die juvenile Polyposis coli (FJP) und das Cowden-Syndrom. Beim PJS handelt es sich um eine autosomal-dominante Erkrankung charakterisiert durch das Auftreten von hamartomatösen Polypen des Gastrointestinaltraktes und vor allem perioralen mukokutanen Melaninpigmentierungen. Zugrunde liegt dieser Erkrankung eine Keimbahnmutation des STK11-/LKB1-Gens. Neben dem Risiko für KRK ist auch das Risiko für Karzinome des 
Magens, Dünndarms, Pankreas, Mamma, Ovars und Uterus erhöht [Giardiello et al. 2000]. Der Verdacht auf FJP besteht bei Diagnose von mehr als 4 juvenilen Polypen im Kolon, Nachweis extrakolischer juveniler Polypen in Magen und Dünndarm oder bei Nachweis eines juvenilen Polypens bei entsprechender Familienanamnese [Schmiegel et al. 2008]. Beim autosomal-dominanten Cowden-Syndrom ist vor allem das Risiko für Mamma- und papilläre Schilddrüsenkarzinome erhöht.

\subsubsection{Patienten mit chronisch-entzündlichen Darmerkrankungen}

Patienten mit Colitis ulcerosa weisen ein erhöhtes Risiko für KRK auf. Dieses Risiko ist abhängig von Ausdehnung, Manifestationsalter, Dauer der Erkrankung und dem Vorhandensein einer primär sklerosierenden Cholangitis [Schmiegel et al. 2008]. In mehreren Studien konnten 5-ASA-Präparate das Risiko senken, hierbei scheint jedoch eine Dauergabe erforderlich zu sein [Bansal und Sonnenberg 1996, Pinczowski et al. 1994, Eaden et al. 2000]. Bei Patienten mit zusätzlicher primär sklerosierenden Cholangitis scheint eine Therapie mit Ursodeoxycholsäure einen protektiven Effekt zu haben [Schmiegel et al. 2008]; möglicherweise besitzt auch Folsäure einen protektiven Effekt bei Patienten mit Colitis ulcerosa [Lashner et al. 1997].

Bei Patienten mit Pancolitis ulcerosa, die länger als 8 Jahre besteht, oder linksseitiger Kolitis, die länger als 15 Jahre besteht, sollte jährlich eine Koloskopie mit Stufenbiopsien erfolgen[Schmiegel et al. 2008]. Die Datenlage zum Morbus Crohn ist spärlich und widersprüchlich.

Durch den Einsatz der Chromoendoskopie mit Indigokarmin oder Methylenblau gelingt eine bessere Abgrenzung flacher Läsionen von der umgebenden Schleimhaut [Tsuda et al. 2002, Brooker et al. 2002, Kudo et al. 2001, Kiesslich et al. 2001, Kudo et al. 2000].

Bei Patienten mit chronisch entzündlichen Darmkrankheiten und HNPCC findet man eine höhere Detektionsrate neoplastischer Läsionen durch die Chromoendoskopie [Hurlstone et al. 2005 a, Hurlstone et al. 2005 b, Kiesslich et al. 2003]. Bei eindeutiger, durch einen zweiten Pathologen bestätigter hochgradiger intraepithelialer Neoplasie in nicht entzündeter Schleimhaut sollte eine kontinenzerhaltende Proktokolektomie durchgeführt werden [Bernstein et al. 1994]. 


\subsubsection{Einteilung KRK}

Die Stadieneinteilung KRK erfolgt gemäß der TNM-Klasifikation nach UICC (2010) [Wittekind und Meyer 2010].

Tabelle 1.1.6/1: Stadieneinteilung KRK nach UICC 2010

\begin{tabular}{|c|c|}
\hline TNM & Spezifikation \\
\hline T0 & Kein Anhalt für Primärtumor \\
\hline Tis & $\begin{array}{l}\text { Carcinoma in situ: intraepithelial oder } \\
\text { Infiltration der Lamina propria }\end{array}$ \\
\hline T1 & Tumor infiltriert Submukosa \\
\hline T2 & Tumor infiltriert Muscularis propria \\
\hline T3 & $\begin{array}{l}\text { Tumor infiltriert durch die Muscularis } \\
\text { propria in die Subserosa oder in nicht } \\
\text { peritonealisiertes perikolisches oder } \\
\text { perirektales Gewebe }\end{array}$ \\
\hline $\mathrm{T} 4$ & $\begin{array}{l}\text { Tumor infiltiert direkt in andere } \\
\text { Organe oder Strukturen und/oder } \\
\text { perforiert das viszerale Peritoneum }\end{array}$ \\
\hline $\mathrm{T} 4 \mathrm{a}$ & $\begin{array}{l}\text { Tumor perforiert das viszerale } \\
\text { Peritoneum }\end{array}$ \\
\hline $\mathrm{T} 4 \mathrm{~b}$ & $\begin{array}{l}\text { Tumor infiltriert direkt in andere } \\
\text { Organe oder Strukturen }\end{array}$ \\
\hline No & $\begin{array}{l}\text { Keine regionären } \\
\text { Lymphknotenmetastasen }\end{array}$ \\
\hline N1 & $\begin{array}{l}\text { Metastasen in 1-3 regionären } \\
\text { Lymphknoten }\end{array}$ \\
\hline $\mathrm{N} 1 \mathrm{a}$ & $\begin{array}{l}\text { Metastasen in einem regionären } \\
\text { Lymphknoten }\end{array}$ \\
\hline N1b & $\begin{array}{l}\text { Metastasen in 2-3 regionären } \\
\text { Lymphknoten }\end{array}$ \\
\hline N1c & $\begin{array}{l}\text { Satellitenherde in der Subserosa } \\
\text { ohne regionäre Lymphknoten }\end{array}$ \\
\hline N2 & $\begin{array}{l}\text { Metastasen in } 4 \text { oder mehr } \\
\text { regionären Lymphknoten }\end{array}$ \\
\hline $\mathrm{N} 2 \mathrm{a}$ & $\begin{array}{l}\text { Metastasen in 4-6 regionären } \\
\text { Lymphknoten }\end{array}$ \\
\hline $\mathrm{N} 2 \mathrm{~b}$ & Metastasen in 7 oder mehr \\
\hline
\end{tabular}




\begin{tabular}{|l|l|}
\hline & regionären Lymphknoten \\
\hline M0 & Keine Fernmetastasen \\
\hline M1 & Fernmetastasen \\
\hline M1a & Fernmetastasen in einem Organ \\
\hline M1b & $\begin{array}{l}\text { Fernmetastasen in mehr als einem } \\
\text { Organ oder Peritoneum }\end{array}$ \\
\hline
\end{tabular}

\begin{tabular}{|c|c|c|c|}
\hline UICC-Stadium & T-Stadium & N-Stadium & M-Stadium \\
\hline 0 & Tis & NO & MO \\
\hline I & $\mathrm{T} 1, \mathrm{~T} 2$ & NO & M0 \\
\hline IIA & T3 & NO & MO \\
\hline IIB & T4 & NO & M0 \\
\hline IIC & $T 4 b$ & NO & MO \\
\hline \multirow[t]{2}{*}{ IIIA } & T1,T2 & N1 & \multirow[t]{2}{*}{ MO } \\
\hline & T1 & $\mathrm{N} 2 \mathrm{a}$ & \\
\hline \multirow[t]{3}{*}{ IIIB } & T3,T4 & N1 & \multirow[t]{3}{*}{ MO } \\
\hline & T2-T3 & $\mathrm{N} 2 \mathrm{a}$ & \\
\hline & T1-T2 & $\mathrm{N} 2 \mathrm{~b}$ & \\
\hline \multirow[t]{3}{*}{ IIIC } & T4a & N2a & \multirow[t]{3}{*}{ MO } \\
\hline & T3-T4a & $\mathrm{N} 2 \mathrm{~b}$ & \\
\hline & T4b & N1-2 & \\
\hline IVA & Jedes T & Jedes N & M1a \\
\hline IVB & Jedes T & Jedes N & M1b \\
\hline
\end{tabular}

\subsubsection{Symptome und Diagnostik KRK}

Zu den Symptomen KRK gehören Gewichtsverlust, Anämie, Blut im Stuhl, peranale Blutung, Obstipation oder Diarrhö ( unter Umständen im Wechsel), Tenesmen, Meteorismus und Flatulenz, gelegentlich führt erst ein akuter lleus den Patienten in die Klinik [Majumdar et al. 1999].

Für die Diagnostik KRK stehen verschiedene Verfahren zur Verfügung [Schmiegel et al. 2008]:

- Guajak-Test (Stuhltestung auf okkultes Blut): mäßige Sensitivität für Karzinome, geringe Sensitivität für Adenome

- Sigmoidoskopie: Nachteilig ist, dass nicht alle Darmabschnitte eingesehen werden können 
- Koloskopie: eine komplette Koloskopie besitzt die höchste Sensitivität und Spezifität für die Detektion KRK und ist im Rahmen der Krebsvorsorgeuntersuchung ab dem Alter von 50 Jahren empfohlen. Bei unauffälligem Befund sollte die darauf folgende Koloskopie nach 10 Jahren erfolgen.

- Digitale rektale Untersuchung: obligat im Rahmen der Krebfrüherkennungsrichtlinie [Schmiegel et al 2008].

Nach Metastasen fahndet man mittels Sonographie des Abdomens (man beachte hierbei vor allem Lebermetastasen (Met)) und mittels Röntgen-Thorax (Lungenmetastasen); mit der Endosonographie des Rektums werden die Tiefeninfiltration und etwaige lokale Lymphknotenmetastasen untersucht. Beim Rektumkarzinom wird zusätzlich ein CT empfohlen, um die Größe des Tumors und Infiltrationen der Nachbarorgane zu beurteilen und gegebenenfalls eine (neoadjuvante) Bestrahlung vorzubereiten [Schmiegel et al. 2008]. Für den Nachweis von Knochenmetastasen steht die Skelettszintigraphie zur Verfügung. Präoperativ werden außerdem die Tumormarker bestimmt, um postoperativ einen Referenzwert zu haben [Schmiegel et al. 2008]. Des weiteren gilt der präoperative CEA (Carcinoembryonales Antigen)-Wert als unabhängiger prognostischer Marker und sollte daher präoperativ bestimmt werden. Präoperative CEA-Werte von mehr als $7,5 \mathrm{ng} / \mathrm{ml}$ gelten hierbei als Risikofaktor. Postoperativ sollten die CEA-Werte alle 6 Monate über einen Zeitraum von 2 Jahren bestimmt werden [Chapman et al. 1998, Duffy 2001, Schmiegel et al. 2008, Takahashi et al. 1996]. Die Bestimmung der Tumormarker dient ausschließlich der Verlaufskontrolle und ist keinesfalls als Screening-Methode geeignet [Schmiegel et al. 2008].

\subsection{Therapiestrategie KRK}

\subsubsection{Polypektomie}

Bei der Polypektomie sollen die Polypen unter Angabe der Lokalisation zur weiteren histologischen Abklärung geborgen werden. Als endoskopische Verfahren stehen zur Verfügung: 1. Polypektomie mit der Schlinge

2. Endoskopische Mukosaresektion (EMR) [Schmiegel et al. 2008].

\subsubsection{Histologische Untersuchung der Polypen}

Jeder abgetragene Polyp muss histologisch nach den WHO-Kriterien untersucht werden [Bernstein et al. 1994]. Diese Untersuchung umfasst Angaben zur Vollständigkeit der 
Abtragung, zum histologischen Wachstumstyp (tubulös/ tubulovillös/ villös) und dem Grad der intraepithelialen Neoplasie (niedrig-/hochgradige IEN).

Beim Karzinomnachweis sollte der histologische Befund enthalten:

- das Ausmaß der Tiefeninfiltration (pT-Kategorie), bei sessilen Polypen die submuköse Invasionsmessung in $\mu \mathrm{m}$

- das histologische Grading

- das Vorhandensein oder Fehlen der Lymphgefäßinvasion

- die Beurteilung der Resektionsränder [Schmiegel et al. 2008].

\subsubsection{Chirurgische Therapie mit kurativem Ziel}

a) Intraoperatives Staging

In jedem Fall sollte intraoperativ eine Inspektion und Palpation der Leber erfolgen, da insbesondere subseröse Lebermetastasen jeglicher präoperativen Bildgebung entgehen können [Schmiegel et al. 2008].

b) Radikalchirurgische Therapie

\section{Karzinome des Zökums und Colon ascendens}

In der Regel erfolgt eine Hemikolektomie rechts mit radikulärer Durchtrennung der A. colica dextra und der A.ileocolica [Schmiegel et al. 2008].

\section{Karzinome der rechten Flexur und des proximalen Kolon transversum}

Hier erfolgt eine erweiterte Hemikolektomie rechts. Dies bedeutet, dass zusätzlich die A. colica media zentral bei ihrem Abgang aus der A.mesenterica sup. ligiert wird [Schmiegel et al. 2008].

\section{Karzinome des mittleren Transversumdrittels}

Es erfolgt eine Transversumresektion mit zentraler Ligatur der A.colica media unter Mitresektion der Flexuren. Das große Netz wird mit dem Lig.gastrocolicum und der A./N. gastroepiploica reseziert [Schmiegel et al. 2008]. 


\section{Karzinome des distalen Transversumdrittels und der linken Kolonflexur}

Es erfolgt eine erweiterte Hemikolektomie links mit Entfernung des Lymphabflussgebietes von A.colica media und A.mesenterica inferior. Die Lymphknoten entlang der A.mesenterica superior sollten bis zur Aorta disseziert werden [Schmiegel et al. 2008].

\section{Karzinome des Colon descendens und proximalen Sigmas}

Hierbei wird eine Hemikolektomie links mit radikulärer Ligatur der A. mesenterica inferior vorgenommen [Schmiegel et al 2008].

\section{Karzinome des mittleren und distalen Sigmas}

Regeloperation ist die Sigmaresektion mit Ligatur der A. mesenterica inferior [Schmiegel et al. 2008].

\section{Karzinome des Rektums}

Für das Rektumkarzinom sind folgende Operationen, je nach Tumorlokalisation, Beziehung zur Linea dentata und Levatorschenkel, der Tiefeninfiltration und der Spinkterfunktion möglich:

- (tiefe) anteriore Rektumresektion

- abdomino-perineale Rektumexstirpation

- intersphinktäre Rektumresektion ( abdomino-peranale Rektumresektion) [Schmiegel et al. 2008]..

Bei low-grade-Tumoren guter oder mäßiger Differenzierung ist ein Sicherheitsabstand von 2 $\mathrm{cm}$ in situ ausreichend; als minimaler Abstand kann $1 \mathrm{~cm}$ gelten, um eine kontinenzerhaltende Resektion zu ermöglichen. Eine lokale chirurgische Tumorexzision ist möglich bei pT1-Tumoren mit einem Durchmesser bis zu $3 \mathrm{~cm}$ und low-risk-Histologie (G1 oder G2) [Schmiegel et al. 2008].

\subsubsection{Postoperative pathologische Diagnostik}

Folgende Angaben durch den Pathologen sind erforderlich:

- Tumortyp nach WHO-Klassifikation 
- Tumorinvasionstiefe ( pT-Klassifikation)

- Status der regionären Lymphknoten ( $\mathrm{pN}$-Klassifikation)

- Mindestanzahl der zu untersuchenden und Anzahl der untersuchten Lymphknoten

- Grading

- Abstand von den Resektionsrändern.

- R-Klassifikation [Schmiegel et al. 2008].

Zur Anzahl der zu untersuchenden Lymphknoten gibt es in der Literatur verschiedene Angaben. Die Zahlenangaben reichen von 12 bis 17 zu untersuchenden Lymphknoten [Goldstein et al. 1996, Wong et al. 1999, Swanson et al. 2003].

\subsubsection{Adjuvante Therapie des Kolonkarzinoms}

Voraussetzung für eine adjuvante Therapie ist die R0-Resektion des Primärtumors. Für Patienten mit einem R0-reseziertem Tumor im UICC Stadium I ist eine adjuvante Therapie nicht erforderlich. Bei Patienten im Stadium III ist eine adjuvante Chemotherapie indiziert; bei Risikopatienten im Stadium II (T4, Tumorperforation, Notfall-OP, Anzahl untersuchter Lymphknoten zu gering) sollte eine adjuvante Chemotherapie erfolgen [Schmiegel et al. 2008). Im Stadium III sollte die Chemotherapie Oxaliplatin enthalten, welches häufig mit 5FU und Folinsäure kombiniert wird [Francini et al. 1994].

\subsubsection{Neoadjuvante Therapie des Rektumkarzinoms}

Im UICC-Stadium II/III ist die neoadjuvante Radio- bzW. Radiochemotherapie angezeigt [Cammà et al. 2000]. Außerdem konnte die Rate sphinktererhaltender Operationsverfahren verdoppelt werden.

Prinzipiell gibt es 2 verschiedene Arten der präoperativen Radiotherapie [Schmiegel et al. 2008]:

- die Kurzzeitbestrahlung mit 25 Gy in 5 Gy-Einzeldosen an 5 aufeinanderfolgenden Tagen unmittelbar vor der Operation

- die konventionell fraktionierte Bestrahlung bis zu einer Gesamtdosis von 45-50,4 Gy in 25-28 Fraktionen, gefolgt von einer 4-6 Wochen späteren Operation.

Die neoadjuvante Radiochemotherapie sollte eine 5-FU-Monochemotherapie gegebenfalls mit Folinsäure enthalten. 


\subsubsection{Adjuvante Therapie des Rektumkarzinoms}

Im Stadium I ist nach R0-Resektionen keine adjuvante Therapie erforderlich. Patienten im Stadium II/III sollten, wenn sie keine neoadjuvante Therapie erhalten haben, eine adjuvante Radiochemotherapie bekommen. Im Vergleich zur alleinigen Operation kann durch eine postoperative Radiochemotherapie (mit einer 5-FU-Monochemotherapie oder als Kombination mit Folinsäure) die Lokalrezidivrate gesenkt und das Gesamtüberleben verbessert werden [Krook et al. 1991].

Die adjuvante Therapie sollte 4-6 Wochen nach der Operation beginnen. Nach neoadjuvanter Radiochemotherapie ist eine adjuvante Chemotherapie unabhängig vom postoperativen Tumorstadium indiziert [Schmiegel et al. 2008].

\subsubsection{Therapie primär resektabler Leber- und Lungenmetastasen}

Resektable Lungen- und Lebermetastasen sollten reseziert werden [Schmiegel et al. 2008]. Voraussetzung hierfür ist, dass eine R0-Resektion prinzipiell möglich ist.

Resektable Lebermetastasen (Met) liegen vor, wenn:

- eine nicht-resektable extrahepatische Manifestation ausgeschlossen ist

- weniger als $70 \%$ des Parenchyms befallen sind

- $\quad$ weniger als 3 Lebervenen und weniger als 7 Segmente betroffen sind

- $\quad$ keine Leberinsuffizienz oder Leberzirrhose Child B/C vorliegt

- $\quad$ keine schwerwiegenden Begleiterkrankungen vorliegen [Schmiegel et al. 2008].

\subsubsection{Patienten mit potentiell resektablen Metastasen}

Bei primärer Irresektabilität von Lungen- und Lebermetastasen sollte eine systemische Chemotherapie begonnen werden. Zu beachten ist hier die regelmäßige Re-Evaluation einer möglichen sekundären Resektabilität nach Remissionsinduktion. In der Regel werden in diesem Fall Kombinationen von Chemotherapeutika (z.B. FOLFIRI + Cetuximab) angewandt, wohingegen in der palliativen Situation oft Monotherapien (z.B. mit 5-FU) bevorzugt werden [Schmiegel et al. 2008].

\subsection{Metastasierung KRK}

Meistens sterben die Patienten auf Grund von Metastasen- allen voran Metastasen der Leber [Melville 1997]. Bei 75\% aller Metastasen handelt es sich um Lebermetastasen (Met), 
gefolgt von Lungenmetastasen (15\%) und Knochenmetastasen (5\%); sehr tief sitzende Rektumkarzinome können primär über die Vena cava inferior in die Lunge metastasieren. $25 \%$ der Patienten weisen bereits bei Diagnosestellung Met auf, weitere $25 \%$ entwickeln diese im Verlauf ihrer Erkrankung, bevorzugt in den ersten 2 Jahren nach chirurgischer Intervention [Millikan et al. 1997]. Ohne Therapie beträgt die Überlebenswahrscheinlichkeit von Patienten mit Met weniger als ein Jahr [Paschos et al. 2008]. Nach Resektion kolorektaler Met beträgt das 5-Jahres-Überleben 28\%-39,2\% [Schmiegel et al. 2008]. Ein weiteres Problem ist, dass nur 10-25\% der Patienten mit Met für einen kurativen chirurgischen Eingriff in Frage kommen [Paschos et al. 2008]. Die Anzahl der Patienten, welche für kurative chirurgische Interventionen geeignet sind, könnte durch präoperative Chemotherapie mit 5- Fluorouracil/Leukovorin in Kombination mit Oxaliplatin erhöht werden [Adam et al. 2004]. Mit Hilfe dieser Chemotherapieverfahren, können ca. 12,5\% der Patienten mit initial nicht-kurativ resezierbaren Met doch noch einer kurativen Operation mit 5-Jahresüberlebensraten von ca. 33\% zugeführt werden [Adam et al. 2004]. Es kommt hierbei nicht nur die anatomische Hemihepatektomie zur Anwendung, sondern auch atypische Resektionsverfahren, auch in Kombination mit vorausgehender Portalvenenembolisation oder in Kombination mit kryochirurgischen oder radiofrequenzablativen Verfahren [Adam et al. 2004]. Unter Anwendung der subtotalen Hepatektomie konnten 5-Jahres- Überlebensraten von 35-40\% erreicht werden [Beard et al. 2000]. Es konnten 7 Faktoren herausgefunden werden, welche mit einer Prognoseverschlechterung für Patienten mit Met KRK einhergehen:

1.Rektumkarzinom als Primärtumor, 2. mehr als 2 Met, 3. präoperative CA 19-9 Werte von mehr als $100 \mathrm{IU} / \mathrm{l}, 4$. präoperative Tumorgröße der Met über $10 \mathrm{~cm}, 5$. nicht-kurative Leberresektion, 6. unvollständige Tumornekrose, 7. im Verlauf wiederholte Eingriffe an der Leber [Adam et al. 2004].

Ein weiteres Problem ist, dass selbst nach R0-Resektion nur ca. 30\% der Patienten mit Met langfristig rezidivfrei bleiben. Es ist in Studien noch nicht abschließend geklärt, ob generell eine adjuvante Chemotherapie nach Resektion von kolorektalen Met empfohlen werden sollte- zumindest sollte diese nach Resektion von kolorektalen Met in Erwägung gezogen werden [Schmiegel et al. 2008].

Unverzichtbar für die Zukunft ist es deshalb, Patienten mit hohem Risiko für die Entwicklung von Met frühzeitig zu identifizieren und mit einer spezifischen Therapie, wie der lokalen Applikation von Chemotherapie in die Leber, zu versorgen. Daher ist es notwendig, therapeutische Strategien zu entwickeln, welche die Entstehung von Metastasen beeinflussen. Hierfür ist eine exakte Aufschlüsselung der biologischen und molekularen Vorgänge der Metastasierung notwendig. 
Der entscheidende Schritt bei der Metastasierung stellt die Invasion der Blutbahn mit metastatischen Zellen dar. Hierbei müssen die metastatischen Zellen die Immunabwehr des Organismus überlisten, um zu anderen Organen zu gelangen [Fidler und Radinsky 1990]. Im Falle einer Metastasierung in die Leber müssen sich die metastatischen Zellen mit den endothelialen Zellen der hepatischen Sinusoide, den Kupfferschen Sternzellen und den natürlichen Killerzellen auseinandersetzen. Meterissian et al. konnten bereits 1993 mit Hilfe von Tumorzellen, die in die Milz von Mäusen eingesetzt wurden, zeigen, dass Zellen mit geringerem metastatischem Potential bereitwilliger an Kupffer-Zellen gebunden haben, und somit eliminiert werden konnten, als solche mit hohem metastatischem Potential [Meterissian et al. 1993]. Sie fanden außerdem heraus, dass konditionierte Medien von Zellen mit hohem metaststatischem Potential in der Lage waren, das Bindungsverhalten von Zellen mit geringem metastatischem Potential an Kupffer-Sternzellen zu reduzieren [Meterissian et al. 1993].

\subsection{Molekulare Grundlagen KRK und der korrespondierenden Metastasen}

Viele Arbeitsgruppen haben sich bis heute mit den molekularen Grundlagen KRK befasst. Bereits 1990 veröffentlichten Fearon und Vogelstein ihr Modell der Adenom-KarzinomSequenz der KRK [Fearon und Vogelstein 1990]. Sie konnten zeigen, dass durch chromosomale Läsionen der Chromosomen 5, 12, 17, 18 zunächst Adenome und schließlich (nach etwa 10 Jahren) invasive und metastasierende Karzinome entstehen können. Zu beachten ist jedoch, dass Zwischenstationen in der Tumorigenese übersprungen werden können.

Tabelle 1.4/1: Adenom-Karzinom- Sequenz

\begin{tabular}{|l|l|l|}
\hline $\begin{array}{l}\text { Chromosomale } \\
\text { Läsion/genetische Läsion }\end{array}$ & $\begin{array}{l}\text { Zellbiologische } \\
\text { Veränderung }\end{array}$ & Histologie \\
\hline $5 q 21 /$ APC-Funktionsverlust & $\begin{array}{l}\text { Verlust der Zell-Zell- } \\
\text { Adhäsion, Enthemmung der } \\
\text { Proliferation }\end{array}$ & Epitheliale Hyperproliferation \\
\hline $12 \mathrm{p} 12 /$ K-ras-Aktivierung & $\begin{array}{l}\text { Deregulierung eines } \\
\text { Abschaltmechanismus in der } \\
\text { Zellaktivierung }\end{array}$ & Adenom \\
\hline $18 q 21 /$ DCC & $\begin{array}{l}\text { Defektes } \\
\text { Zelladhäsionsmolekül }\end{array}$ & Adenom \\
\hline $17 p 13 / p 53$ & Verlust DNA-Reparatur- und & Invasives Karzinom \\
\hline
\end{tabular}




\begin{tabular}{|l|l|l|}
\hline & Zellzykluskontrolle & \\
\hline weitere wie 17q21 & & Metastasierendes Karzinom \\
\hline
\end{tabular}

Mertens et al. untersuchten 1997333 Patienten mit KRK. Sie fanden Amplifikationen der Chromosomen (-arme) 7, 8q, 13 und 20, sowie Deletionen bei 1p, 5q, 8p, 14p, 17p, 18 und 22 [Mertens et al. 1997]. Ried et al. verwendeten 1996 die Comparative Genomic Hybridization ( $\mathrm{CGH}$ ), um chromosomale Instabilitäten bei kolorektalen Adenomen und Karzinomen zu identifizieren. Dabei fanden sie bei Karzinomen Zugewinne der Chromosomen 1,13,20 und der Chromosomenarme $7 p$ und $8 q$ sowie Verluste der Chromosomen 4 und der Chromosomenarme 8p und 10q [Ried et al. 1996].

Die molekularen Grundlagen der Metastasierung bei KRK sind dennoch bis heute nicht suffizient aufgeklärt. Neueren Erkenntnissen zu Folge sind Met phänotypisch verschieden im Vergleich zum Primärtumor (PT). Diese Erkenntnis deklariert die Met als eigenständige Krankheitsgruppe [Bird et al. 2006].

Die Arbeitsgruppe um Al-Mulla [Al-Mulla et al. 1999] untersuchte 26 Tumoren von Patienten mit metastasierenden KRK unter Zuhilfenahme der CGH. Dabei wurden die PT mit ihren Lymphknotenmetastasen von 5 Patienten im Stadium Dukes C und die PT inklusive der Met von 7 Patienten im Stadium Dukes D analysiert (2 dieser Patienten wiesen zusätzlich zu den Met Lymphknotenmetastasen auf), um die genetischen Unterschiede zwischen primären KRK und Met KRK derselben Patienten herauszufinden. Sie zeigten, dass häufig dieselben genetischen Veränderungen in den PT und ihren Metastasen auftraten, jedoch in den Metastasen zusätzlich Veränderungen zu finden waren, die in den dazugehörigen PT nicht vorhanden waren. Interessanterweise schienen im Vergleich zu Met bei Lymphknotenmetastasen eine höhere Anzahl an chromosomalen Veränderungen vorhanden zu sein. Eine Deletion des Chromosomenarms 17p wurde signifikant häufiger bei Patienten mit Lymphknotenmetastasen gefunden. Eine Amplifikation von $6 p$ und $17 q$ wurde eher bei Patienten mit Met gefunden [Al- Mulla et al. 1999]. Diese Ergebnisse legen die Vermutung nahe, dass Lymphknotenmetastasen häufig nicht einfach nur die Vorstufe von weiteren Metastasen, in diesem Falle von Met, darstellen.

$20 \mathrm{q}$ war sowohl bei Leber- als auch bei Lymphknotenmetastasen amplifiziert [Al- Mulla et al. 1999]. Auch ein Zugewinn von 7p wurde häufig in den PT und/oder Metastasen gefunden [Al-Mulla et al. 1999]. In beiden Dukes-Stadien fanden sich häufig Deletionen der Chromosomen 4, 18, 22 [Al- Mulla et al. 1999]. Aragane et al. untersuchten 200130 primäre KRK und 16 Met mit Hilfe der CGH [Aragane et al. 2001]. Bei den primären KRK fanden sie häufige Zugewinne der Chromosomen 7p21, 7q31-36, 8q23-24, 12p, 14q24-32, 16p, 20p, 20q, 21q sowie Verluste von 18q12-23. Bei 
metastasierenden Tumoren konnte die Arbeitsgruppe signifikant mehr Zugewinne und Verluste von DNA-Sequenzen nachweisen. Hierzu zählen Zugewinne von 8q23-24 (62,5\% in metastasierenden Tumoren vs. 43\% in primären Tumoren), 15q21-26 (37,5\%vs.20\%), 19p (43,8\% vs. $20 \%$ ), $20 q$ ( $81,3 \%$ vs. $63,3 \%)$ und Verluste von $18 q 12-23$ (50\% vs. $36,7 \%)$. Sie fokussierten ihre Arbeit auf die Zugewinne von $8 \mathrm{q}$ (c-myc) und 20q, sowie Verluste bei $18 \mathrm{q}$ (DCC) und postulierten, dass die Inzidenz von Met bei Patienten mit diesen genetischen Veränderungen höher sei und damit ein geeigneter Marker zur Identifizierung von RisikoPatienten darstellen könnte [Aragane et al. 2001].

Korn et al. verwendeten die CGH und FISH-Analyse, um Metastasen von KRK zu untersuchen. Auch diese Arbeitsgruppe bestätigte Amplifikationen von 20 q bei $85 \%$ der Metastasen [Korn et al. 1999]. Zugewinne von 20q wurden auch in einer Reihe von weiteren Tumoren gefunden. Hierzu zählen Brustkrebs, Ovarialkrebs, Blasenkrebs und Tumoren des Pankreas [Solinas-Toldo et al. 1996, Kallioniemi A et al. 1994, Iwabuchi et al. 1995, Kallioniemi A et al. 1999]. Auch Diep et al. untersuchten 200317 Met KRK mit Hilfe der CGH [Diep et al. 2003].Sie bestätigten Verluste von 18, 4q, 8p, 17p und Zugewinne von 6p, 8q, $13 q, 7,20$.

Die Zugewinne der Chromosomen 7 und 13 resultieren häufig aus einer Trisomie dieser Chromosomen [Diep et al. 2003]. Sie scheinen schon früh in der kolorektalen Tumorigenese vorhanden zu sein, v.a. eine Trisomie des Chromosoms 7 ist häufig die einzige chromosomale Veränderung bei kolorektalen Adenomen [Ried et al. 1996]. Diese Beobachtungen legen die Vermutung nahe, dass die Chromosomen 13 und vor allem 7 in die initiale Tumorigenese involviert sind. Ein 20q-Zugewinn jedoch wird häufiger bei Karzinomen als bei Adenomen gesehen [Ried et al. 1996] und wird mit der Immortalisierung von Tumorzellen in Zusammenhang gebracht [Savelieva et al. 1997]. Ein Zugewinn von 6p wird mit einem fortgeschrittenen Tumorstadium (Dukes D) assoziiert [Al-Mulla et al. 1999]. Eine Deletion von $8 p$ und eine Amplifikation von $8 q$ wird häufiger in KRK und deren Metastasen beobachtet, als bei Adenomen. Dies legt die Vermutung nahe, dass Chromosom 8 in die Tumorprogression involviert ist [Diep et al. 2003]. Der Verlust von $8 p$ ist auch mit einer Mikroinvasion und einem verkürzten Überleben assoziiert [Halling et al. 1999].

Auch Nakao et al. befassten sich mit Met KRK. Die Arbeitsgruppe untersuchte 35 primäre KRK, darunter 16 primäre KRK mit korrespondierenden Met [Nakao et al. 2001] mit Hilfe der $\mathrm{CGH}$ und flow cytometry. Sie vermuten einen Zusammenhang der Met mit Zugewinnen von $6 q, 7 q, 8 q, 13 q$ und 20q und dem Verlust von 18q und 17p. In dieser Studie wurden relativ mehr Zugewinne von 20q als 18q(DCC)-Verluste bei Met KRK gefunden [Nakao et al. 2001]. Paredes-Zaglul et al. berichteten bereits 1998 über den Zusammenhang von einem Zugewinn von 20q und dem Auftreten von Met [Paredes-Zaglul et al.1998]. Besonders häufig 
wird ein Zusammenhang zwischen dem Zugewinn von 20q13 und dem Auftreten von Met bei Patienten mit KRK beschrieben [Al-Mulla et al. 1999, Korn et al. 1999]. Im distalen Abschnitt des Chromosoms 20q wurden daraufhin einige mögliche Gene identifiziert, die an der Metastasierung beteiligt sein könnten. Hierzu gehören das cellular-apoptosis-susceptibility (CAS-)Gen, das BTAK-Gen (ein mutmaßliches Serin/Threonin-Kinase Gen) und das AIB1Gen, ein Steroid-Rezeptor-Koaktivator Gen [Anzick et al. 1997]. Darüber hinaus hebt die Arbeitsgruppe den Zugewinn bei 8q heraus. In dieser Region befindet sich das Gen c-myc, dem auch eine Rolle bei der Invasion der Lunge durch das kleinzellige Bronchialkarzinom zugeschrieben wird [Little et al. 1983].

Knosel et al. untersuchten 200463 unterschiedliche Tumorgewebe von 40 Patienten. Darin enthalten waren 30 PT KRK, 22 systemische Metastasen (12 Met, 6 Hirnmetastasen, 4 Abdominalmetastasen) und 11 Lymphknotenmetastasen [Knosel et al. 2004]. Hierbei rekonstruierten sie die chromosomalen Veränderungen vom Adenom $(+7,+20)$ über das invasive Karzinom (++8q,++13q,++20q; -4,-8p), Lymphknotenmetastasen (+8q,++20q; --8p,$9 p,-18-21 q 21$ ) bis schließlich hin zum metastasierenden Karzinom (allen voran Metastasen in die Leber +1q, +7p,+11,+12qter,+13,+16,+17q12-21,+19,+22q; -1p,-2q,-3,-4,--5q12-31,-8p,9p,-10q,--21q21). In ihrer Arbeit heben sie zwei bekannte Pathomechanismen hervor, nämlich 1. dass Metastasen unmittelbar nach dem Auftreten eines invasiven PT vorhanden sein können und 2. dass die hämatogene Ausbreitung unabhängig von der lymphogenen Metastasierung in Erscheinung treten kann [Knosel et al. 2004]. Die Autoren postulieren weiter, dass die Akkumulation der verschiedenen chromosomalen Veränderungen und weniger die Reihenfolge dieser Veränderungen für die Progression KRK verantwortlich ist [Knosel et al. 2004].

Nakao et al. konnten 2009 vor allem einen Zugewinn von 20q und den Verlust von 18q bei KRK beschreiben. Zusätzlich zu diesen Veränderungen beschreiben sie Zugewinne bei 7p, $8 q, 13$ und Verluste bei $8 p$ und 17p [Nakao et al. 2009].

Liu et al. zeigten 2007 bei Tumoren im UICC-Stadium I Zugewinne bei 8q21-22, 13q21-31 und 20q12qter sowie Verluste bei 17p12pter. Im Stadium III/IV beschreiben sie Zugewinne von 8q23qter sowie Verluste von 8p12pter und 18q12qter [Liu 2007].

\subsection{Fragestellung und Ziele der Arbeit}

Das Ziel der vorliegenden Arbeit ist es, herauszufinden, ob weitere, im Vergleich zur bestehenden Literatur, chromosomale Aberrationen KRK und der korrespondierenden Met gefunden und bestätigt werden können und ob es möglich ist, genetische Aberrationen als Prognosefaktor für das metastatische Potential des PT festzulegen. 


\section{Material und Methoden}

\subsection{Darstellung des Kollektivs}

\subsubsection{Allgemeine Präsentation des Kollektivs}

Die im Folgenden beschriebenen untersuchten Tumoren wurden im Zeitraum von 1994-2007 operiert.

Die Comparative Genomic Hybridization (CGH) von 34 Primärtumoren (PT) kolorektaler Karzinome (KRK) und 102 Lebermetastasen (Met) KRK wurde von 1995-2008 in der Abteilung für Gastroenteropathologie am Universitätsklinikum Göttingen durchgeführt. Insgesamt wurden in das Kollektiv 93 Patienten mit KRK und/ oder Met des KRK eingeschlossen. Bei 25 Patienten lag sowohl der PT KRK als auch die korrespondierende(n) Met vor. Im Median vergingen 19,6 Monate von der Operation des PT bis zur Operation der ersten Met (Range 0,0-55,0 Monate). Tabelle 2.1.1 zeigt die wichtigsten Kenngrößen des untersuchten Kollektivs.

Tabelle 2.1.1/1: Darstellung des Kollektivs

\begin{tabular}{|l|r|}
\hline Parameter & Kenngröße \\
\hline Anzahl Patienten & 93 \\
Anzahl PT & 34 \\
Anzahl Met & 102 \\
Anzahl Patienten mit PT und korrespondierender & 25 \\
Met & \\
Anzahl der korrespondierenden Met von 25 & \\
Patienten mit PT KRK & 60 (65\%) \\
\hline Geschlecht & $33(35 \%)$ \\
Männlich & \\
Weiblich & $61.5+/-9.8$ \\
\hline Alter (Mittelwert +/- Standardabw.) & $60.4+/-9.3$ \\
Total & $63.6+/-10.5$ \\
\hline Männer & \\
Frauen & \\
\hline
\end{tabular}




\subsubsection{Lokalisation des PT}

Bei 7 Patienten (21\%) lag der PT im proximalen Kolon (Coecum, Colon ascendens, Colon transversum), bei 13 Patienten (38\%) lag der PT im distalen Kolon (Colon descendens, Sigma) und bei 14 Patienten (41\%) lag ein Rektumkarzinom vor.

\subsubsection{Klassifikation der PT KRK und der Met}

Für die Klassifikation der PT wurden die allgemein gültigen UICC-Stadien verwendet. Tabelle 1.1.6/1 im Einleitungsteil zeigt die UICC- Stadien.

Die Met wurden nach der mTNM-Klassifikation nach Gayowski eingeteilt [Gayowski et al. 1994](Tab. 2.1.3/1).

Tabelle 2.1.3/1: mTNM- Stadien nach Gayowski

\begin{tabular}{|l|l|}
\hline mT1 & Solitär <2 cm \\
\hline mT2 & Solitär $>2 \mathrm{~cm}$, multipel< 2cm, unilobär \\
\hline mT3 & Multipel>2cm, unilobär \\
\hline mT4 & $\begin{array}{l}\text { Solitär oder multipel, Invasion großer } \\
\text { Gefäße: V.portae, A. hepatica, Gallengang }\end{array}$ \\
\hline N1 & Abdominelle Lymphknoteninfiltration \\
\hline M1 & Extrahepatischer Tumornachweis \\
\hline
\end{tabular}

\section{$2.2 \quad$ Material}

\subsubsection{Chemikalien und Biochemikalien}

6X Loading Dye Solution

Actinomycin-D-Mannitol

Agarose - LE

Albumin Fraktion $\mathrm{V}$

Aqua ad iniectabilia

Aqua bidest

Borsäure

DAPI

Dextransulfat
Fermentas

Sigma-Aldrich

Biozym

Merck

Delta Select

UMG

Merck

Sigma-Aldrich

Merck
St. Leon-Rot

Hamburg

Hessisch Oldendorf

Darmstadt

Dreieich

Göttingen

Darmstadt

Hamburg

Darmstadt 


\begin{tabular}{|c|c|c|}
\hline DNS-Puffer & Fermentas & St. Leon-Rot \\
\hline EDTA & Serva Electrophoresis & Heidelberg \\
\hline Ethanol $100 \%$ & Sigma-Aldrich & Hamburg \\
\hline Ethanol $70 \%$ & Sigma-Aldrich & Hamburg \\
\hline Ethanol $85 \%$ & Sigma-Aldrich & Hamburg \\
\hline Ethidiumbromid & Sigma-Aldrich & Hamburg \\
\hline Formalin & Sigma-Aldrich & Hamburg \\
\hline Formamid & Sigma-Aldrich & Hamburg \\
\hline $\mathrm{Na}_{2} \mathrm{HPO}_{4}$ & Merck & Darmstadt \\
\hline $\mathrm{NaH}_{2} \mathrm{PO}_{4}$ & Merck & Darmstadt \\
\hline Natriumacetat & Merck & Darmstadt \\
\hline Natriumchlorid & Merck & Darmstadt \\
\hline Polysorbat 20\% (Tween 20\%) & Sigma-Aldrich & Hamburg \\
\hline Resin & Bio-Rad & München \\
\hline Salzsäure 1 molar & Merck & Darmstadt \\
\hline Salzsäure $37 \%$ & Merck & Darmstadt \\
\hline Salzsäure 5 molar & Merck & Darmstadt \\
\hline tri-Natriumcitratdihydrat & Merck & Darmstadt \\
\hline Tris & Merck & Darmstadt \\
\hline Tris-Borat-EDTA-Puffer (TBE) & Merck & Darmstadt \\
\hline Tris - HCl & Merck & Darmstadt \\
\hline Vectashield Mounting Medium & Vector Laboratories & Burlingame, USA \\
\hline Xylol & Carl Roth & Karlsruhe \\
\hline
\end{tabular}

\subsubsection{Geräte}

$\begin{array}{lll}\text { Anregungsfilter DAPI } & \text { Genetix } & \text { New Milton, Großbritannien } \\ \text { Anregungsfilter FITC } & \text { Genetix } & \text { New Milton, Großbritannien } \\ \text { Anregungsfilter TRITC/TxRed } & \text { Genetix } & \text { New Milton, Großbritannien } \\ \text { BioPhotometer } & \text { Eppendorf } & \text { Hamburg } \\ \text { Brutschrank } & \text { Memmert } & \text { Schwabach } \\ \text { CCD-Kamera } & \text { Photometrics SENSYS } & \text { München } \\ \text { Elektrophoresekammer } & \text { Serva Electrophoresis } & \text { Heidelberg } \\ \begin{array}{l}\text { BlueMarine 100 } \\ \text { Feinwaage BL 1500S }\end{array} & \\ \text { Hybridisierungskammer HYBrite } & \text { Vysis } & \text { Göttingen } \\ \text { Magnetrührer MR 3001 } & \text { Heidolph Instruments } & \text { Sowners Grove, USA }\end{array}$




$\begin{array}{lll}\text { Mikroskop Axioskop 40 FL } & \text { Carl Zeiss } & \begin{array}{l}\text { Jena } \\ \text { Mikrotom HM 400 }\end{array} \\ \begin{array}{l}\text { Microm } \\ \text { Objektiv Plan-Neofluar 10x/0,30 }\end{array} & \text { Carl Zeiss } & \text { Jena } \\ \text { Objektiv Plan-Neofluar 63x/1,25 } & \text { Carl Zeiss } & \text { Jena } \\ \text { Oil } & & \\ \text { pH-Meter CG820 } & \text { Schott Geräte } & \text { Mainz } \\ \text { Pipetten } & \text { Eppendorf } & \text { Hamburg } \\ \text { Polaroid-Kamera MP4+ ICS } & \text { Polaroid } & \text { Dreieich-Sprendlingen } \\ \text { Power Mac G3 } & \text { Apple } & \text { Cupertino, USA } \\ \text { Power Mac G5 } & \text { Apple } & \text { Cupertino, USA } \\ \text { Thermomixer comfort } & \text { Eppendorf } & \text { Hamburg } \\ \text { UV-Transluminator FLX 20.M } & \text { Vilber Lourmat } & \text { Eberhardzell } \\ \text { Vortex-Genie 2 } & \text { Scientific Industries } & \text { Bohemia, USA } \\ \text { Zentrifuge Centrifuge 5417R } & \text { Eppendorf } & \text { Hamburg } \\ \text { Zentrifuge Concentrator 5301 } & \text { Eppendorf } & \text { Hamburg }\end{array}$

\subsubsection{Verbrauchsmaterialien, Isolierungssysteme, molekulare Standards}

$\begin{array}{lll}\text { Deckgläser } & \text { Menzel-Gläser } & \text { Braunschweig } \\ \text { Eppendorf-Cups } & \text { Eppendorf } & \text { Hamburg } \\ \text { Fixogum } & \text { Marabu } & \text { Tamm } \\ \text { Küvetten } & \text { Eppendorf } & \text { Hamburg } \\ \text { Objektträger } & \text { Menzel-Gläser } & \text { Braunschweig } \\ \text { Pipettenspitzen } & \text { Sarstedt } & \text { Nümbrecht } \\ \text { Reagiergefäße 1,5 ml } & \text { Sarstedt } & \text { Nümbrecht } \\ \text { QiAmp DNA Mini Kit } & & \\ & \text { Qiagen } & \text { Hilden } \\ \text { Lambda-DNA/EcoRI Marker } & \text { Fermentas } & \\ \text { pUC19 DNA/Mspl (Hpall) Marker } & \text { Fermentas } & \text { St. Leon-Rot }\end{array}$

\subsubsection{Nukleotide und DNS-Präparate}

$\begin{array}{lll}\text { Biotin-16-dUTP } & \text { Roche } & \text { Penzberg } \\ \text { COT Human DNA } & \text { Roche } & \text { Penzberg } \\ \text { Digoxigenin-11-dUTP } & \text { Roche } & \text { Penzberg } \\ \text { Sequencing Grade dNTP Set } & \text { Amersham Biosciences } & \text { Piscataway, USA }\end{array}$




\subsubsection{Fluoreszenzfarbstoffkonjugate}

$\begin{array}{lll}\text { Anti-Digoxigenin-Rhodamin } & \text { Roche } & \text { Penzberg } \\ \text { Fluorescein Avidin DCS } & \text { Vector Laboratories } & \text { Burlingame, USA }\end{array}$

\subsubsection{Enzyme}

$\begin{array}{lll}\text { DNA-Polymerase I, E.coli } & \text { Fermentas } & \text { St. Leon-Rot } \\ \text { DNAse I } & \text { Roche } & \text { Mannheim } \\ \text { Pepsin } & \text { Sigma-Aldrich } & \text { Hamburg } \\ \text { Proteinase K } & \text { Roche } & \text { Mannheim }\end{array}$

\subsubsection{Metaphasenpräparate und Ausarbeitungssoftware}

$\begin{array}{lll}\text { CGH Metaphase Target Slides } & \text { Abbott Molecular } & \text { Wiesbaden } \\ \text { ISIS FISH Imaging System } & \text { Metasystems GmbH } & \text { Altlussheim } \\ \text { Version 5.1.16 } & & \\ \text { Metafer4 Version 3.2.2 } & \text { Metasystems GmbH } & \text { Altlussheim } \\ \text { CCD-Kamera } & \text { Metasystems GmbH } & \text { Altlussheim }\end{array}$

\subsection{Methoden}

\subsubsection{Tumorgewebe}

Das operativ entfernte Tumormaterial wurde in 4\% gepuffertem Formalin fixiert und in Paraffin eingebettet. Die histopathologische Klassifikation erfolgte an Hämatoxylin-Eosin (HE) gefärbten Präparaten.

\subsubsection{Referenzgewebe}

Zur Herstellung der Referenz-DNS wurde Lebergewebe männlicher und weiblicher Patienten benutzt, da Lebergewebe auf Grund der hohen Zelldichte viel DNS besitzt und sich somit optimal als Referenzgewebe eignet. 
Soweit nicht anders angegeben wurden alle Puffer und Lösungen mit Aqua bidest. angesetzt.

\subsubsection{DNA-Isolierung}

\subsubsection{Gewinnung genomischer Tumor-DNS aus Paraffinblöcken}

Um möglichst viele Tumorzellen für die DNS-Isolierung zu erhalten, wurden die zu den jeweiligen Paraffinblöcken korrespondierenden HE-Schnitte mikroskopisch durchsucht, damit die verwendeten Gewebestücke zumindest einen Anteil von 75\% Tumorzellen enthielten. Mit dem Mikrotom wurden 15 Schnitte mit einer Dicke von 10 $\mu \mathrm{m}$ aus den jeweiligen Tumorbezirken der Paraffinblöcke geschnitten und in Eppendorf-Cups (E-Cups) aufbewahrt. Zur Extraktion des Gewebes aus dem Paraffin wurde jeweils zweimal $1000 \mu$ Xylol und anschließend in 2 Durchgängen jeweils $1000 \mu \mathrm{l}$ Ethanol in die E-Cups pipettiert, $10 \mathrm{~min}$ inkubiert, zentrifugiert und letztendlich wieder abpipettiert. Zum Trocknen wurden die Proben für 45 min geöffnet in den Brutschrank $\left(60^{\circ} \mathrm{C}\right)$ gestellt.

Zu den extrahierten Gewebeproben wurde $200 \mu$ DNA- Isolierungspuffer und $40 \mu \mathrm{l}$ Proteinase $\mathrm{K}$ hinzugefügt. Nachdem die Proben gut gevortext wurden, blieben sie über Nacht bei $55^{\circ} \mathrm{C}$ und $850 \mathrm{rpm}$ auf dem Thermomixer.

Am nächsten Tag folgte zunächst die Inaktivierung der Proteinase K. Hierzu wurden die Proben für $8 \mathrm{~min}$ bei $95^{\circ} \mathrm{C}$ auf den Thermomixer gestellt und anschließend für $10 \mathrm{~min}$ bei 13500 rpm zentrifugiert. Der Überstand (die DNA!) wurde nun in neue Cups pipettiert.

Nun begann die Aufreinigung der Proben mit dem Qiagen Kit. Pro Cup fügte man $200 \mu \mathrm{AL}-$ Puffer (25-50\% Guadiniumchlorid; Puffer lag dem QiAmp DNA Mini Kit bei, der Hersteller macht keine genauen Angaben) hinzu, vortexte die Proben und stellte sie 10 min bei $70^{\circ} \mathrm{C}$ und $1400 \mathrm{rpm}$ auf den Thermomixer. Schließlich wurden $240 \mu$ reiner Ethanol hinzu pipettiert und alles aus den Cups $(650 \mu \mathrm{l})$ auf die Filter übertragen und 2 min bei $10000 \mathrm{rpm}$ und Raumtemperatur zentrifugiert. Die Flüssigkeitssäule wurde verworfen und der Filter mit der darin befindlichen DNS auf eine neue Säule gesetzt und erneut 2 min bei 10000 rpm und Raumtemperatur zentrifugiert. Auch diese Flüssigkeitssäule wurde verworfen und der Filter auf eine neue Säule gesetzt. Nun wurden pro Filter 500 l AW1 Puffer (50-100\% Guadiniumchlorid; Puffer lag dem QiAmp DNA Mini Kit bei, der Hersteller macht keine genauen Angaben) hinzu pipettiert und die Proben erneut bei 10000 rpm 2 min zentrifugiert, die Flüssigkeitssäule wieder verworfen und $500 \mu \mathrm{l}$ AW2 Puffer (Puffer lag dem QiAmp DNA Mini Kit bei, der Hersteller macht keine genauen Angaben) auf die in die neuen Säulen gesetzten Filter pipettiert. Nachdem diese 3 min bei 14000 rpm zentrifugiert wurden und die Flüssigkeitssäule verworfen worden ist, beginnt das Herauslösen der DNS aus dem Filter. 
Dazu werden $50 \mu \mathrm{l}$ AE-Puffer (Puffer lag dem QiAmp DNA Mini Kit bei, der Hersteller macht keine genauen Angaben) auf die Filter pipettiert, nach 2 min Wartezeit wurden die Proben 2 min bei 10000 rpm zentrifugiert. Der gesamte Vorgang des Herauslösens der DNS aus dem Filter muss nun noch $1 \mathrm{x}$ wiederholt werden, um ein DNS-Endvolumen von $100 \mu \mathrm{l}$ zu erzielen. Zur Kontrolle der ungefähren Größe der Moleküle folgt nun die Auftrennung der DNS auf einem Agarosegel mittels der Gelelektrophorese. Dabei wandert die negativ geladene DNS im elektrischen Feld von der Kathode zur Anode. Auf Grund des Molekularsiebeffektes geschieht dies umso schneller, je kleiner die Größe der Moleküle ist.

Das Agarosegel wurde mit $75 \mathrm{mg}$ Agarose, $45 \mathrm{ml}$ Aqua bidest. und $5 \mathrm{ml} 10$ x TBE hergestellt.

Auf einer Mikrotiterplatte wurden zunächst von jeder Probe $5 \mu$ LNS mit $3 \mu$ L Loading Puffer versetzt. Der Standard bestand aus $3 \mu \mathrm{l}$ Loading Puffer, $5 \mu$ l Aqua ad iniect. und 1,5 $\mu \mathrm{l}$ Lambda-DNA/EcoRI Marker mit Fragmentlängen von 21226, 7421, 5804, 5643, 4878 und 3530 Basenpaaren. Im Gelraum wurde zu dem Gel 7,5 $\mu$ l Ethidiumbromid pipettiert und die Proben plus Standard auf das Gel aufgetragen.

Die Auftrennung erfolgte bei $80 \mathrm{~V}$ für $45 \mathrm{~min}$, danach wurde das Gel bei einer Wellenlänge von $312 \mathrm{~nm}$ unter UV-Licht fotografiert.

Zusätzlich erfolgte eine photometrische Messung der DNS-Konzentration doppelsträngiger DNS bei einer Wellenlänge von $260 \mathrm{~nm}$ im Photometer.

Dabei gilt: $E=-\lg (T)$, wobei $E$ für die Extinktion und $T$ für die Transmission steht.

Gemäß des Lambert-Beer'schen Gesetzes ist die Extinktion proportional dem molaren Extinktionskoeffizienten, der Konzentration des gelösten Stoffes und der Schichtdicke $(\Delta \mathrm{E}=\mathrm{e}(\mathrm{mol}) \mathrm{x} \mathrm{c} \times \mathrm{d})$, wobei $\Delta \mathrm{E}$ für die Extinktionsdifferenz, $\mathrm{e}(\mathrm{mol})$ den für den molekularen Extinktionskoeffizienten in $\mathrm{Lx} \mathrm{mol}^{-1} \mathrm{x} \mathrm{cm}^{-1}, \mathrm{c}$ für die Konzentration in $\mathrm{mol} / \mathrm{l}$ und $\mathrm{d}$ für die Schichtdicke der Küvette in cm steht. Dadurch lässt sich die DNS-Konzentration der Lösung in $\mu \mathrm{g} / \mathrm{ml}$ bestimmen.

Durch Messung der Extinktion bei 280 nm (Absorptionsmaximum von Proteinen) ließ sich ein Quotient bilden mit dessen Hilfe die Reinheit der DNS beurteilt werden konnte. Optimal waren dabei Werte zwischen 1,8 und 2,0.

Zur Messung der Konzentration wurden $5 \mu$ l DNS mit $95 \mu$ Aqua ad iniect. verdünnt und die Extinktion bei 260 und $280 \mathrm{~nm}$ gegen Aqua ad iniect. als Leerwert im Photometer gemessen.

\subsubsection{Gewinnung genomischer Referenz-DNS}

Aus dem bei $-80{ }^{\circ} \mathrm{C}$ gelagerten Lebergewebe wurden ca. $5 \mathrm{~mm}^{3}$ große Stücke herausgelöst, zerkleinert und mit $360 \mu \mathrm{l}$ ATL-Puffer (Puffer lag dem QiAmp DNA Mini Kit bei, der Hersteller macht keine genauen Angaben) sowie $40 \mu$ I Proteinase K versetzt. Nach der Inkubationszeit 
über Nacht auf dem Photometer bei $55^{\circ} \mathrm{C}$ erfolgte die weitere Verarbeitung gemäß den oben beschriebenen Arbeitsschritten zur Gewinnung der Tumor-DNS.

\subsubsection{Nicktranslation}

Bei der Nicktranslation handelt es sich um eine standardisierte Methode zur Markierung der DNS. Durch DNAse-I wurden zunächst Lücken („nicks“) in die DNS geschnitten. Es handelt sich dabei um Einzelstrangbrüche, wobei ein 3'-Ende mit einer freien Hydroxylgruppe in der DNS entsteht. Durch das Enzym DNS-Polymerase I folgte dann der Einbau markierter Nukleotide in die DNS. Mit ihrer 5'-3'- Endonukleaseaktivität nutzt die DNS-Polymerase I die "nicks" als Primer zur Entfernung der bestehenden Nukleotide und synthetisiert an das freie 3'- Ende mit Hilfe der markierten Nukleotide in gleicher Richtung einen komplementären DNS-Strang [Kelly et al. 1970]. Zur Markierung wurden Biotin (für die Tumor-DNS) und Digoxigenin (für die Referenz-DNS) verwendet [Brigati et al. 1983]. Die Länge der DNSFragmente sollte nach der Nicktranslation 150-650 bp betragen. In diesem Bereich findet man eine verstärkte Intensität und die einheitlichsten Ergebnisse bei der Hybridisierung. Die Länge der DNS-Fragmente kann durch Änderung der Konzentration der DNase und Polymerase sowie durch Veränderung der Reaktionszeit verändert werden.

Grundsätzlich wurde bei der Nicktranslation auf Eis pipettiert, um die Enzyme nicht vorzeitig zu aktivieren.

Die Berechnung des DNS-Ansatzes erfolgte nach der Formel: 1000/DNS Konzentration $(\mu \mathrm{g} / \mathrm{ml}) \times 3(\mu \mathrm{g})=\ldots . \mu \mathrm{l}$

$\mathrm{Zu}$ den Proben wurden jeweils die aus der oben genannten Formel resultierende Menge an Aqua ad iniect., $10 \mu \mathrm{l}$ Puffer, $2 \mu \mathrm{l}$ dATP dCTP dGTP-Lösung (bestehend aus $5 \mu \mathrm{l}$ dATP, $5 \mu \mathrm{l}$ dCTP, $5 \mu \mathrm{l}$ dGTP und $485 \mu \mathrm{l}$ Aqua bidest), $1 \mu \mathrm{l}$ dTTP Lösung (bestehend aus 495 $\mu \mathrm{l}$ Aqua bidest. und $5 \mu \mathrm{l}$ dTTP), $1 \mu \mathrm{l}$ Biotin, $2 \mu \mathrm{l}$ Polymerase und 1,2 $\mu$ INAse Lösung (bestehend aus $98 \mu \mathrm{l}$ TRIS-HCL und $2 \mu$ DNAse) hinzupipettiert.

Anschließend wurden die Proben bei $15^{\circ} \mathrm{C}$ für 50 min inkubiert.

Die Herstellung der Referenz-DNS erfolgte analog, mit dem Unterschied, dass anstatt Biotin Digoxigenin verwendet wurde und die Inkubationszeit der Proben 60 min betrug.

Die Nicktranslation wurde nach der abgelaufenen Zeit durch Einfrieren der Proben bei -20 ${ }^{\circ} \mathrm{C}$ gestoppt.

Nach der Inkubationszeit erfolgte die DNS-Auftrennung der Nick-Produkte im Agarosegel. Der Vorgang wurde im Punkt DNS-Isolierung ausführlich beschrieben und unterschied sich bei der Nick-Translation nur dadurch, dass der Loading Buffer mit EDTA versetzt war $(900 \mu \mathrm{l}$ Loading Dye, $100 \mu$ I EDTA) und anstatt von Lambda beim Standard puc 19 DNA/Mspl (Hpall) Marker mit Fragmentlängen von 501, 489, 404, 331, 242, 190, 147, 111, 110, 67, 34 
und 26 Basenpaaren verwendet wurde. EDTA diente hierbei der Inaktivierung der Desoxyribonuklease sowie der DNS-Polymerase I.

\subsubsection{Comparative Genomic Hybridisation (CGH)}

Bei der CGH handelt es sich um ein Verfahren, bei dem unterschiedlich markierte TumorDNS (mit Biotin) und Referenz-DNS (mit Digoxigenin) gemischt und auf Metaphasenpräparate hybridisiert werden. Die Metaphasenpräparate wurden aus Lymphozytenkulturen männlicher gesunder Spender durch Arrest in der Metaphase hergestellt; die Referenz-DNS aus gesundem Lebergewebe männlicher und weiblicher Patienten.

\subsubsection{Herstellung des DNS-Pellets}

Zu $100 \mu \mathrm{l}$ Nick-Tumor-DNS wurden $67 \mu \mathrm{l}$ Nick-Referenz- DNS, $80 \mu \mathrm{l}$ Cot-1 DNS (verhindert die unspezifische Hybridisierung noch repetitiver Sequenzen, vor allem an Zentromer- und Telomerregionen), $12 \mu \mathrm{I} \mathrm{NaAc}(\mathrm{pH} 4,8 / 3 \mathrm{M})$ und $680 \mu \mathrm{l}$ reiner Ethanol $\left(-20{ }^{\circ} \mathrm{C}\right)$ pipettiert. Anschließend müssen die Proben mindestens $30 \mathrm{~min}$ bei $-80^{\circ} \mathrm{C}$ aufbewahrt und danach bei $4{ }^{\circ} \mathrm{C}$ und $14000 \mathrm{rpm}$ über 30 min zentrifugiert werden. Nun wurde der Überstand abpipettiert und das Pellet in $800 \mu 170 \%$ Ethanol bei $45^{\circ} \mathrm{C}$ und $1400 \mathrm{rpm}$ zur Lösung von Salzen gewaschen und bei $4{ }^{\circ} \mathrm{C}$ und 14000 rpm für 5 min zentrifugiert. Nach erneutem Abnehmen des Überstands wurde das Pellet für 30 min unter dem Abzug getrocknet. Abschließend wurde zum Pellet $6 \mu$ l deionisiertes Formamid hinzu gegeben und das Pellet im Thermomixer bei $37^{\circ} \mathrm{C}$ und 14000 rpm gelöst.

\subsubsection{Pepsin- Verdau}

Die pepsinolytische Behandlung der Metaphasenpräparate wurde durchgeführt, um die Proteine des Kernplasmas und des Chromatingerüstes zu entfernen.

Zum Pepsin-Verdau wurden $20 \mu \mathrm{l}$ Pepsin und $700 \mu \mathrm{l} 1$ molare $\mathrm{HCl}$ in eine Glasküvette gegeben und vermischt.

Die Objektträger (von Vysis) wurden $5 \mathrm{~min}$ in die Glasküvette getaucht, dann $5 \mathrm{~min}$ in $100 \mathrm{ml}$ 2x SSC, für 5 min in $70 \%$ Ethanol, 5 min in $85 \%$ Ethanol und für 5 min in 100\% Ethanol. Abschließend wurden die Objektträger 30 min zum Trocknen stehen gelassen. 
Tabelle 2.3.5.2/1: Inhaltsstoffe 20 x SSC

\begin{tabular}{|l|l|l|}
\hline Stammlösung & Zusammensetzung & Hersteller \\
\hline 20xSSC & $\begin{array}{l}175,5 \mathrm{~g} \text { Natriumchlorid } \\
88,29 \mathrm{~g} \text { Natriumcitrat- } \\
\text { dihydrat }\end{array}$ & $\begin{array}{l}\text { Merck ; Darmstadt, } \\
\text { Deutschland }\end{array}$ \\
& $\begin{array}{l}1000 \mathrm{ml} \text { Aqua bidest. } \\
\mathrm{pH} 7,0\end{array}$ & \\
\hline
\end{tabular}

\subsubsection{Denaturierung der Objektträger}

Um Kontroll- und Tumor-DNS auf die Metaphasen-Chromosomen hybridisieren zu können, müssen diese als Einzelstränge vorliegen.

Zunächst wurde die Denaturierungslösung hergestellt. Diese bestand aus $5 \mathrm{ml} 20 \times \mathrm{SSC}$ (pH 7), $5 \mathrm{ml} \mathrm{NaH}{ }_{2} \mathrm{PO}_{4}(\mathrm{pH} 7), 5 \mathrm{ml}$ Aqua bidest. und $35 \mathrm{ml}$ deionisiertem Formamid. Bei dieser Lösung wurde ein $\mathrm{pH}$ von 7 eingestellt und sie wurde im Wasserbad auf $69^{\circ} \mathrm{C}$ erhitzt. Jeweils 2 Objektträger wurden nun zunächst für 2 min in die Denaturierungslösung gebracht, dann für jeweils 5 min erst in $70 \%$ Ethanol, dann in $85 \%$ Ethanol, dann in 100\% Ethanol. Abschließend wurden die Objektträger getrocknet und bei $37^{\circ} \mathrm{C}$ auf den Hybrite gelegt.

Tabelle 2.3.5.3/1: Denaturierungslösung

\begin{tabular}{|l|l|l|}
\hline Stammlösung & Zusammensetzung & Hersteller \\
\hline Denaturierungslösung & $5 \mathrm{ml} 20 \mathrm{x} \mathrm{SSC} \mathrm{pH} \mathrm{7,0}$ & \\
& $5 \mathrm{ml} 0,5 \mathrm{M}$ & Merck; Darmstadt, \\
& Natriumdihydrogenphosphat & Deutschland \\
& $5 \mathrm{ml}$ Aqua bidest. & \\
& $35 \mathrm{ml}$ deionisiertes & Fluka; Buchs, Schweiz \\
& Formamid & \\
& $\mathrm{pH} \mathrm{7,0}$ & \\
\hline
\end{tabular}

\subsubsection{Denaturierung der Proben}

Hierzu werden $7 \mu$ l Master Mix (30\% Dextransulfat) zu den Proben pipettiert, 6 min bei $78{ }^{\circ} \mathrm{C}$ denaturiert und 30 min bei $37^{\circ} \mathrm{C}$ vorhybridisiert. 


\subsubsection{Hybridisierung}

Die Hybridisierung ist der ausschlaggebende Faktor für die Auswertbarkeit der Ergebnisse. Wichtig ist, dass die Färbung des Schwesterchromatins eines Chromosoms, die Färbung homologer Chromosomen einer Metaphase und die Färbung gleicher Chromosomen in unterschiedlichen Metaphasen gleich ist. Außerdem soll die Bindung der markierten DNS an die Zentromerregion und an heterochromatinreiche Regionen gering sein und die Metaphasen nur eine geringe Hintergrundfärbung besitzen [Kallioniemi OP et al. 1994]. Die Proben wurden zunächst zentrifugiert, dann wurden $13 \mu$ DNS-Mastermix auf ein Objektträgerfeld aufgetragen. Jedes Objektträgerfeld wurde mit Deckgläschen der Größe $15 \times 15 \mathrm{~mm}$ und Fixogum verschlossen und für 3 Tage in den Hybrite gelegt.

\subsubsection{Ansetzen der Lösungen}

\section{Lösung A (70\% Formamid, 2 x SSC)}

Unter dem Abzug wurden $75 \mathrm{ml}$ nicht-deionisiertes Formamid in ein Becherglas pipettiert, dazu kamen $15 \mathrm{ml} 20$ x SSC und $60 \mathrm{ml}$ Aqua bidest. Mit 5 molarer $\mathrm{HCl}$ wurde der pH-Wert der Lösung auf 7 eingestellt.

\section{Lösung B (2 x SSC)}

In ein Becherglas wurde $40 \mathrm{ml} 20$ x SSC und $360 \mathrm{ml}$ Aqua bidest. gegeben. Mit 5 molarer $\mathrm{HCl}$ wurde auch hier ein $\mathrm{pH}-$ Wert von 7 eingestellt.

\section{Lösung C (4 x SSC, 0,1\%Tween20)}

In ein Becherglas wurden $60 \mathrm{ml} 20$ x SSC, $240 \mathrm{ml}$ Aqua bidest und $300 \mu \mathrm{l}$ Tween20 pipettiert. Mit 5 molarer $\mathrm{HCl}$ wurde ein $\mathrm{pH}$-Wert von 7 eingestellt.

\section{Blockinglösung(3\%)}

$0,15 \mathrm{~g}$ BSA (bovines Serumalbumin) wurden auf einer Feinwaage abgewogen und in einem E-Cup mit $5 \mathrm{ml}$ Lösung $\mathrm{C}$ vermischt.

\section{Detektionslösung(1\%)}

$1 \mathrm{ml}$ Blockinglösung wurde mit $2 \mathrm{ml}$ Lösung $\mathrm{C}$ in einem E-Cup vermischt. 


\subsubsection{Waschen}

Zunächst wurden 3 Küvetten mit Lösung $A$ und 4 Küvetten mit Lösung $B$ im Wasserbad (mit Schüttelefekt) auf $42{ }^{\circ} \mathrm{C}$ erwärmt. Parallel dazu wurde mit Aqua dest. eine Feuchtkammer hergestellt und die Deckgläschen der Objektträger abgepustet. Anschließend wurden die Objektträger 2 min in Lösung B eingetaucht, um das Fixogum einzuweichen. Nachdem das Fixogum herunter genommen wurde, wurden die Objektträger jeweils 5 min 3x durch Lösung A getaucht, anschließend 3x für jeweils 5 min in Lösung $B$, um Verunreinigungen und unspezifisch hybridisierte DNS zu entfernen.

\section{$\underline{\text { 2.3.5.8 Blocken }}$}

Zum Blocken wurden auf jeden Objektträger $300 \mu \mathrm{l}$ Blockinglösung pipettiert, mit einem 24x60 mm großen Deckglas möglichst luftblasenfrei abgedeckt und in der feuchten Kammer eingedeckt. Die Kammer wurde $30 \mathrm{~min}$ bei $37^{\circ} \mathrm{C}$ inkubiert. Die Blockinglösung diente dazu, unspezifische Bindungen der Antikörper zu verhindern.

\subsubsection{Detektieren}

Zunächst muss die Detektionslösung hergestellt werden. Dazu werden $1000 \mu \mathrm{lder}$ Detektionslösung in ein dunkles E-Cup pipettiert und $15 \mu$ l Digoxigenin-Rhodamin und $5 \mu \mathrm{l}$ FITC-Avidin hinzugegeben und $10 \mathrm{~min}$ bei $37^{\circ} \mathrm{C}$ auf den Thermomixer mit Schütteleffekt (1000 rpm) gestellt und anschließend 3 min bei 8000 rpm zentrifugiert. Den Überstand (860$900 \mu \mathrm{l}) \mathrm{gab}$ man in ein neues, mit Alufolie abgedunkeltes E-Cup. Diese Menge reichte für 2-3 Objektträger aus.

Wichtig ist, dass von nun an im Dunklen gearbeitet wurde, da Fluoreszin-Avidin und antiDigoxigenin-Rhodamin lichtempfindlich sind. Fluoreszin-Avidin bindet an Biotin, antiDigoxigenin-Rhodamin bindet an Digoxigenin. In dem Wellenlängenbereich ihrer Emission senden diese Fluorchrome bei Anregung rotes bzw. grünes Licht aus, welches proportional zur Menge der DNS ist. Zunächst wurden die Objektträger aus der feuchten Kammer genommen, die Deckgläschen vorsichtig entfernt und die Objektträger mit Lösung $C 3 x$ abgespült. Anschließend wurden $300 \mu$ l Detektionslösung auf jeden Objektträger gegeben und neue Deckgläser aufgesetzt. Die Objektträger wurden dann 45-60 min in der feuchten Kammer inkubiert. Währenddessen wurde Lösung $\mathrm{C}$ im Wasserbad auf $42{ }^{\circ} \mathrm{C}$ erwärmt. Nach der Inkubationszeit wurden die Deckgläser erneut entfernt und die Objektträger $3 x$ für je 5 min in Lösung $C$ gestellt. Nun wurde das DAPI angesetzt. Dazu wurde das fertige DAPI aus der Zytogenetik ( $1 \mathrm{ml}$ Vectashield, $50 \mu$ l Actinomycin, $1 \mu$ DAPI) verwendet. Anschließend 
wurden auf jeden Objektträger $20 \mu \mathrm{L}$ DAPI pipettiert und die Objektträger mit 24x60 mm großen Deckgläsern versehen.

DAPI bindet an A-T-reiche Regionen, ist Actinomycin-D-Mannitol gefärbt und gibt den Chromosomen so das charakteristische QFH-Bandenmuster [Schweizer 1976 a, b; Schweizer und Nagl 1976].

Die Objektträger wurden nun im Präparatekasten bei $4{ }^{\circ} \mathrm{C}$ gelagert und innerhalb der nächsten 2 Wochen fotografiert.

\subsubsection{Auswertung der CGH}

\subsubsection{Fotografieren}

Mit Hilfe des Fluoreszenz-Mikroskops und der Metafer-Software wurden Metaphasen mit einem 10x Übersichtsobjektiv und einem 63x Ölimmersionsobjektiv gesucht, die sich besonders für die Auswertung eigneten. Gemeint sind damit Metaphasen, bei welchen die Chromosomen möglichst nebeneinander liegen und sich nicht überkreuzen. Pro Metaphase wurden dann mit einer aufgesetzten computergesteuerten CCD-Kamera (charge-coupleddevice) bei 820x Vergrößerung 3 monochrome Bilder für FITC, Rhodamin (TRITC) und DAPI mit dafür geeigneten Lichtfiltern aufgenommen. Die Anregung der Fluorchrome erfolgte für DAPI bei 330-370 nm, für FITC (grün) bei $505 \mathrm{~nm}$ und für Rhodamin (rot) bei 580-590 nm. Die Emission wurde für DAPI bei einer Wellenlänge von 450-460 nm, für grün bei $535 \mathrm{~nm}$ und für rot bei 615-639 nm gemessen. Daraufhin wurden die drei Bilder überlagert, sodass ein Tripel-Bild entstanden ist. Pro Fall wurden 20 Bilder fotografiert.

\subsubsection{Auswertung der Bilder}

Mit Hilfe des CGH-Auswertungsprogramms wurden pro untersuchter Gewebeprobe 20 Metaphasen ausgewertet und ein CGH- Profil erstellt. Die einzelnen Chromosomen wurden mit einer Scherefunktion ausgeschnitten, an Hand ihrer Bänderung karyotypisiert und nach der Nomenklatur für humane Chromosomen geordnet [Shaffer und Tommeruo 2005]. Stark verunreinigte, verbogene und übereinanderliegende Chromosomen wurden aussortiert. Abbildung 2.3.6.2/1 zeigt das Bild einer Metaphase nach CGH sowie korrektem Fotografieren und Legen des Karyogrammes. 


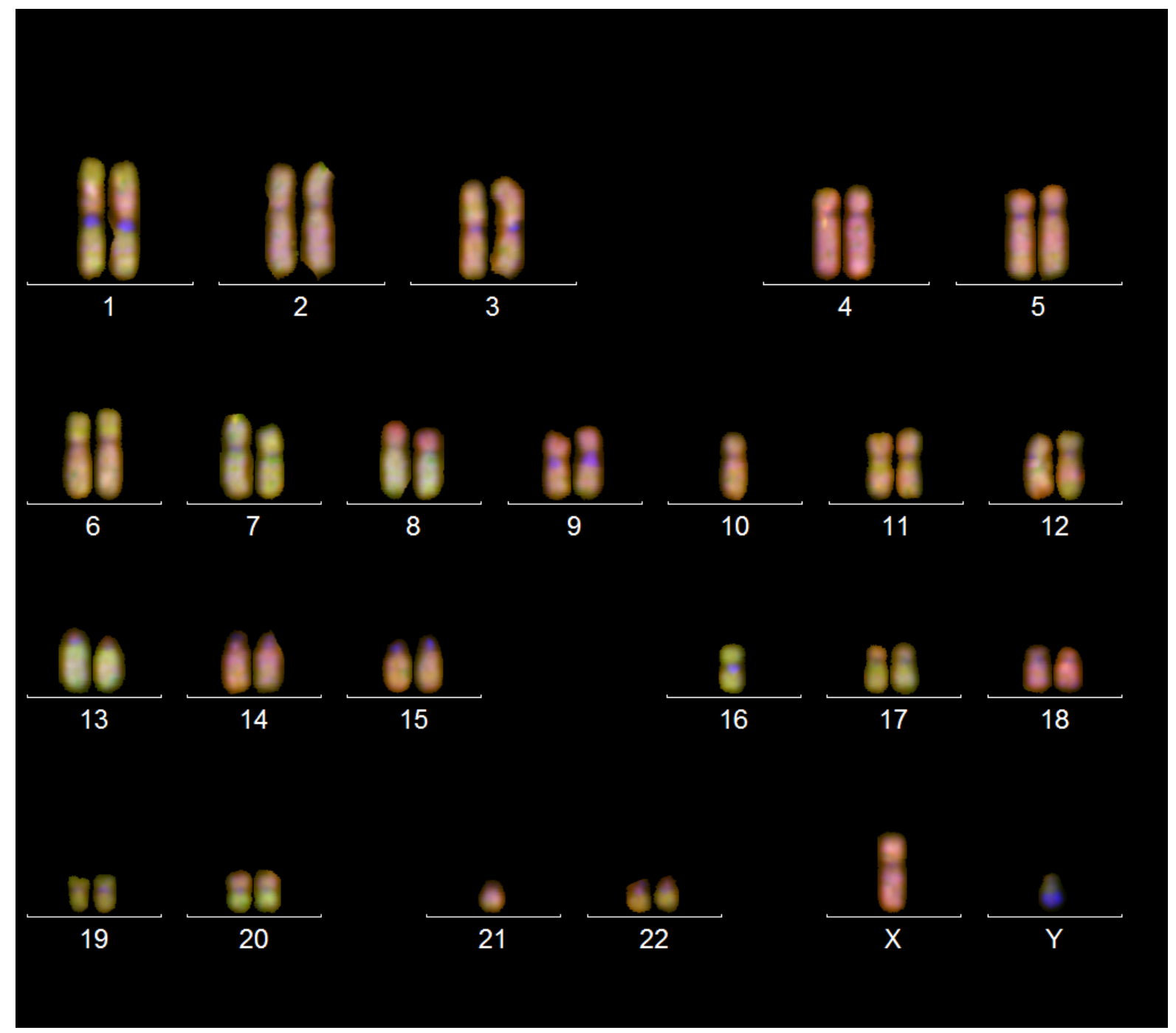

Abbildung 2.3.6.2/1: Bild einer Metaphase nach CGH

Nach der Karyotypisierung konnte mit der Software ein Fluoreszenzprofil erstellt werden, das das Verhältnis der Intensitäten von FITC zu TRITC widerspiegelte.

Abbildung 2.3.6.2/2 verdeutlicht, wie ein CGH-Profil erstellt wird.

Die Linie in der Mitte entspricht dem Ratio-Wert 1, Tumor- und Referenz-DNS liegen also in gleicher Menge vor. Eine Verschiebung der Kurve nach rechts zeigt einen Zugewinn von Chromosomenmaterial, also einer Zunahme der Intensität des grünen Fluoreszenzlichtes. Analog entspricht eine Verschiebung der Kurve nach links einer Deletion, also einer Intensitätszunahme des roten Fluoreszenzlichtes. 


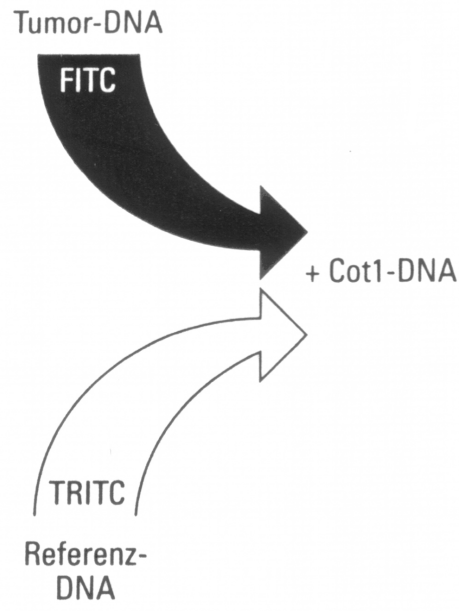

Abbildung 2.3.6.2/2: Erstellung eines CGH- Profiles [aus Hentze et al. 2000, S.20] Aussage treffen zu können.

Abbildung 2.3.6.2/3 zeigt ein solches Summenideogramm.

Die Grenze für den Verlust wurde bei 0,8 und für den Zugewinn bei 1,2 gesetzt. Als Amplifikation galt ein Zugewinn von $>1,5$.

Grüne Balken visualisieren Überschreitungen des 95\% Konfidenzintervalls über das RatioVerhältnis $>1,2$. Rote Balken zeigen ein Ratio-Verhältnis von $<0,8$.

Im Einzelfall wurden, wenn diese Grenzen nicht erreicht wurden, aber ein eindeutiger Trend vorhanden war, diese Veränderungen auch als trend-Verlust bzw. als trend-Gewinn definiert. Erkennbar waren diese Veränderungen durch rote bzw. grüne Balken neben den Chromosomen. Sie wurden mittels der Nomenklatur für humane Chromosomen [Shaffer und Tommeruo 2005] beschrieben.

Die Chromosomen (-arme) 1p, 16p, 17, 19, 20q, 22q und y wurden mit besonderer Vorsicht interpretiert. 


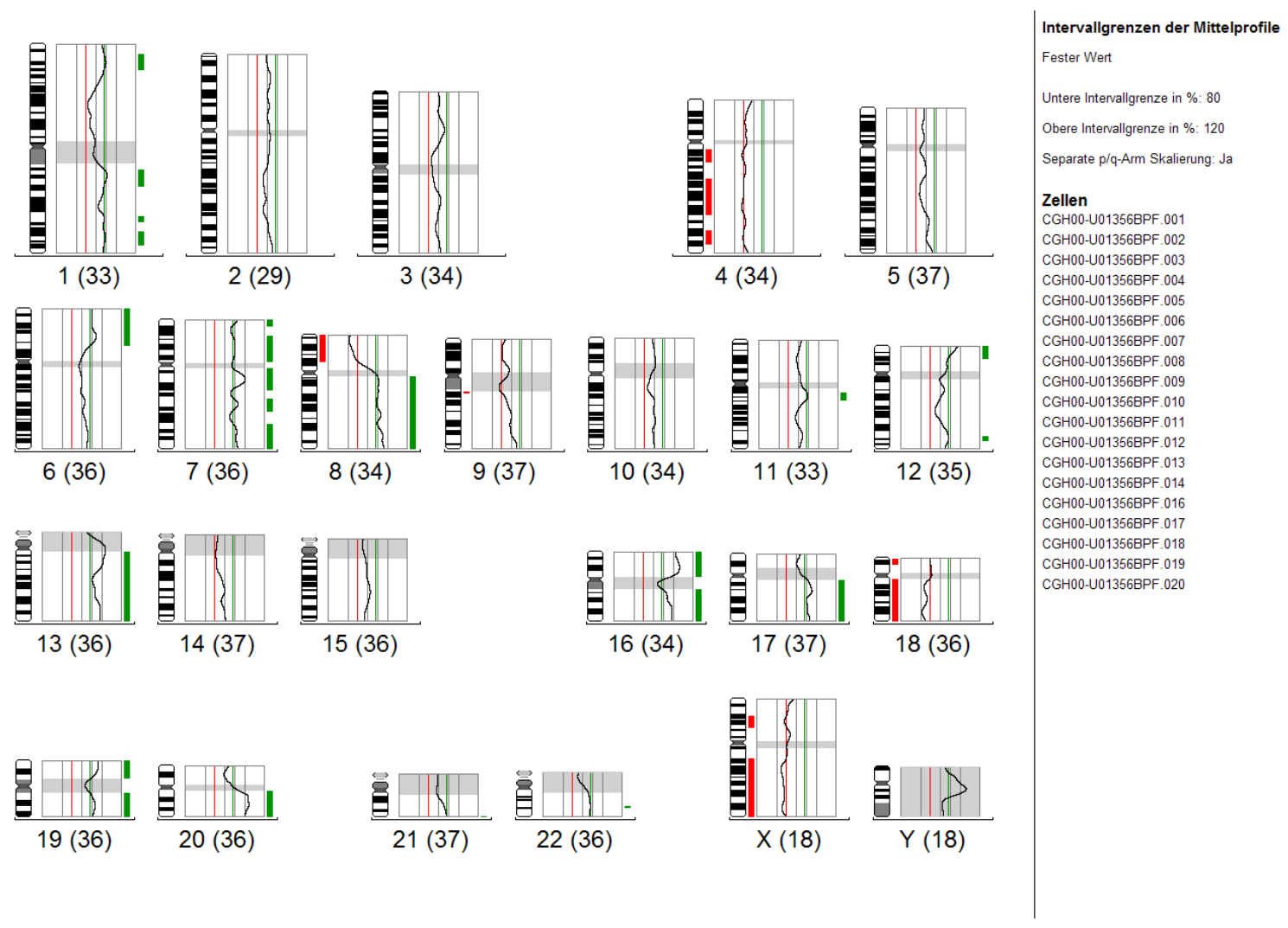

Abbildung 2.3.6.2/3: Summenideogramm

In 11 Fällen ist die CGH trotz Wiederholung nicht gelungen. Diese Fälle wurden in der Auswertung nicht berücksichtigt. Chromosomale Aberrationen wurden in 32 von 34 PT (94\%) und in 94 von 102 (92\%) der Lebermetastasen gefunden.

\subsection{Statistische Methoden}

Die Gesamtanzahlen an Veränderungen, Zugewinnen, Verlusten und Amplifikationen sowie die Häufigkeit der Veränderungen der Einzelarme wurden jeweils mit einer einfaktoriellen Varianzanalyse für Daten mit Messwiederholungen (teilweise mehrere Metastasen pro Patient) zwischen den Primärtumoren (PT) und den zugehörigen Lebermetastasen (Met) verglichen. In gleicher Weise wurden der Einfluss der Parameter Geschlecht, T- und NKlassifikation und Lokalisation auf die Genetik untersucht.

Der vorliegende Datensatz setzt sich aus Messwerten für PT und Met zusammen, die zum Teil von denselben Patienten stammen, zum Teil aber unabhängig voneinander sind. Hierbei handelt es sich insgesamt um 34 PT und 102 Met, darunter 25 PT mit 29 korrespondierenden Met von 25 Patienten mit PT KRK. Dies beinhaltet, dass teilweise Informationen über Met ohne zugehörigen PT vorliegen, andererseits Informationen über PT ohne zugehörige Met vorliegen. 
Die statistische Gegenüberstellung von PT $(n=25)$ und ihren zugehörigen Met $(n=29)$ lässt sich wie oben beschrieben mit varianzanalystischen Verfahren für Daten mit Messwiederholungen, bzw. mit gemischten linearen Modellen, durchführen. Diese Gegenüberstellung habe ich sowohl für die Einzelarme, als auch für die Gesamtzahlen an Veränderungen, Verlusten, Gewinnen und Amplifikationen in meine Arbeit mit aufgenommen.

Für die Gegenüberstellung der unabhängigen 34 PT und den (nur teilweise korrespondierenden) 102 Met lässt sich die Varianzanalyse nicht unverzerrt durchführen. Hier wurden daher nur absolute und relative Häufigkeiten betrachtet und in die Arbeit mit aufgenommen. Die Angabe eines verlässlichen p-Wertes ist hier nicht möglich. Dazu habe ich mich eingehend in der Abteilung Medizinische Statistik der Georg-August-Universität Göttingen beraten lassen.

Die Dauer von der OP des PT bis zur ersten Metastase wurden mit Kaplan-Meier-Kurven analysiert. Die onkogenetischen Bäume wurden nach dem von-Heydebreck-Modell [von Heydebreck et al. 2004] berechnet. Die Wurzel des Baumes zeigt das Stadium einer normalen Zelle, welche ihre erste genetische Veränderung erfährt. Jede sichtbare genetische Veränderung wird durch ein terminales Blatt des Baumes dargestellt. Die Knoten innerhalb des Baumes repräsentieren versteckte genetische Alterationen, welche nicht direkt beobachtet werden können. Häufige, früh auftretende genetische Veränderungen sind stammnah aufgezeichnet. Eine positive Korrelation zwischen genetischen Veränderungen, die dazu neigen gemeinsam aufzutreten, sind an dem Schnittpunkt ihrer Wege zu erkennen. Das Signifikanzniveau wurde mit $\alpha=5 \%$ festgelegt. Bei den Einzelarmen wurden die $p$ Werte bezüglich einer False Discovery Rate von ebenfalls 5\% adjustiert, um eine zu hohe Zahl an falsch positiven Testentscheidungen zu verhindern. Alle Analysen wurden mit der freien Software R (Version 2.8, www.r-project.org) sowie mit der Software GraphPad Prism, 4. Version vorgenommen.

\subsection{Ethische Aspekte}

Die vorliegende Dissertation ist Teil der Studie "Molekulargenetische Charakterisierung von chemotherapierten und nicht-chemotherapierten kolorektalen Karzinomen und ihre Leber-, Lungen-und Gehirnmetastasen mittels der komparartiven genomischen Hybridisierung“.

Die Ethik-Kommission der Universitätsmedizin der Georg-August-Universität hat am 25.11.05 keine ethischen oder rechtlichen Bedenken gegenüber der Studie geäußert. 


\section{Ergebnisse}

Das Gesamtkollektiv mit 34 Primärtumoren (PT) kolorektaler Karzinome (KRK) und102 Lebermetastasen (Met) KRK enthält ein kleineres Teilkollektiv, bei dem die PT von 25 Patienten mit PT KRK und deren korrespondierende Met $(n=29)$ vorhanden waren. Es wird erst dieses kleinere Kollektiv ausgewertet, anschließend erfolgt die Auswertung aller untersuchten PT KRK ( $n=34)$ und aller untersuchten Met $(n=102)$ von 93 Patienten mit PT KRK und/oder korrespondierenden Met.

\subsection{Auswertung der 25 PT KRK und ihrer korrespondierenden 29 Met}

\subsubsection{Auswertung der PT von 25 Patienten mit PT KRK und korrespondierenden Met $(n=29)$}

a) TNM-Stadium

\section{pT-Klassifikation}

Im untersuchten Kollektiv befanden sich 25 Patienten, bei denen sowohl der PT $(n=25)$ als auch die dazugehörigen Met $(n=29)$ untersucht wurden. Von den 25 PT wurden $5(20 \%)$ als pT2, 19 (76\%) als pT3 und 1 (4\%) als pT4 klassifiziert.

\section{pN-Klassifikation}

Bei 8 Patienten (32\%) fand sich ein pN0-, bei 8 Patienten (32\%) ein pN1- und bei 9 Patienten $(36 \%)$ ein pN2- Stadium (Tab. 3.1.1/1).

Tabelle 3.1.1/1: Zusammenhang zwischen dem pT- und dem pN- Stadium der PT von 25 Patienten mit PT KRK und korrespondierenden Met $(n=29)$

\begin{tabular}{|l|l|l|l|}
\hline & $\mathrm{pT} 2$ & $\mathrm{pT} 3$ & $\mathrm{pT} 4$ \\
\hline $\mathrm{pN} 0$ & 2 & 5 & 1 \\
\hline pN1 & 1 & 7 & 0 \\
\hline pN2 & 2 & 7 & 0 \\
\hline
\end{tabular}


Bei 12 (48\%) Patienten lagen bereits bei OP des PT Met vor, bei den verbliebenen 13 (52\%) Patienten war der Status der Fernmetastasen zum Zeitpunkt der Untersuchung des OPPräparates des PT nicht eruiert wurden.

\section{b) Klinische Angaben}

Im Median entwickelten die 25 Patienten unseres Kollektivs mit PT KRK und korrespondierenden Met nach 19,6 Monaten Met.

Die Wahrscheinlichkeit 12 Monate nach der OP des PT keine Metastasen zu haben beträgt 66\%, 24 Monate nach der OP des PT 40\%, 36 Monate nach der OP des PT 20\% und 48 Monate nach der OP des PT 10\% (Abb. 3.1.1/1).

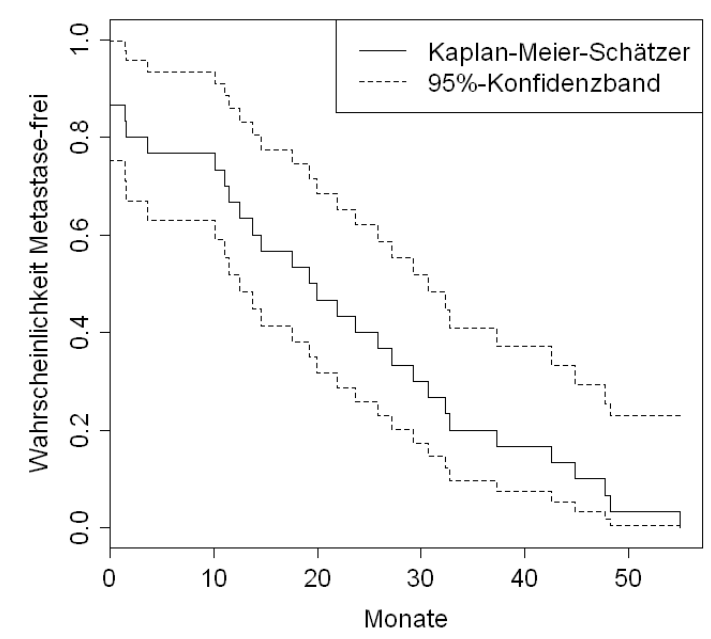

Abbildung 3.1.1/1: Kaplan-Meier-Kurve für das Nichtauftreten von Met nach OP des PT $(n=25)$ von 25 Patienten mit PT KRK und korrespondierenden Met $(n=29)$

c) $\mathrm{CGH}$ der PT von 25 Patienten mit PT KRK und korrespondierenden Met $\underline{(n=29)}$

Bei den PT von 25 Patienten mit PT KRK und korrespondierenden Met waren es insgesamt im Median 8 chromosomale Aberrationen. Die Anzahl der Zugewinne betrug insgesamt im Median 3, die der Verluste insgesamt im Median ebenfalls 3 und die Anzahl der Amplifikationen betrug im Median 0 (Tab. 3.1.1/2). 
Tabelle 3.1.1/2: Übersicht über die CGH-Ergebnisse der 25 PT von 25 Patienten mit PT KRK und korrespondierenden Met $(n=29)$

\begin{tabular}{|l|l|}
\hline Parameter & $\begin{array}{l}\text { PT } \\
(\mathrm{n}=25)\end{array}$ \\
\hline Median Aberrationen (Range) & $8(0-21)$ \\
\hline Median Zugewinne (Range) & $3(0-10)$ \\
\hline Median Verluste (Range) & $3(0-12)$ \\
\hline Median Amplifikationen (Range) & $0(0-3)$ \\
\hline
\end{tabular}

Bei den 5 pT2-Tumoren von 25 Patienten mit PT KRK und korrespondierenden Met waren es insgesamt im Median 8 chromosomale Aberrationen, die Anzahl der Zugewinne betrug im Median 2, die der Verluste 3. Bei den 19 pT3-Tumoren von 25 Patienten mit PT KRK und korrespondierenden Met waren es insgesamt im Median 9 chromosomale Aberrationen, darunter befanden sich im Median 4 Zugewinne und 3 Verluste. Bei dem einen pT4-Tumor von 25 Patienten mit PT KRK und korrespondierenden Met fanden wir 5 chromosomale Aberrationen, darunter 4 Zugewinne und einen Verlust (Tab. 3.1.1/3).

Tabelle 3.1.1/3: Anzahl der chromosomalen Aberrationen bezogen auf das pT-Stadium der 25 PT von 25 Patienten mit PT KRK und korrespondierenden Met $(n=29)$

\begin{tabular}{|l|l|l|l|l||}
\hline & pT2 & pT3 & pT4 & $\begin{array}{l}\text { p-Wert } \\
\text { (Kruskal- } \\
\text { Wallis-Test) }\end{array}$ \\
\hline $\mathbf{n}$ & 5 & 19 & 1 & 0,76 \\
\hline $\begin{array}{l}\text { Median } \\
\text { Aberrationen } \\
\text { (Range) }\end{array}$ & $8(0-8)$ & $9(0-21)$ & $5(0-5)$ & 0,47 \\
\hline $\begin{array}{l}\text { Median } \\
\text { Zugewinne } \\
\text { (Range) }\end{array}$ & $2(0-6)$ & $4(0-12)$ & $4(0-4)$ & 0,45 \\
\hline $\begin{array}{l}\text { Median Verluste } \\
\text { (Range) }\end{array}$ & $3(0-6)$ & $3(0-12)$ & $1(0-1)$ & \\
\hline
\end{tabular}

Bei den 8 pN0-Tumoren von 25 Patienten mit PT KRK und korrespondierenden Met waren es insgesamt im Median 5 chromosomale Aberrationen, darunter im Median 4 Zugewinne und ein Verlust. Bei den 8 pN1-Tumoren von 25 Patienten mit PT KRK und 
korrespondierenden Met waren es insgesamt im Median 5 chromosomale Aberrationen. Die Anzahl der Zugewinne betrug bei den 8 pN1-Tumoren von 25 Patienten mit PT KRK und korrespondierenden Met im Median 2, die der Verluste 3. Bei den 9 pN2-Tumoren von 25 Patienten mit PT KRK und korrespondierenden Met waren es insgesamt im Median 10 chromosomale Aberrationen, darunter im Median 5 Zugewinne und 5 Verluste (Tab. 3.1.1/4).

Tabelle 3.1.1/4: Anzahl der chromosomalen Aberrationen bezogen auf das pN-Stadium der 25 PT von 25 Patienten mit PT KRK und korrespondierenden Met $(n=29)$

\begin{tabular}{|l|l|l|l|l||}
\hline & pN0 & pN1 & pN2 & $\begin{array}{l}\text { p-Wert } \\
\text { (Kruskal- } \\
\text { Wallis-Test) }\end{array}$ \\
\hline $\mathbf{n}$ & 8 & 8 & 9 & 0,04 \\
\hline $\begin{array}{l}\text { Median } \\
\text { Aberrationen } \\
\text { (Range) }\end{array}$ & $5(0-13)$ & $5(0-10)$ & $10(0-16)$ & 0,27 \\
\hline $\begin{array}{l}\text { Median } \\
\text { Zugewinne } \\
\text { (Range) }\end{array}$ & $4(0-10)$ & $2(0-7)$ & $5(0-11)$ & 0,02 \\
\hline $\begin{array}{l}\text { Median Verluste } \\
\text { (Range) }\end{array}$ & $1(0-3)$ & $3(0-7)$ & $5(0-10)$ & \\
\hline
\end{tabular}

Der Zusammenhang zwischen der Zeitspanne der OP des PT und der OP der Met sowie der Anzahl der Aberrationen des PT ist in Tab. 3.1.1/5 dargestellt.

Tabelle 3.1.1/5: Zusammenhang zwischen der Zeitspanne Operation (OP) des PT bis OP der Met und Anzahl der Aberrationen des PT von 25 Patienten mit PT KRK und korrespondierenden Met $(n=29)$

\begin{tabular}{|l|l|l|}
\hline $\begin{array}{l}\text { Patient } \\
\text { (anonymisiert) }\end{array}$ & $\begin{array}{l}\text { Zeitspanne OP PT- } \\
\text { OP Met }\end{array}$ & $\begin{array}{l}\text { Anzahl der } \\
\text { Aberrationen des } \\
\text { PT }\end{array}$ \\
\hline 1 & 29 Monate, 9 Tage & 21 \\
\hline 2 & 55 Monate & 5 \\
\hline 3 & 0 Monate, 0 Tage & 0 \\
\hline 4 & $\begin{array}{l}1 . \text { Met: 19 Monate, 5 } \\
\text { Tage }\end{array}$ & 3 \\
\hline
\end{tabular}




\begin{tabular}{|c|c|c|}
\hline & $\begin{array}{l}\text { 2.Met: } 30 \text { Monate, } 23 \\
\text { Tage }\end{array}$ & \\
\hline 5 & 10 Monate, 1 Tag & 5 \\
\hline 6 & 0 Monate, 0 Tage & 9 \\
\hline 7 & 0 Monate, 0 Tage & 10 \\
\hline 8 & $\begin{array}{l}\text { 1.Met: } 0 \text { Monate, } 0 \\
\text { Tage } \\
\text { 2.Met: } 13 \text { Monate, } 18 \\
\text { Tage } \\
\text { 3.Met: } 27 \text { Monate, } 3 \\
\text { Tage }\end{array}$ & 10 \\
\hline 9 & 21 Monate, 25 Tage & 5 \\
\hline 10 & 3 Monate, 20 Tage & 9 \\
\hline 11 & 47 Monate, 25 Tage & 10 \\
\hline 12 & 1 Monat, 13 Tage & 13 \\
\hline 13 & 17 Monate, 17 Tage & 6 \\
\hline 14 & 11 Monate, 14 Tage & 10 \\
\hline 15 & 1 Monat, 18 Tage & 8 \\
\hline 16 & 23 Monate, 19 Tage & 10 \\
\hline 17 & 25 Monate, 26 Tage & 8 \\
\hline 18 & 14 Monate, 17 Tage & 11 \\
\hline 19 & 19 Monate, 29 Tage & 5 \\
\hline 20 & 42 Monate, 18 Tage & 8 \\
\hline 21 & 32 Monate, 6 Tage & 17 \\
\hline 22 & 37 Monate, 9 Tage & 2 \\
\hline 23 & $\begin{array}{l}\text { 1.Met: } 11 \text { Monate, } 1 \\
\text { Tag } \\
\text { 2.Met: } 12 \text { Monate, } 15 \\
\text { Tage }\end{array}$ & 1 \\
\hline 24 & 32 Monate, 23 Tage & 5 \\
\hline 25 & 48 Monate, 8 Tage & 0 \\
\hline
\end{tabular}




\section{d) Onkogenetischer Baum der 25 PT von 25 Patienten mit PT KRK und korrespondierenden Met $(n=29)$}

Aus dem Stammbaum der PT von 25 Patienten mit PT KRK und korrespondierenden Met (Abb. 3.1.1/2) lässt sich herleiten, dass der Zugewinn von 13q und $20 q$ sowie der Verlust von $18 q$ bereits sehr früh in der Tumorigenese KRK auftritt. Spät hingegen fanden sich Verluste von $4 p, 8 p$ und $17 p$. Häufige gemeinsame Veränderungen sind der Zugewinn von $7 p$ gemeinsam mit dem Zugewinn von 7q, der Verlust von $8 p$ gemeinsam mit dem Zugewinn von $8 \mathrm{q}$, der Verlust von 17p gemeinsam mit dem Verlust von 18p sowie der gemeinsame Verlust von $4 p$ und $4 q$.

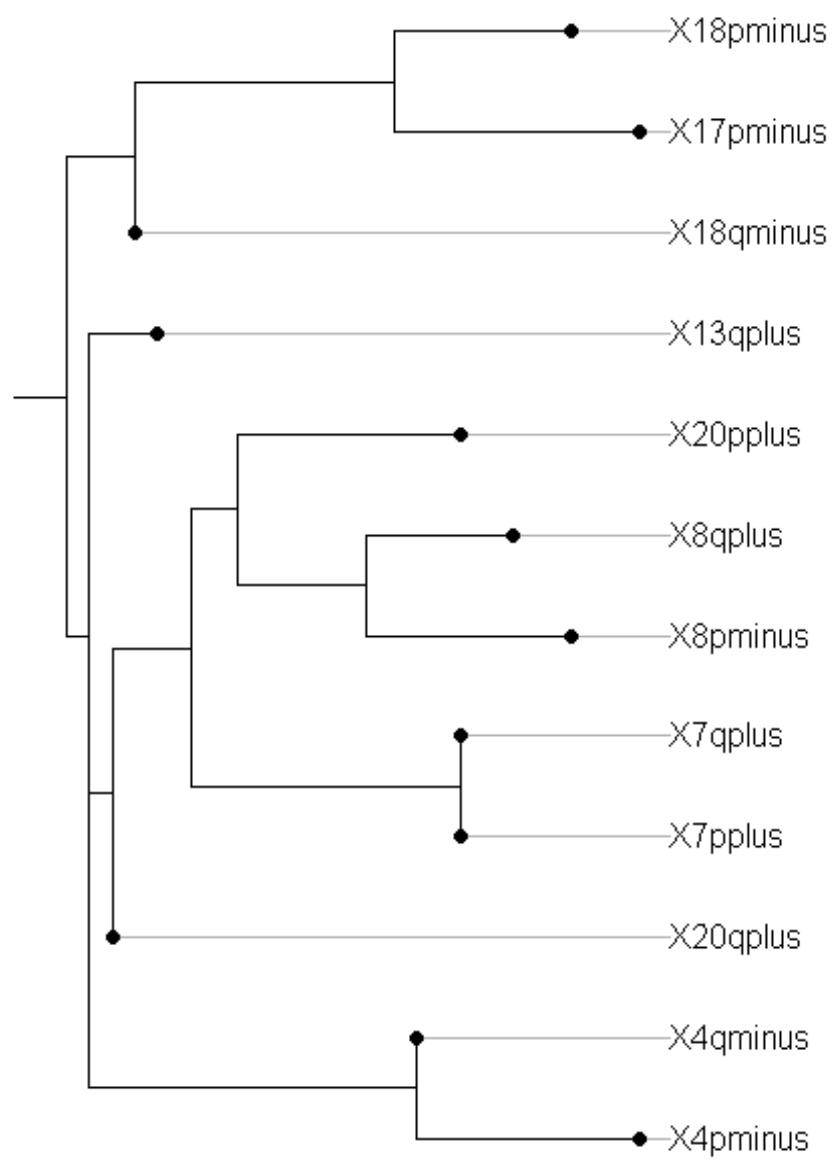

Abbildung 3.1.1/2: Onkogenetischer Baum der 25 PT von 25 Patienten mit PT KRK und korrespondierenden Met $(n=29)$ 


\subsubsection{Auswertung der 29 korrespondierenden Met der 25 Patienten mit PT KRK und korrespondierenden Met}

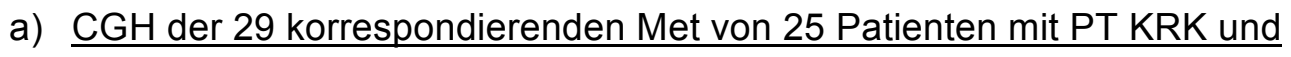
korrespondierenden Met

Bei den 29 korrespondierenden Met von 25 Patienten mit PT KRK fanden sich insgesamt im Median 8 chromosomale Aberrationen. Die Anzahl der Zugewinne betrug bei den 29 korrespondierenden Met insgesamt im Median 3, die der Verluste 3 und die Anzahl der Amplifikationen betrug im Median 0 (Tab. 3.1.2/1).

Tabelle 3.1.2/1: Übersicht über die CGH-Ergebnisse der Met ( $n=29)$ der 25 PT KRK

\begin{tabular}{|l|r|}
\hline Parameter & $\begin{array}{l}\text { Met } \\
(\mathrm{n}=29)\end{array}$ \\
\hline Median Aberrationen (Range) & $8(0-29)$ \\
\hline Median Zugewinne (Range) & $3(0-18)$ \\
\hline Median Verluste (Range) & $3(0-10)$ \\
\hline Median Amplifikationen (Range) & $0(0-5)$ \\
\hline
\end{tabular}

b) Onkogenetischer Baum der 29 korrespondierenden Met von 25 Patienten mit PT KRK

Analog gilt für den Stammbaum der korrespondierenden 29 Met von 25 Patienten mit PT KRK (Abb. 3.1.2/1), dass Zugewinne von 13q und 20q sowie ein Verlust von 18q früh in der Tumorigenese auftreten, wohingegen wir Verluste von 1p und 18p, sowie einen Zugewinn von 17q erst spät in der Tumorigenese beschreiben können. Häufig tritt ein Zugewinn von 8q gemeinsam mit einem Verlust von 8p auf. Weitere gemeinsame Veränderungen sind Zugewinne von $7 p$ und $7 q$, Verluste von $18 p$ und $18 q$ sowie einen Zugewinn von $20 p$ gemeinsam mit einem Verlust von $4 \mathrm{q}$.

Im Vergleich zu den PT KRK zeigen die Met zusätzliche im Verlauf der Tumorigenese auftretende Zugewinne von Chromosomenarm $6 p$ und 17q, sowie spät auftretende Verluste von Chromosomenarm $1 \mathrm{p}$. 


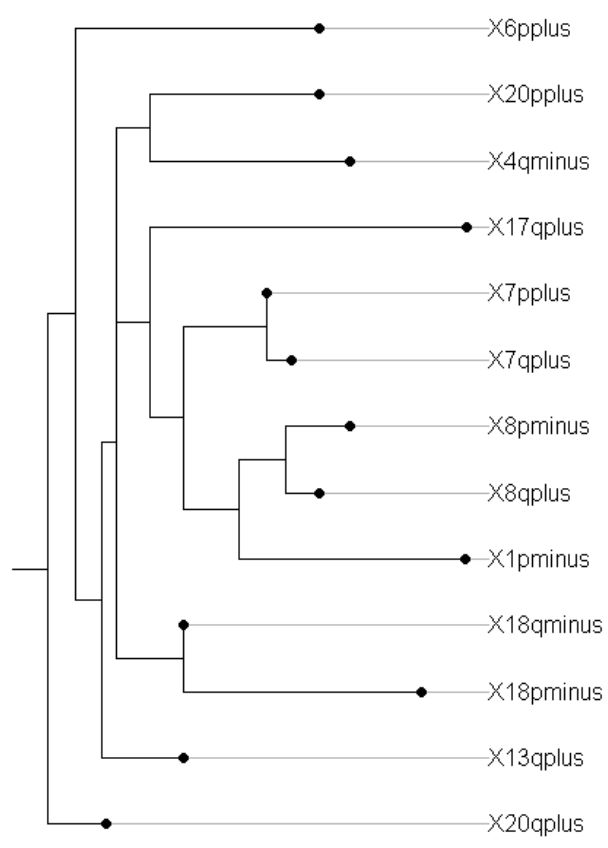

Abbildung 3.1.2/1: Onkogenetischer Baum der korrespondierenden Met $(n=29)$ der 25 PT KRK

3.1.3 Vergleich zwischen den 25 PT KRK und den korrespondierenden 29 Met

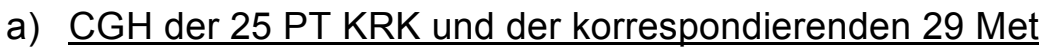

Insgesamt fanden sich bei den PT von 25 Patienten mit PT KRK und korrespondierenden Met im Median 8 chromosomale Aberrationen, darunter im Median insgesamt 3 Zugewinne, 3 Verluste und 0 Amplifikationen. Bei den korrespondierenden 29 Met von 25 Patienten mit PT KRK fanden sich insgesamt ebenfalls im Median 8 chromosomale Aberrationen, darunter im Median 3 Zugewinne, 3 Verluste und 0 Amplifikationen. Es fand sich kein signifikanter Unterschied an Zugewinnen, Verlusten und Amplifikationen zwischen den 25 PT KRK und deren korrespondierenden Met $(n=29)$ (Tab. 3.1.3/1). 
Tabelle 3.1.3/1: Übersicht über die CGH-Ergebnisse der 25 PT KRK und ihrer korrespondierenden Met $(n=29)$

\begin{tabular}{|l|r|r|r|}
\hline Parameter & \multicolumn{1}{l|}{$\begin{array}{l}\text { PT } \\
(\mathrm{n}=25)\end{array}$} & $\begin{array}{l}\text { Met } \\
(\mathrm{n}=29)\end{array}$ & $\begin{array}{l}\text { Whitney-U Test) } \\
\text { Wedian Aberrationen (Range) }\end{array}$ \\
\hline Median Zugewinne (Range) & $3(0-10)$ & $3(0-18)$ & 0,96 \\
\hline Median Verluste (Range) & $3(0-12)$ & $3(0-10)$ & 0,75 \\
\hline Median Amplifikationen (Range) & $0(0-3)$ & $0(0-5)$ & 1,0 \\
\hline
\end{tabular}

Die Abbildungen 3.1.3/1-4 verdeutlichen sowohl die gemeinsamen chromosomalen Aberrationen der 25 PT KRK und ihrer korrespondierenden 29 Met als auch die zusätzlichen chromosomalen Aberrationen der 25 PT KRK beziehungsweise die zusätzlichen chromosomalen Aberrationen der 29 korrespondierenden Met.

Die Auswertung erfolgt hierbei separat bei 22 Patienten mit einer untersuchten korrespondierenden Met (Abb. 3.1.3/1+2) bzw. 3 Patienten mit 2-3 untersuchten korrespondierenden Met (Abb. 3.1.3/3+4). In den Abbildungen aufgeführt sind nur die Chromosomenarme, an welchen Aberrationen detektiert wurden.

Die häufigsten gemeinsamen Zugewinne der 22 PT KRK mit einer untersuchten korrespondierenden Met waren Zugewinne von 6p, 7, 8q, 13q, 17q und 20. Der häufigste primär bei den PT zu beobachtende Zugewinn war der Zugewinn von 13q. Die häufigsten zusätzlichen Zugewinne der Met waren Zugewinne von 6p, 7 und 12q (Abb. 3.1.3/1).

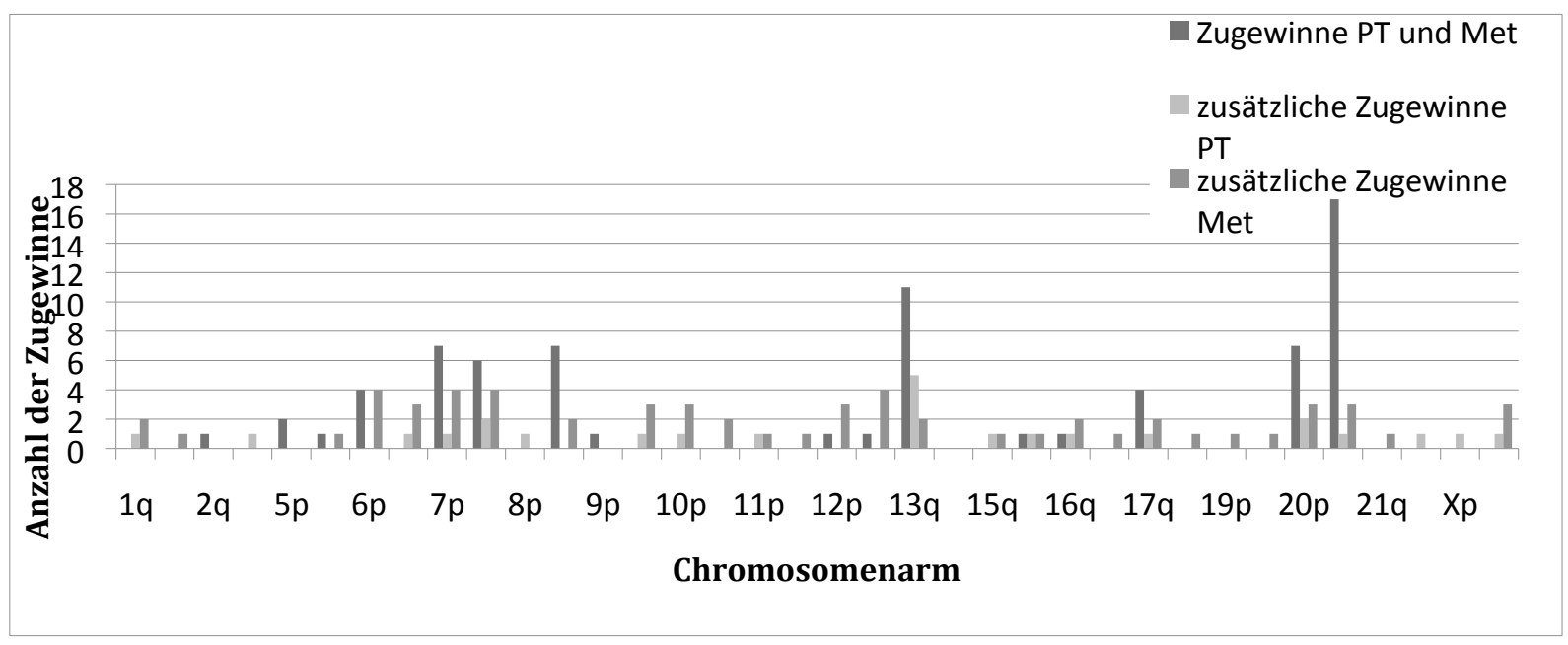

Abbildung 3.1.3/1: Zugewinne bei PT mit einer korrespondierenden Met $(n=22)$

Die häufigsten gemeinsamen Verluste der 22 PT mit einer untersuchten korrespondierenden Met waren Verluste von 4q, 8p und 18q, die häufigsten vorrangig bei den PT zu 
beobachteten Verluste waren Verluste von 4 und 18q. Die häufigsten zusätzlichen Verluste der Met waren Verluste von 1p und 18p (Abb. 3.1.3/2).

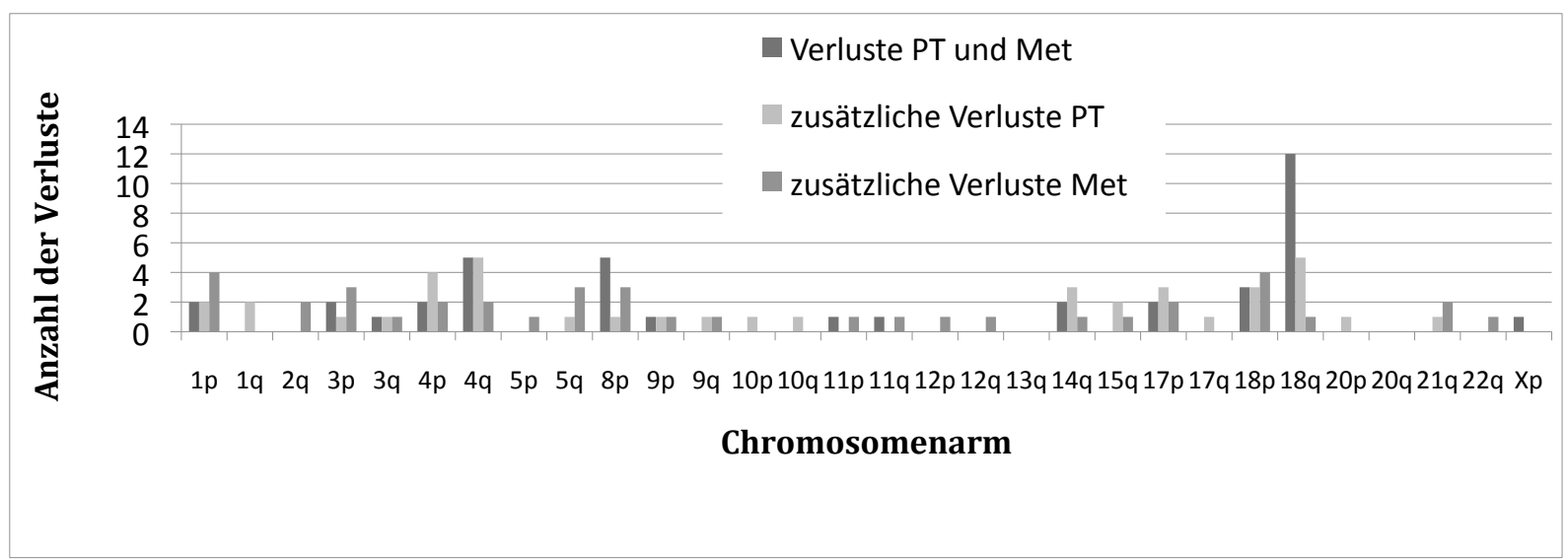

Abbildung 3.1.3/2: Verluste bei PT mit einer korrespondierenden Met $(n=22)$

Bei 3 Patienten mit PT KRK haben wir 2-3 korrespondierende Met untersucht. Die CGHErgebnisse dieser Patienten sind im Folgenden dargestellt (Abbildungen 3.1.3/3+4).

Der häufigste gemeinsame Zugewinn bei 3 Patienten mit PT KRK und 2-3 untersuchten korrespondierenden Met ist ein Zugewinn von 13q, der häufigste primär bei den PT zu beobachtende Zugewinn ist ein Zugewinn von 20q und der häufigste zusätzliche Zugewinn der Met ist ein Zugewinn von 6p (Abb. 3.1.3/3).

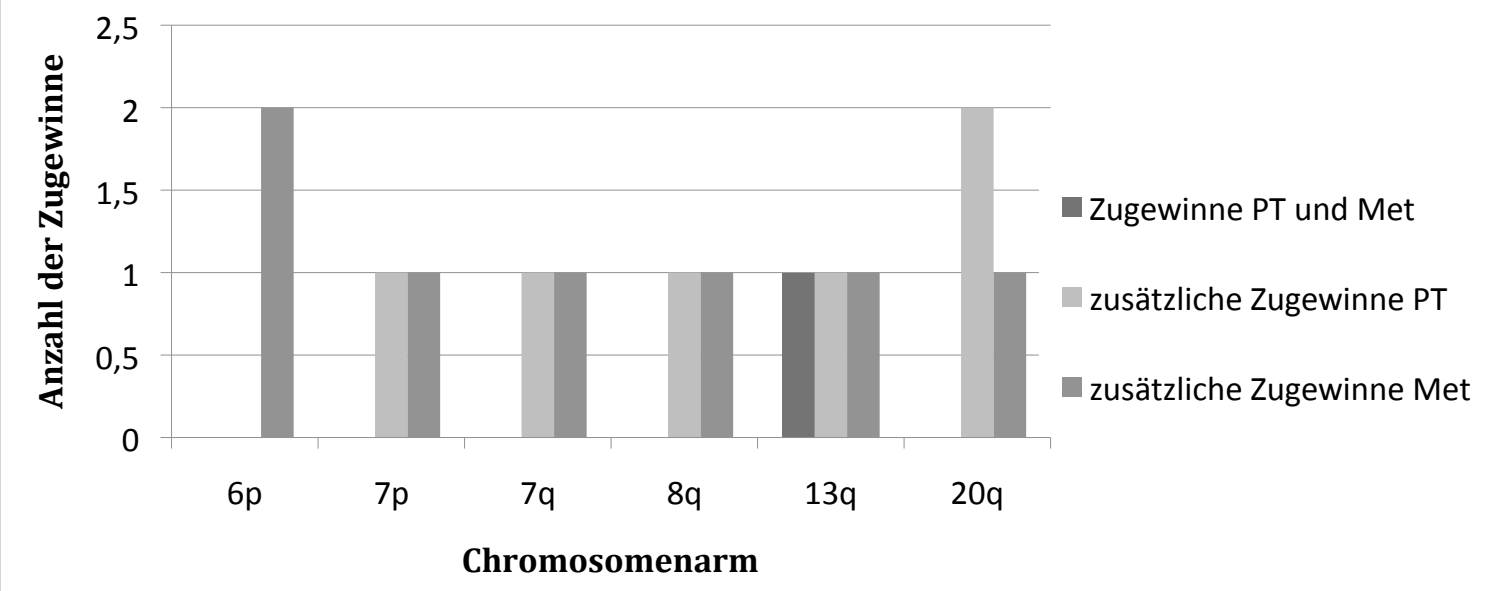

Abbildung 3.1.3/3: Zugewinne der PT mit 2-3 korrrespondierenden Met $(n=3)$ 
Die häufigsten gemeinsamen Verluste der PT von 3 Patienten mit PT KRK und 2-3 untersuchten korrespondierenden Met waren Verluste von 13q und 18q. Die häufigsten zusätzlichen Verluste der Met waren Verluste von 4q und 6q (Abb. 3.1.3/4).

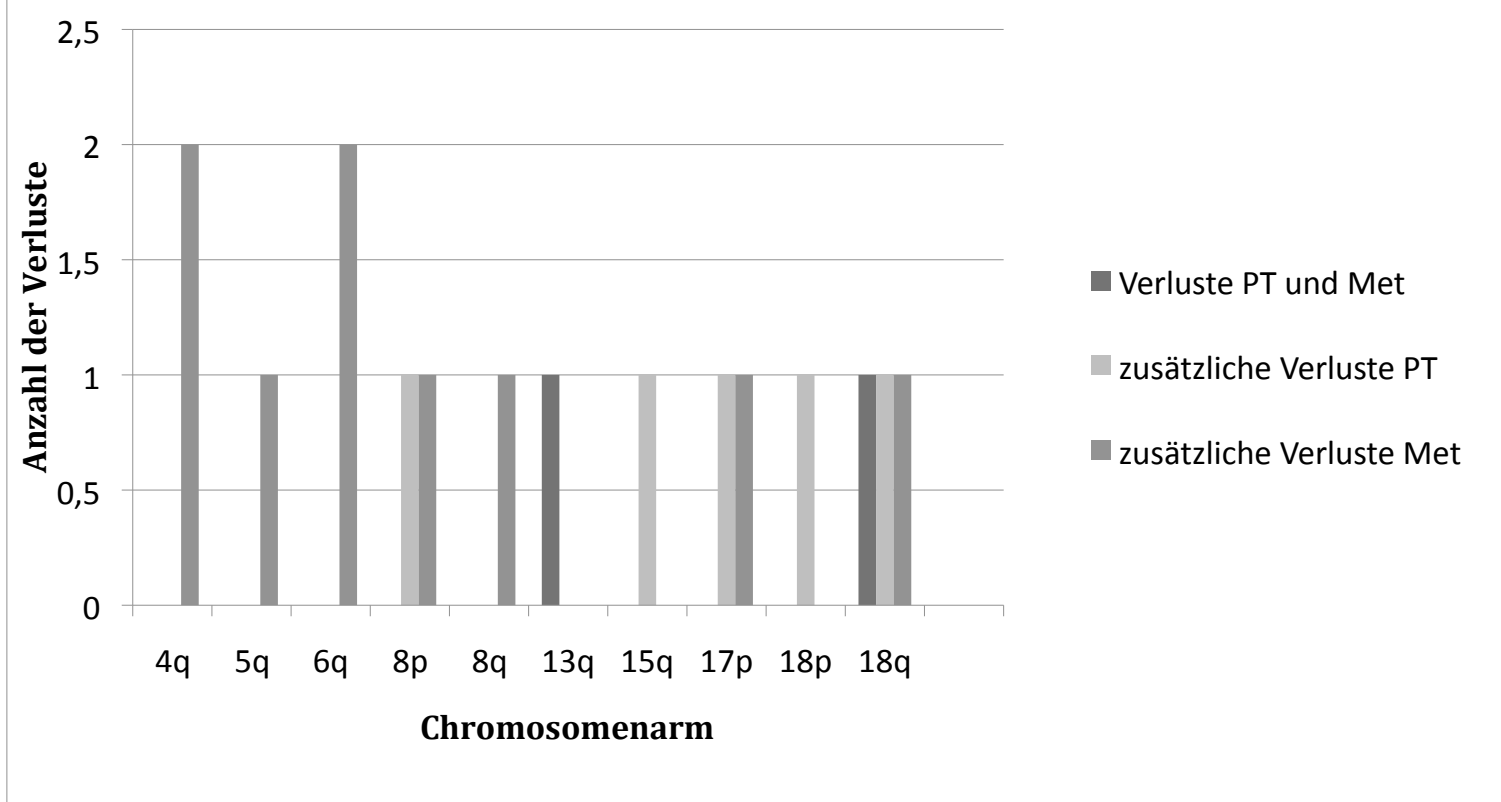

Abbildung 3.1.3/4: Verluste der PT mit 2-3 korrespondierenden Met $(n=3)$

Die Tabellen 3.1.3/2-5 zeigen, wie häufig die einzelnen Chromosomen (-arme) von chromosomalen Aberrationen betroffen sind. Die Tabellen 3.1.3/2+3 fokussieren sich hierbei zunächst auf die gemeinsamen chromosomalen Aberrationen von 25 PT KRK und den korrespondierenden Met ( $n=29)$. Die Tabellen 3.1.3/4+5 zeigen die zusätzlichen chromosomalen Aberrationen der 29 korrespondierenden Met von 25 Patienten mit PT KRK. Aufgeführt sind nur die Chromosomenarme, an denen chromosomale Aberrationen detektiert wurden.

Es wurden 118 gemeinsame Aberrationen bei 25 PT von Patienten mit KRK und korrespondierenden Met $(n=29)$ gefunden (Tab. 3.1.3/2+3).

Bei den gemeinsamen Aberrationen zwischen den 25 PT KRK und ihren korrespondierenden Met $(n=29)$ fanden wir $74(62,7 \%)$ Zugewinne und 44 (37,3\%) Verluste. Der am häufigsten gesehene gemeinsame Zugewinn war ein Zugewinn von 20q, gefolgt von Zugewinnen von $13 q$ sowie von $7 p$, $8 q$ und $20 p$; gefolgt von Zugewinnen von $7 q$, sowie von $6 p$ und $17 q$. Als häufigsten gemeinsamen Verlust fanden wir einen Verlust von18q, gefolgt von Verlusten von $4 q$ und $8 p$. 
Tabelle 3.1.3/2: Gemeinsame Zugewinne der 25 PT KRK und ihrer korrespondierenden Met $(n=29)$

\begin{tabular}{|c|c|c|c|c|c|c|c|}
\hline $\begin{array}{l}\text { Chromosom (- } \\
\text { enarm) }\end{array}$ & $20 q$ & $13 q$ & $\begin{array}{l}7 p, 8 q \\
20 p\end{array}$ & $7 q$ & $6 p, 17 q$ & $5 p$ & $\begin{array}{l}2 q, 5 q, \\
9 p, 12, \\
16\end{array}$ \\
\hline $\begin{array}{l}\text { Anzahl der } \\
\text { Aberrationen } \\
\text { (\% an } 118 \\
\text { gemeinsamen } \\
\text { chromosomalen } \\
\text { Aberrationen) }\end{array}$ & $\begin{array}{l}17 \\
(14,4 \%)\end{array}$ & $\begin{array}{l}13 \\
(11 \%)\end{array}$ & $\begin{array}{l}\text { jeweils } 7 \\
(5,9 \%)\end{array}$ & $\begin{array}{l}6 \\
(5,1 \%)\end{array}$ & $\begin{array}{l}\text { jeweils } 4 \\
(3,4 \%)\end{array}$ & $\begin{array}{l}2 \\
(1,7 \%)\end{array}$ & $\begin{array}{l}\text { jeweils } \\
1 \\
(0,8 \%)\end{array}$ \\
\hline
\end{tabular}

Tabelle 3.1.3/3: Gemeinsame Verluste der 25 PT KRK und ihrer korrespondierenden Met ( $n=$ 29)

\begin{tabular}{|l|l|l|l|l|l|}
\hline $\begin{array}{l}\text { Chromosom (- } \\
\text { enarm) }\end{array}$ & $18 q$ & $4 q, 8 p$ & $18 p$ & $\begin{array}{l}1 p, 3 p, 4 p, \\
13 q, 14 q, \\
17 p\end{array}$ & $\begin{array}{l}3 q, 9 p, 11, \\
\text { Xp }\end{array}$ \\
\hline $\begin{array}{l}\text { Anzahl der } \\
\text { Aberrationen } \\
\text { (\% an } 118 \\
\begin{array}{l}\text { gemeinsamen } \\
\text { chromosomalen } \\
\text { Aberrationen) }\end{array}\end{array}$ & $14(11,9 \%)$ & $\begin{array}{l}\text { jeweils 5 } \\
(4,2 \%)\end{array}$ & $3(2,5 \%)$ & $\begin{array}{l}\text { jeweils 2 } \\
(1,7 \%)\end{array}$ & $\begin{array}{l}\text { jeweils 1 } \\
(0,8 \%)\end{array}$ \\
\hline
\end{tabular}

Insgesamt wurden 115 zusätzliche chromosomale Aberrationen der korrespondierenden Met $(n=29)$ im Vergleich zu ihren PT gefunden. Die Tabellen 3.1.3/4+5 zeigen die betroffenen Chromosomen(-arme) und den Anteil der jeweiligen Aberration an den zusätzlich gefundenen Aberrationen.

Es wurden bei den zusätzlichen chromosomalen Aberrationen der untersuchten 29 korrespondierenden Met von 25 Patienten mit PT KRK 67 Zugewinne (58,3\% der Aberrationen) und 48 Verluste (41,7\% der Aberrationen) gefunden.

Die häufigsten zusätzlichen Zugewinne der korrespondierenden Met waren Zugewinne von $6 p$ und 7 gefolgt von Zugewinnen von 12q und 20q. Die häufigsten zusätzlichen Verluste der korrespondierenden Met waren Verluste von 1p, 4q, 5q, 8p und 18p. 
Tabelle 3.1.3/4: Zusätzliche Zugewinne der Met $(n=29)$ von 25 PT KRK

\begin{tabular}{|c|c|c|c|c|c|c|}
\hline $\begin{array}{l}\text { Chromosom ( - } \\
\text { enarm) }\end{array}$ & $6 p$ & 7 & $12 q, 20 q$ & $\begin{array}{l}6 q, 8 q \\
9 q, 10 p \\
12 p, 13 q \\
20 p, \times q\end{array}$ & $\begin{array}{l}1 q, 10 q \\
16 q, 17 q\end{array}$ & $\begin{array}{l}2 p, 5 q \\
11,15 q \\
16 p, 17 p \\
18 q, 19 \\
21 q\end{array}$ \\
\hline $\begin{array}{l}\text { Anzahl der } \\
\text { Aberrationen } \\
\text { (\% an } 115 \\
\text { zusätzlichen } \\
\text { chromosomalen } \\
\text { Aberrationen der } \\
\text { korrespondierenden } \\
\text { Met) }\end{array}$ & $6(5,2 \%)$ & $5(4,3 \%)$ & $\begin{array}{l}\text { jeweils } 4 \\
(3,5 \%)\end{array}$ & $\begin{array}{l}\text { jeweils } 3 \\
(2,6 \%)\end{array}$ & $\begin{array}{l}\text { jeweils } 2 \\
(1,7 \%)\end{array}$ & $\begin{array}{l}\text { jeweils } 1 \\
(0,9 \%)\end{array}$ \\
\hline
\end{tabular}

Tabelle 3.1.3/5: Zusätzliche Verluste der Met $(n=29)$ von 25 PT KRK

\begin{tabular}{|l|l|l|l|l|}
\hline $\begin{array}{l}\text { Chromosom( - } \\
\text { enarm) }\end{array}$ & $\begin{array}{l}1 p, 4 q, 5 q, \\
8 p, 18 p\end{array}$ & $3 p, 17 p$ & $2 q, 4 p, 6 q$, & $3 q, 5 p, 8 q$, \\
& $18 q, 21 q$ & $\begin{array}{l}9,11,12, \\
14 q, 15 q, \\
22 q\end{array}$ \\
\hline $\begin{array}{l}\text { Anzahl der } \\
\text { Aberrationen (\% an } \\
115 \text { zusätzlichen } \\
\text { chromosomalen } \\
\begin{array}{l}\text { Aberrationen der } \\
\text { korrespondierenden } \\
\text { Met) }\end{array}\end{array}$ & jeweils 4 & jeweils 3 & jeweils 2 & jeweils1 \\
$(3,5 \%)$ & $(2,6 \%)$ & $(1,7 \%)$ & $(0,9 \%)$ \\
\hline
\end{tabular}

Die Auswertung der chromosomalen Aberrationen der 25 PT KRK und der korrespondierenden 29 Met ist in Tabelle 3.1.3/6 dargestellt. Es sind nur die Chromosomenarme aufgeführt, an denen chromosomale Aberrationen detektiert wurden. Ein statistisch signifikanter Unterschied der chromosomalen Aberrationen zwischen PT und Met lässt sich nicht nachweisen. Auffallend ist jedoch, dass $8 \%$ der von uns untersuchten PT von 25 Patienten mit PT KRK und korrespondierenden Met einen Verlust von Chromosomenarm $1 q$ aufweisen, wohingegen keine der von uns untersuchten korrespondierenden Met diese Veränderung aufweist $(p=0,13)$. Des Weiteren sind $34 \%$ der von uns untersuchten 
korrespondierenden Met von einem Zugewinn von Chromosomenarm 6p betroffen, wohingegen der Zugewinn von Chromosomenarm 6p nur 16\% der dazugehörigen PT betrifft $(p=0,13)$. Auch der Zugewinn von Chromosomenarm 12q lässt sich bei $17 \%$ der untersuchten korrespondierenden Met, jedoch nur bei $4 \%$ der untersuchten korrespondierenden PT nachweisen $(p=0,13)$. Weiterhin zeigt sich der Verlust von $18 q$ bei 76\% der untersuchten PT von 25 Patienten mit PT KRK, bei den korrespondierenden Met lässt sich der Verlust von 18q nur bei 55\% der untersuchten Proben nachweisen $(p=0,11)$.

Tabelle 3.1.3/6: Auswertung der chromosomalen Aberrationen der 25 PT KRK und der korrespondierenden 29 Met

\begin{tabular}{|l|l|l|l|}
\hline $\begin{array}{l}\text { Chromosomale } \\
\text { Aberration }\end{array}$ & $\begin{array}{l}\text { Anzahl der von } \\
\text { der Aberration } \\
\text { betroffenen PT } \\
(\%)\end{array}$ & $\begin{array}{l}\text { Anzahl der } \\
\text { von der } \\
\text { Aberration } \\
\text { betroffenen } \\
\text { Met (\%) }\end{array}$ & $\mathbf{p}$ \\
\hline 1qplus & $1(4 \%)$ & $2(7 \%)$ & 0,65 \\
\hline 1pminus & $4(16 \%)$ & $6(21 \%)$ & 0,67 \\
\hline 1qminus & $2(8 \%)$ & $0(0 \%)$ & 0,13 \\
\hline 2pplus & $0(0 \%)$ & $1(3 \%)$ & 0,36 \\
\hline 2qplus & $1(4 \%)$ & $1(3 \%)$ & 0,92 \\
\hline 2qminus & $0(0 \%)$ & $2(7 \%)$ & 0,19 \\
\hline 3pplus & $1(4 \%)$ & $0(0 \%)$ & 0,29 \\
\hline 3pminus & $3(12 \%)$ & $5(17 \%)$ & 0,6 \\
\hline 3qminus & $2(8 \%)$ & $2(7 \%)$ & 0,88 \\
\hline 4pminus & $6(24 \%)$ & $4(14 \%)$ & 0,34 \\
\hline 4qminus & $10(40 \%)$ & $9(31 \%)$ & 0,5 \\
\hline $5 p p l u s$ & $2(8 \%)$ & $2(7 \%)$ & 0,88 \\
\hline $5 q p l u s$ & $1(4 \%)$ & $2(7 \%)$ & 0,65 \\
\hline 5pminus & $0(0 \%)$ & $1(3 \%)$ & 0,36 \\
\hline $5 q m i n u s$ & $1(4 \%)$ & $4(14 \%)$ & 0,22 \\
\hline 6pplus & $4(16 \%)$ & $10(34 \%)$ & 0,13 \\
\hline 6qplus & $1(4 \%)$ & $3(10 \%)$ & 0,38 \\
\hline 6qminus & $0(0 \%)$ & $2(7 \%)$ & 0,19 \\
\hline 7pplus & $9(36 \%)$ & $12(41 \%)$ & 0,69 \\
\hline $7 q p l u s$ & $9(36 \%)$ & $11(38 \%)$ & 0,89 \\
\hline 8pplus & $1(4 \%)$ & $0(0 \%)$ & 0,29 \\
\hline 8qplus & $8(32 \%)$ & $10(34 \%)$ & 0,85 \\
\hline 8pminus & $7(28 \%)$ & $9(31 \%)$ & 0,82 \\
\hline 8qminus & $0(0 \%)$ & $1(3 \%)$ & 0,36 \\
\hline 9pplus & $1(4 \%)$ & $1(3 \%)$ & 0,92 \\
\hline 9qplus & $1(4 \%)$ & $3(10 \%)$ & 0,38 \\
\hline 9pminus & $2(8 \%)$ & $2(7 \%)$ & 0,88 \\
\hline 9qminus & $1(4 \%)$ & $1(3 \%)$ & 0,92 \\
\hline $10 p p l u s$ & $1(4 \%)$ & $3(10 \%)$ & 0,38 \\
\hline $10 q p l u s$ & $0(0 \%)$ & $2(7 \%)$ & 0,19 \\
\hline $10 p m i n u s$ & $1(4 \%)$ & $0(0 \%)$ & 0,29 \\
\hline $10 q m i n u s$ & $1(4 \%)$ & $0(0 \%)$ & 0,29 \\
\hline & & & \\
\hline
\end{tabular}




\begin{tabular}{|c|c|c|c|}
\hline 11pplus & $1(4 \%)$ & $1(3 \%)$ & 0,92 \\
\hline 11qplus & $0(0 \%)$ & $1(3 \%)$ & 0,36 \\
\hline $11 \mathrm{pminus}$ & $1(4 \%)$ & $2(7 \%)$ & 0,65 \\
\hline 11qminus & $1(4 \%)$ & $2(7 \%)$ & 0,65 \\
\hline 12pplus & $1(4 \%)$ & $4(14 \%)$ & 0,22 \\
\hline 12qplus & $1(4 \%)$ & $5(17 \%)$ & 0,13 \\
\hline 12pminus & $0(0 \%)$ & $1(3 \%)$ & 0,36 \\
\hline 12qminus & $0(0 \%)$ & $1(3 \%)$ & 0,36 \\
\hline 13qplus & $18(72 \%)$ & $16(55 \%)$ & 0,21 \\
\hline 13qminus & $1(4 \%)$ & $2(7 \%)$ & 0,65 \\
\hline 14qminus & $5(20 \%)$ & $3(10 \%)$ & 0,33 \\
\hline 15qplus & $1(4 \%)$ & $1(3 \%)$ & 0,92 \\
\hline 15qminus & $3(12 \%)$ & $1(3 \%)$ & 0,24 \\
\hline 16pplus & $2(8 \%)$ & $2(7 \%)$ & 0,88 \\
\hline 16qplus & $2(8 \%)$ & $3(10 \%)$ & 0,77 \\
\hline 17pplus & $0(0 \%)$ & $1(3 \%)$ & 0,36 \\
\hline 17qplus & $5(20 \%)$ & $6(21 \%)$ & 0,95 \\
\hline 17pminus & $6(24 \%)$ & $5(17 \%)$ & 0,55 \\
\hline 17qminus & $1(4 \%)$ & $0(0 \%)$ & 0,29 \\
\hline 18qplus & $0(0 \%)$ & $1(3 \%)$ & 0,36 \\
\hline 18pminus & $7(28 \%)$ & $7(24 \%)$ & 0,75 \\
\hline 18qminus & $19(76 \%)$ & $16(55 \%)$ & 0,11 \\
\hline 19pplus & $0(0 \%)$ & $1(3 \%)$ & 0,36 \\
\hline 19qplus & $0(0 \%)$ & $1(3 \%)$ & 0,36 \\
\hline 20pplus & $9(36 \%)$ & $10(34 \%)$ & 0,91 \\
\hline 20qplus & $20(80 \%)$ & $21(72 \%)$ & 0,52 \\
\hline 20pminus & $1(4 \%)$ & $0(0 \%)$ & 0,29 \\
\hline 21qplus & $0(0 \%)$ & $1(3 \%)$ & 0,36 \\
\hline 21qminus & $1(4 \%)$ & $2(7 \%)$ & 0,65 \\
\hline 22qplus & $1(4 \%)$ & $0(0 \%)$ & 0,29 \\
\hline 22qminus & $0(0 \%)$ & $1(3 \%)$ & 0,36 \\
\hline Xpplus & $1(4 \%)$ & $0(0 \%)$ & 0,29 \\
\hline Xqplus & $1(4 \%)$ & $3(10 \%)$ & 0,38 \\
\hline Xpminus & $1(4 \%)$ & $1(3 \%)$ & 0,92 \\
\hline
\end{tabular}

3.2 Auswertung der PT aller Patienten $(n=93)$ des Kollektivs

\subsubsection{Auswertung der PT aller Patienten des Kollektivs ( $n=93)$}

a) Lokalisation der PT aller Patienten

Bei 16 der insgesamt 93 Patienten des Kollektivs (17\%) lagen keine Informationen zur genauen Lokalisation des KRK vor. 
Bei den meisten Patienten befand sich der PT im Rektum (47\% der Patienten), ein etwas geringerer Anteil der PT lag im Sigma (35\%), 13\% der PT lag im rechtsseitigen Colon und jeweils $2,5 \%$ im Colon transversum und im Colon descendens.

Tabelle 3.2.1/1: Lokalisation der PT von 77 der insgesamt 93 Patienten des Kollektivs

\begin{tabular}{|l|l|l|}
\hline Lokalisation & Absolute Anzahl $(\mathbf{n = 7 7})$ & $\%$ \\
\hline Coecum/Colon ascendens & 10 & 13 \\
\hline Colon transversum & 2 & 2,5 \\
\hline Colon descendens & 2 & 2,5 \\
\hline Sigma & 27 & 35 \\
\hline Rektum & 36 & 47 \\
\hline
\end{tabular}

b) TNM-Stadium der PT aller Patienten $(n=93)$

Bei 30 der 93 Patienten (32\%) konnte bei Untersuchung der Met keine genaue TNMKlassifikation des PT eruiert werden (Tab. 3.2.1/2).

Bei $1,5 \%$ der untersuchten Patienten lag ein pT1-Stadium vor, bei $16 \%$ ein pT2-, bei $73 \%$ ein pT3- und bei 9,5\% der Patienten des untersuchten Kollektivs lag ein pT4-Stadium des PT vor. Bei 35\% der untersuchten Patienten lag ein pN0- Stadium vor, bei $29 \%$ ein pN1-, bei $35 \%$ ein pN2- und bei $1 \%$ der untersuchten Patienten lag ein pNx-Stadium vor. Bei $1 \%$ der untersuchten Patienten lag bei Untersuchung des PT ein pM0-Stadium vor, bei $37 \%$ der untersuchten Patienten lag bereits ein pM1-Stadium vor. Bei den pM1-Stadien war bei allen 23 Patienten das KRK in die Leber metastasiert, bei einem Patienten bestanden darüber hinaus Metastasen in den Ovarien. Bei $62 \%$ der Patienten waren bei der pathologischen Untersuchung keine sicheren Angaben über Fernmetastasen bekannt (cMX).

Tabelle 3.2.1/2: TNM-Klassifikation der PT von 63 der insgesamt 93 Patienten des Kollektivs

\begin{tabular}{|l|l|l|}
\hline TNM & Absolute Anzahl (n=63) & \% \\
\hline pT1 & 1 & 1,5 \\
\hline pT2 & 10 & 16 \\
\hline pT3 & 46 & 73 \\
\hline pT4 & 6 & 9,5 \\
\hline pN0 & 22 & 35 \\
\hline pN1 & 18 & 29 \\
\hline pN2 & 22 & 35 \\
\hline pNx & 1 & 1 \\
\hline
\end{tabular}




\begin{tabular}{|l|l|l|}
\hline pM0 & 1 & 1 \\
\hline pM1 & 23 & 37 \\
\hline pMx & 39 & 62 \\
\hline
\end{tabular}

\subsection{Auswertung aller untersuchten PT KRK $(n=34)$ und aller untersuchten Met $(n=102)$}

\subsubsection{Auswertung der $\mathbf{3 4}$ untersuchten PT KRK}

a) TNM-Stadium und Grading

\section{pT-Klassifikation}

Insgesamt wurden 34 PT KRK untersucht. Bei 6 Patienten (18\%) lag bei Diagnose des PT das Tumorstadium pT2, bei 26 Patienten (76\%) das Tumorstadium pT3 und bei 2 Patienten (6\%) das Tumorstadium pT4 vor.

\section{pN-Klassifikation}

Bei Operation des PT hatten 10 von 34 Patienten (30\%) tumorfreie Lymphknoten (pN0), darunter befanden sich 2 (20\%) pT2, 7 (70\%) pT3 und 1 (10\%) pT4- Tumoren. Bei 12 Patienten (35\%) lag bereits ein pN1-Stadium vor. Darunter befanden sich 1 (8\%) pT2-Tumor und 11 (92\%) pT3-Tumoren.

Bei 12 Patienten (35\%) lag ein pN2-Stadium vor. Davon waren 2 (17\%) pT2-Tumoren, 9 (75\%) pT3-Tumoren und 1 ( 8\%) pT4-Tumor (Tab. 3.3.1/1).

Tabelle 3.3.1/1: Zusammenhang zwischen dem pT- und dem pN- Stadium der 34 PT KRK

\begin{tabular}{|l|l|l|l|}
\hline & pT2 & pT3 & TT4 \\
\hline pN0 & 2 & 7 & 1 \\
\hline pN1 & 1 & 11 & 0 \\
\hline pN2 & 2 & 9 & 1 \\
\hline
\end{tabular}


Bei 18 (53\%) Patienten lagen zum Zeitpunkt der Operation Met vor (pM1). Darunter waren 1 (5,5\%) pT2-Tumor, 16 (89\%) pT3-Tumoren und 1 (5,5\%) pT4-Tumor.

Bei 16 (47\%) Patienten war der Status der Fernmetastasen nicht eruiert wurden (pMx). Darunter befanden sich 4 (25\%) pT2-Tumoren, 11 (68,75\%) pT3-Tumoren und 1 (6,25\%) pT4-Tumor.

Grading

Von den 34 PT wurden 33 (97\%) als G2 eingestuft, 1 (3\%) als G4.

b) Anzahl der chromosomalen Aberrationen von 34 PT KRK

Bei 2 von 34 Patienten wurden keine chromosomalen Aberrationen festgestellt, wohingegen bei einem Patienten 21 chromosomale Veränderungen festgestellt wurden. Im Median betrug die Anzahl der Aberrationen bei den 34 PT KRK insgesamt 7,5 (Range 0-21).

Die Anzahl an Zugewinnen betrug bei den 34 PT KRK im Median insgesamt 3,5 (Range 010), die der Verluste im Median 2,5 (Range 0-12) und die Anzahl der Amplifikationen betrug im Median 0 (Range 0-3) (Tab. 3.3.1/2).

Tabelle 3.3.1/2: Übersicht über die CGH-Ergebnisse der 34 untersuchten PT KRK

\begin{tabular}{|l|l|}
\hline Parameter & PT $(\mathrm{n}=34)$ \\
\hline $\begin{array}{l}\text { Median } \\
\text { Aberrationen(Range) }\end{array}$ & $7,5(0-21)$ \\
\hline $\begin{array}{l}\text { Median Zugewinne } \\
\text { (Range) }\end{array}$ & $3,5(0-10)$ \\
\hline Median Verluste (Range) & $2,5(0-12)$ \\
\hline $\begin{array}{l}\text { Median Amplifikationen } \\
\text { (Range) }\end{array}$ & $0(0-3)$ \\
\hline
\end{tabular}

Bei den 5 pT2-Tumoren von 34 PT KRK fanden sich insgesamt im Median 8 chromosomale Aberrationen. Die Anzahl der Zugewinne betrug insgesamt im Median 2, die der Verluste 3. Bei den 27 pT3-Tumoren von 34 PT KRK waren es insgesamt im Median 8 chromosomale Aberrationen, darunter im Median insgesamt 4 Zugewinne und 2 Verluste. Bei den 2 pT4- 
Tumoren von 34 PT KRK betrug die Anzahl der chromosomalen Aberrationen im Median 6, darunter befanden sich insgesamt im Median 3,5 Zugewinne und 2,5 Verluste (Tab. 3.3.1/3).

Tabelle 3.3.1/3: Anzahl der chromosomalen Aberrationen bezogen auf das pT-Stadium von 34 PT KRK

\begin{tabular}{|l|l|l|l|l|}
\hline & pT2 & pT3 & pT4 & $\begin{array}{l}\text { p-Wert } \\
\text { (Kruskal- } \\
\text { Wallis-Test) }\end{array}$ \\
\hline $\mathbf{n}$ & 5 & 27 & 2 & 0,87 \\
\hline $\begin{array}{l}\text { Median } \\
\text { Aberrationen } \\
\text { (Range) }\end{array}$ & $8(0-8)$ & $8(0-21)$ & $6(0-2)$ & 0,39 \\
\hline $\begin{array}{l}\text { Median } \\
\text { Zugewinne } \\
\text { (Range) }\end{array}$ & $2(0-6)$ & $4(0-12)$ & $3,5(0-1)$ & 0,52 \\
\hline $\begin{array}{l}\text { Median Verluste } \\
\text { (Range) }\end{array}$ & $3(0-6)$ & $2(0-12)$ & $2,5(0-3)$ & \\
\hline
\end{tabular}

Bei den 10 pN0-Tumoren von 34 PT KRK fanden sich insgesamt im Median 5 chromosomale Aberrationen, darunter im Median insgesamt 4 Zugewinne und 1 Verlust. Bei den 12 pN1Tumoren von 34 PT KRK waren es insgesamt im Median 5 chromosomale Aberrationen, die Anzahl der Zugewinne betrug insgesamt im Median 3, die der Verluste 2. Bei den 12 pN2Tumoren von 34 PT KRK fanden sich insgesamt im Median 10 chromosomale Aberrationen, darunter insgesamt im Median 5 Zugewinne und 5 Verluste (Tab. 3.3.1/4). 
Tabelle 3.3.1/4: Anzahl der chromosomalen Aberrationen bezogen auf das $\mathrm{pN}$-Stadium von 34 PT KRK

\begin{tabular}{|l|l|l|l|l||}
\hline & pN0 & pN1 & pN2 & $\begin{array}{l}\text { p-Wert } \\
\text { (Kruskal- } \\
\text { Wallis-Test) }\end{array}$ \\
\hline $\mathbf{n}$ & 10 & 12 & 12 & 0,08 \\
\hline $\begin{array}{l}\text { Median } \\
\text { Aberrationen } \\
\text { (Range) }\end{array}$ & $5(0-13)$ & $5(0-11)$ & $10(0-20)$ & 0,48 \\
\hline $\begin{array}{l}\text { Median } \\
\text { Zugewinne } \\
\text { (Range) }\end{array}$ & $4(0-10)$ & $3(0-8)$ & $5(0-12)$ & \\
\hline $\begin{array}{l}\text { Median Verluste } \\
\text { (Range) }\end{array}$ & $1(0-3)$ & $2(0-7)$ & $5(0-11)$ & $<0,01$ \\
\hline
\end{tabular}

c) $\quad$ CGH der 34 untersuchten PT KRK

Die häufigsten Zugewinne der 34 untersuchten PT KRK sind Zugewinne von 13q und 20q, der häufigste Verlust ist ein Verlust von 18q (Abb. 3.3.1/1 + Tab. 3.3.1/5). Es sind nur die Chromosomenarme aufgeführt, an welchen chromosomale Aberrationen detektiert wurden.

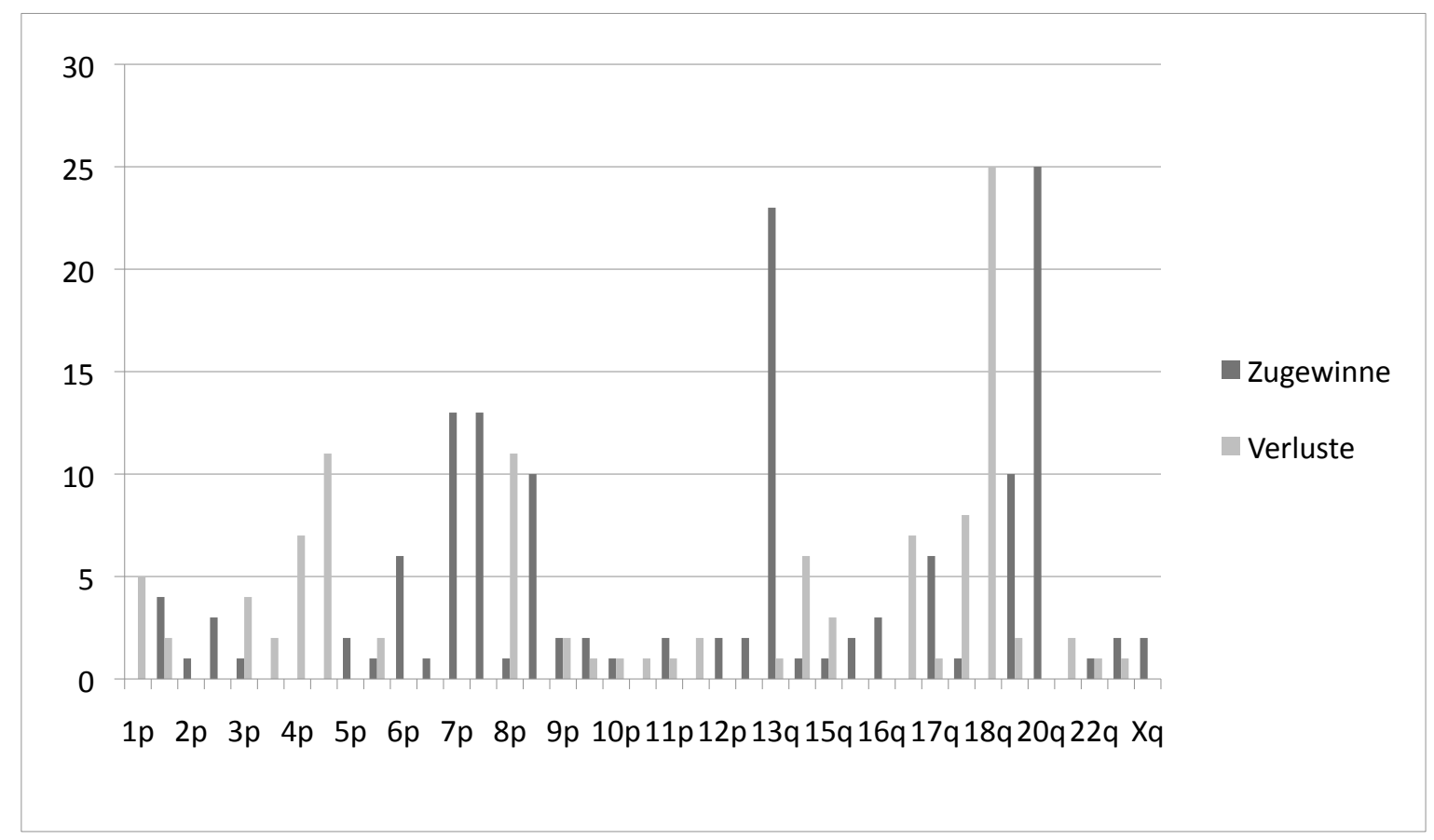


Abbildung 3.3.1/1: Graphische Darstellung der CGH-Ergebnisse der 34 untersuchten PT KRK

Tabelle 3.3.1/5 zeigt die gefundenen chromosomalen Aberrationen der 34 untersuchten PT KRK. Chromosomale Aberrationen, die bei mindestens 20\% der 34 untersuchten PT KRK auftraten sind in rot hervorgehoben. Es handelt sich hierbei um Zugewinne von 7, 8q, 13q und 20, sowie um Verluste von 4, 8p, 17p und 18.

Tabelle 3.3.1/5: Übersicht über die chromosomalen Aberrationen der 34 untersuchten PT KRK

\begin{tabular}{|c|c|c|}
\hline & Zugewinne PT & Verluste PT \\
\hline $1 p$ & 0 & $5(15 \%)$ \\
\hline $1 q$ & $4(12 \%)$ & $2(6 \%)$ \\
\hline $2 p$ & $1(3 \%)$ & 0 \\
\hline $2 q$ & $3(9 \%)$ & 0 \\
\hline $3 p$ & $1(3 \%)$ & $4(12 \%)$ \\
\hline $3 q$ & 0 & $2(6 \%)$ \\
\hline $4 p$ & 0 & $7(21 \%)$ \\
\hline $4 q$ & 0 & $11(32 \%)$ \\
\hline $5 p$ & $2(6 \%)$ & 0 \\
\hline $5 q$ & $1(3 \%)$ & $2(6 \%)$ \\
\hline $6 p$ & $6(18 \%)$ & 0 \\
\hline $6 q$ & $1(3 \%)$ & 0 \\
\hline $7 p$ & $13(38 \%)$ & 0 \\
\hline $7 q$ & $13(38 \%)$ & 0 \\
\hline $8 p$ & $1(3 \%)$ & $11(32 \%)$ \\
\hline $8 q$ & $10(29 \%)$ & 0 \\
\hline $9 p$ & $2(6 \%)$ & $2(6 \%)$ \\
\hline $9 q$ & $2(6 \%)$ & $1(3 \%)$ \\
\hline $10 p$ & $1(3 \%)$ & $1(3 \%)$ \\
\hline $10 q$ & 0 & $1(3 \%)$ \\
\hline $11 p$ & $2(6 \%)$ & $1(3 \%)$ \\
\hline $11 q$ & 0 & $2(6 \%)$ \\
\hline $12 p$ & $2(6 \%)$ & 0 \\
\hline $12 q$ & $2(6 \%)$ & 0 \\
\hline $13 q$ & $23(68 \%)$ & $1(3 \%)$ \\
\hline $14 q$ & $1(3 \%)$ & $6(18 \%)$ \\
\hline
\end{tabular}




\begin{tabular}{|l|l|l|}
\hline $15 q$ & $1(3 \%)$ & $3(9 \%)$ \\
$16 p$ & $2(6 \%)$ & 0 \\
$16 q$ & $3(9 \%)$ & 0 \\
$17 p$ & 0 & $7(21 \%)$ \\
$17 q$ & $6(18 \%)$ & $1(3 \%)$ \\
$18 p$ & $1(3 \%)$ & $8(24 \%)$ \\
$18 q$ & 0 & $25(74 \%)$ \\
$20 p$ & $10(29 \%)$ & $2(6 \%)$ \\
$20 q$ & $25(74 \%)$ & 0 \\
$21 q$ & 0 & $2(6 \%)$ \\
$22 q$ & $1(3 \%)$ & $1(3 \%)$ \\
$X p$ & $2(6 \%)$ & $1(3 \%)$ \\
$X q$ & $2(6 \%)$ & 0 \\
\hline
\end{tabular}

d) Onkogenetischer Baum der 34 untersuchten PT KRK

Die Abbildung 3.3.1/2 zeigt, dass Zugewinne von 13q und 20q und ein Verlust von 18q bereits sehr früh in der Tumorigenese der 34 PT KRK auftreten. Verluste von $4 p$ und 17p treten hingegen erst recht spät auf.

Häufig gemeinsam auftretende Aberrationen der 34 untersuchten PT KRK sind Zugewinne von $20 q$ mit $20 p$, Verluste von $4 p$ und $4 q$, Verluste von $17 p$ gemeinsam mit 18p, Zugewinne von $8 q$ gemeinsam mit Verlusten von $8 p$ und Zugewinne von $7 p$ und $7 q$. In dieser Hinsicht unterscheidet sich der onkogenetische Baum der 34 untersuchten PT KRK nicht von dem onkogenetischen Baum der 25 PT KRK mit untersuchten korrespondierenden Met ( Abb.

3.1.1/2). Einzig auffallend am onkogenetischen Baum der 34 PT KRK war ein, im Vergleich zu dem onkogenetischen Baum der 25 PT KRK mit korrespondierenden Met, früher auftretender Verlust von Chromosomenarm 8p. 


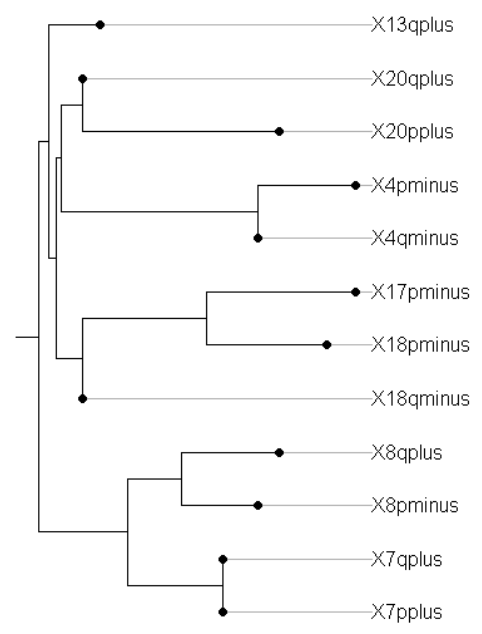

Abbildung 3.3.1/2: Onkogenetischer Baum der 34 untersuchten PT KRK

\subsubsection{Auswertung aller 102 untersuchten Met}

a) Grading und mT- Klassifikation der insgesamt 102 untersuchten Met

\section{Grading}

1 (1\%) der untersuchten 102 Met wurde als G1-2 eingestuft, 95 (93\%) der Met als G2, 5 (5\%) als G3, 1 (1\%) als G2-3.

$\underline{\text { mT-Klassifikation }}$

Bei $4(6 \%)$ der untersuchten 102 Met fanden wir ein mT1-Stadium, bei $33(49 \%)$ der untersuchten Met ein mT2-Stadium, bei 17 (25\%) ein mT3-Stadium und bei 14 (21\%) der untersuchten Met ein mT4-Stadium. Bei 34 Met ist das mT-Stadium unbekannt.

b) Anzahl der chromosomalen Aberrationen aller untersuchten Met $(n=102)$

Bei den 102 untersuchten Met fanden wir insgesamt im Median 9 chromosomale Aberrationen.

Die Anzahl der Zugewinne betrug insgesamt im Median 3,5, die Anzahl der Verluste 4 und die Anzahl der Amplifikationen betrug im Median 0 (Tab. 3.3.2/1). 
Tabelle 3.3.2/1: Übersicht über die CGH-Ergebnisse der 102 Met KRK

\begin{tabular}{|l|l|}
\hline & Met $(\mathrm{n}=102)$ \\
\hline $\begin{array}{l}\text { Median Aberrationen } \\
\text { (Range) }\end{array}$ & $9(0-29)$ \\
\hline Median Zugewinne (Range) & $3,5(0-18)$ \\
\hline Median Verluste (Range) & $4(0-13)$ \\
\hline $\begin{array}{l}\text { Median Amplifikationen } \\
\text { (Range) }\end{array}$ & $0(0-7)$ \\
\hline
\end{tabular}

c) $\underline{\mathrm{CGH}}$ aller Met $(\mathrm{n}=102)$

Chromosomale Aberrationen wurden in 94 von 102 (92\%) der Met gefunden. Abbildung 3.3.2/1 und Tabelle 3.3.2/2 zeigen die CGH-Ergebnisse aller 102 untersuchten Met. Es sind nur die Chromosomenarme dargestellt, an denen chromosomale Aberrationen detektiert wurden.

Am häufigsten fanden wir Zugewinne von 7p, 8q, 13q und 20q. Weitere häufige Zugewinne waren Zugewinne von 1q, 6p, 7q und 20p. Verluste sahen wir am häufigsten bei $8 p$ und 18q. Weitere häufige Verluste waren Verluste von $4 p, 4 q, 5 q, 14 q, 17 p$ und 18p.

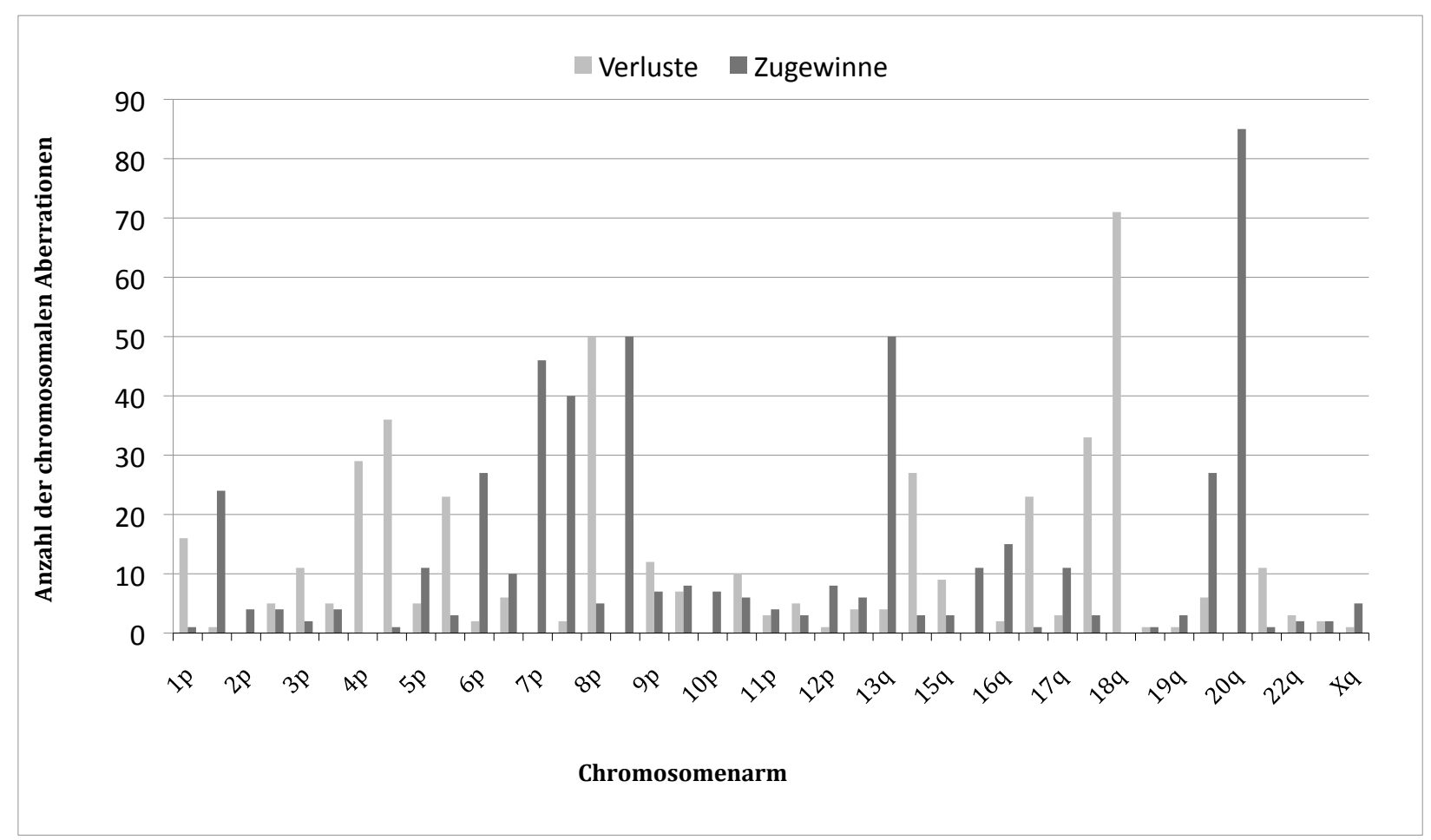

Abbildung 3.3.2/1 CGH- Ergebnisse der 102 untersuchten Met 
Chromosomale Veränderungen, von denen jeweils mindestens 20\% der 102 untersuchten Met betroffen waren, sind in rot hervorgehoben. Es handelt sich dabei um Zugewinne von $1 q, 6 p, 7,8 q, 13 q, 20$, sowie um Verluste von 4, 5q, 8p, 14q,17p und 18 (Tab. 3.3.2/2).

Tabelle 3.3.2/2: Übersicht über die chromosomalen Aberrationen der 102 untersuchten Met. Chromosomale Aberrationen von denen mindestens 20\% der untersuchten Met betroffen sind, sind in rot hervorgehoben

\begin{tabular}{|c|c|c|}
\hline & $\begin{array}{l}\text { Zugewinne Met } \\
\text { (\% der Met, } \\
\text { welche von der } \\
\text { genetischen } \\
\text { Aberration } \\
\text { betroffen sind) }\end{array}$ & $\begin{array}{l}\text { Verluste Met } \\
\text { (\% der Met, } \\
\text { welche von der } \\
\text { genetischen } \\
\text { Aberration } \\
\text { betroffen sind) }\end{array}$ \\
\hline $1 p$ & $1(1 \%)$ & $16(16 \%)$ \\
\hline $1 \mathrm{q}$ & $24(24 \%)$ & $1(1 \%)$ \\
\hline $2 p$ & $4(4 \%)$ & 0 \\
\hline $2 q$ & $4(4 \%)$ & $5(5 \%)$ \\
\hline $3 p$ & $2(2 \%)$ & $11(11 \%)$ \\
\hline $3 q$ & $4(4 \%)$ & $5(5 \%)$ \\
\hline $4 p$ & 0 & $29(29 \%)$ \\
\hline $4 q$ & $1(1 \%)$ & $36(35 \%)$ \\
\hline $5 p$ & $11(11 \%)$ & $5(5 \%)$ \\
\hline $5 q$ & $3(3 \%)$ & $23(23 \%)$ \\
\hline $6 p$ & $27(26 \%)$ & $2(2 \%)$ \\
\hline $6 q$ & $10(10 \%)$ & $6(6 \%)$ \\
\hline $7 p$ & $46(45 \%)$ & 0 \\
\hline $7 q$ & $40(39 \%)$ & $2(2 \%)$ \\
\hline $8 p$ & $5(5 \%)$ & $50(49 \%)$ \\
\hline $8 q$ & $50(49 \%)$ & 0 \\
\hline $9 p$ & $7(7 \%)$ & $12(12 \%)$ \\
\hline $9 q$ & $8(8 \%)$ & $7(7 \%)$ \\
\hline $10 p$ & $7(7 \%)$ & 0 \\
\hline $10 q$ & $6(6 \%)$ & $10(10 \%)$ \\
\hline $11 p$ & $4(4 \%)$ & $3(3 \%)$ \\
\hline $11 q$ & $3(3 \%)$ & $5(5 \%)$ \\
\hline
\end{tabular}




\begin{tabular}{|l|l|l|}
\hline $12 p$ & $8(8 \%)$ & $1(1 \%)$ \\
$12 q$ & $6(6 \%)$ & $4(4 \%)$ \\
$13 q$ & $50(49 \%)$ & $4(4 \%)$ \\
$14 q$ & $3(3 \%)$ & $27(26 \%)$ \\
$15 q$ & $3(3 \%)$ & $9(9 \%)$ \\
$16 p$ & $11(11 \%)$ & $2(2 \%)$ \\
$16 q$ & $15(15 \%)$ & $23(23 \%)$ \\
$17 p$ & $1(1 \%)$ & $3(3 \%)$ \\
$17 q$ & $11(11 \%)$ & $33(32 \%)$ \\
$18 p$ & $3(3 \%)$ & $71(70 \%)$ \\
$18 q$ & 0 & $1(1 \%)$ \\
$19 p$ & $1(1 \%)$ & $1(1 \%)$ \\
$19 q$ & $3(3 \%)$ & $6(6 \%)$ \\
$20 p$ & $27(26 \%)$ \\
$20 q$ & $85(83 \%)$ \\
$21 q$ & $1(1 \%)$ & 0 \\
$22 q$ & $2(2 \%)$ & $11(11 \%)$ \\
$X p$ & $2(2 \%)$ & $3(3 \%)$ \\
$X q$ & $5(2 \%)$ \\
\hline
\end{tabular}

d) Onkogenetischer Baum aller 102 untersuchten Met

Die Abbildung 3.3.2/2 zeigt frühe Zugewinne von 20q, sowie frühe Verluste von 18q. Dahingegen treten Verluste von $17 p$ und $5 q$ erst spät in der Tumorigenese der Met auf. Häufig gemeinsam auftretende chromosomale Aberrationen sind Verluste von $8 p$ und 17p, Zugewinne von $7 p$ und $7 q$, Verluste von $4 p$ und $4 q$, Verluste von $18 p$ und $18 q$, sowie Zugewinne von 20p und 20q. Im Vergleich zu dem onkogenetischen Baum der 29 korrespondierenden Met von 25 Patienten mit PT KRK (Abb. 3.1.2/1) finden sich beim onkogenetischen Baum aller 102 untersuchten Met spät auftretende Verluste von 4p, 5q, 14q und 17p. Bei dem onkogenetischen Baum der 29 korrespondierenden Met von 25 Patienten mit PT KRK (Abb. 3.1.2/1) finden sich hingegen zusätzlich ein später Zugewinn von 17q und ein später Verlust von 1p. 


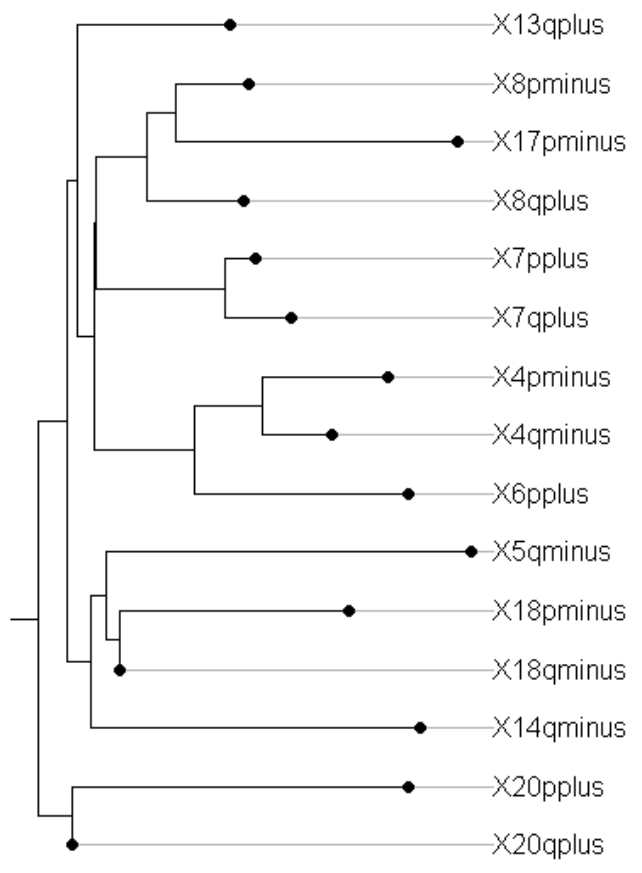

Abbildung 3.3.2/2: Onkogenetischer Baum von 102 Met 


\section{Diskussion}

\subsection{Klinische Problematik}

Mit 70.000 Neuerkrankungen und 30.000 Todesfällen pro Jahr ist das kolorektale Karzinom (KRK) bei Männern die zweithäufigste und bei Frauen die dritthäufigste Krebstodesursache [Jemal et al. 1997, Almendingen et al. 2001].

Der Großteil der Patienten mit KRK entwickelt diese im Bereich des Rektums und des Sigmas. Diese Verteilung zeigt sich auch in unserem Kollektiv, wobei $82 \%$ der PT KRK im rekto-sigmoidalen Bereich lagen.

Die meisten Patienten sterben auf Grund von Metastasen, wobei das bevorzugte Organ für Metastasen die Leber ist [Melville 1997].

Bei Erstdiagnose haben bereits 25\% der Patienten mit KRK Lebermetastasen (Met), weitere 25\% entwickeln diese im Verlauf der Erkrankung [Millikan et al. 1997].

In der Literatur wird die Metastasierung KRK in die Leber vor allem in den ersten 2 Jahren nach OP des PT beschrieben [Bakalakos et al. 1998]. Bakalakos et al. beschreiben in ihren Arbeiten, dass $80 \%$ der Met KRK innerhalb der ersten 2 Jahre nach OP des PT detektiert werden, <5\% werden 5 Jahre nach OP des PT entdeckt [Bakalakos et al. 1998].

Die Prognose der Patienten mit Met bei KRK ist trotz neuer Therapieoptionen schlecht geblieben. Bei primär operablen Met findet man 5-Jahres-Überlebensraten von 25-40\%; zu bedenken ist hierbei jedoch, dass $80-85 \%$ der Met primär inoperabel sind [Poston et al. 2008].

Für die Zukunft ist deshalb unbedingt erforderlich, Möglichkeiten zu finden, um Patienten mit einem hohen Risiko für die Entwicklung von Met möglichst frühzeitig zu identifizieren, um diese gegebenenfalls noch kurativ behandeln zu können. Ideal hierfür wären Prognosefaktoren, mit deren Hilfe man Patienten mit einem hohen Risiko für die Entstehung von Met schon vor der eigentlichen Metastasierung bzw. in einem sehr frühen Stadium detektieren könnte und die Metastasierung , zum Beispiel mit der lokalen Instillation von Chemotherapeutika bzw. mit einer kurativen Operation zu verhindern bzw. aufzuhalten wüsste.

In dieser Arbeit wurden insgesamt 34 Primärtumoren (PT) und 102 Met mit Hilfe der CGH untersucht. Im Kollektiv befanden sich insgesamt 93 Patienten, darunter waren 25 Patienten, bei denen wir sowohl den PT, als auch die korrespondierenden Met $(n=29)$ untersuchen konnten. Die Patienten unseres Kollektives entwickelten im Median 19,6 Monate nach OP des PT Met. In dieser Hinsicht unterscheiden sich die Patienten unseres Kollektivs nicht von Patienten anderer Kollektive [Paschos und Bird 2008]. 
Das Ziel der Arbeit ist es herauszufinden, ob weitere, im Vergleich zur bestehenden Literatur, chromosomale Aberrationen KRK und der korrespondierenden Met gefunden und bestätigt werden können und ob es möglich ist, genetische Aberrationen als Prognosefaktor für das metastatische Potential des PT festzulegen.

\subsection{Bewertung der Methode CGH}

Mit Hilfe der $\mathrm{CGH}$ wurde das Kollektiv retrospektiv auf chromosomale Aberrationen untersucht. Durch die so detektierten Aberrationen können Vermutungen über den Genort von Onkogenen bzw. Tumorsuppressorgenen geäußert werden. Somit kann versucht werden, eine Aussage über die Entwicklung und Progression von Tumoren treffen zu können. Dank der klinischen Angaben konnte versucht werden, prognostische Faktoren auf Grund der gefundenen chromosomalen Aberrationen zu finden und beurteilen zu können. Ein weiterer großer Vorteil der Methode ist, dass archiviertes Material untersucht werden kann und somit große Kollektive auch retrospektiv untersucht werden können [Weiss et al. 1999].

Die Methode eignet sich vor allem für solide Tumoren, die eine große Anzahl an, mitunter sehr komplexen, Aberrationen und unbalancierten Translokationen aufweisen [Kallioniemi A. et al. 1992]. Somit eignen sich KRK und Met als solide Tumoren mit reichlichen, komplexen chromosomalen Aberrationen optimal für diese Methode.

In 11 Fällen konnten keine chromosomalen Aberrationen festgestellt werden, in anderen Fällen wurden die Grenzen von 0,8 bzw. 1,2 nur knapp erreicht, in diesen Fällen wurden die Ergebnisse als trend- Zugewinn bzw. trend- Verlust gekennzeichnet.

Die Sensitivität kann durch Verunreinigung der Probe mit gesunden Zellen bzw.

Entzündungszellen eingeschränkt werden. Es wird gefordert, dass zumindest $50 \%$ der Zellen der untersuchten Probe Tumorzellen sind [Hermsen et al. 1996]. Dafür wurden die histologischen Schnitte zunächst durchgemustert, um den Tumorbereich möglichst genau festzulegen. Nur dieser Bereich wurde aus den Gewebeblöcken für die CGH verwendet. Trotz sorgfältigster Arbeit kann nicht 100\% reines Tumorgewebe garantiert werden, Ein weiterer Nachteil ist, dass der Nachweis von Verlusten bzw. Zugewinnen erst ab einer Grenze von $10 \mathrm{Mb}$ möglich ist, chromosomale Veränderungen in kleineren Bereichen können nicht detektiert werden [Forozan et al. 1997].

Weiterhin kann es zur Verunreinigung durch Salze und Paraffin kommen. Um diese Verunreinigung möglichst gering zu halten wurde die DNS nach der Isolierung mehrfach aufgereinigt. 
Zusammengefasst bleibt die CGH trotz der oben genannten Schwachpunkte eine zuverlässige Methode zum Screening solider Tumoren. Die häufige Anwendung dieser Methode zeigt sich in der zunehmenden Anzahl der Veröffentlichungen und Arbeitsgruppen, die diese Methode verwenden. Die so gefundenen chromosomalen Instabilitäten können mit anderen Methoden auf molekulargenetischer Ebene weiter untersucht werden. Die CGH ermöglicht so in Kombination mit anderen Methoden eine genaue Identifizierung am Tumorprogress beteiligter Gene.

Eine Weiterentwicklung der CGH stellt die array-CGH dar. Mit Hilfe dieser Methode können bereits Veränderungen von wenigen $\mathrm{Kb}-1 \mathrm{Mb}$ detektiert werden. Durch die array-CGH konnte eine Brücke zwischen der zytogenetischen und der molekularen Biologie von Tumoren etabliert werden [Andrieux et al. 2009], welche in Zukunft nicht nur bei der Untersuchung von Tumoren eine effiziente und zuverlässige Methode darstellen wird, sondern u.a. bereits häufig bei der Untersuchung von Instabilitäten der Telomerenregionen bei mentaler Retardierung eingesetzt wird [Shaffer und Bejjani 2006].

\subsection{Diskussion der chromosomalen Aberrationen der 25 PT von 25 Patienten mit PT KRK und korrespondierenden Met}

\subsubsection{Diskussion der Anzahl chromosomaler Aberrationen der 25 PT}

Im Median fanden wir bei den PT 8 Aberrationen. Darunter befanden sich insgesamt im Median 3 Zugewinne und 3 Verluste.

Auffallend ist, dass besonders bei fortgeschrittener lymphogener Metastasierung (N2) eine zunehmende Anzahl an chromosomalen Aberrationen beobachtet werden kann (5 Aberrationen im Median bei N0/N1- vs. 10 Aberrationen bei N2-Stadien). Hierbei haben wir keinen Unterschied zwischen der Anzahl der Zugewinne (Median= 5) und der Anzahl der Verluste (Median= 5) finden können.

Die Meta-Analyse von Diep et al. [Diep et al. 2006] beschrieb vor allem einen Zugewinn von $1 \mathrm{q}$ im Zusammenhang mit Dukes-C Stadien. In dieser Meta-Analyse konnte gezeigt werden, dass mit weiter fortschreitenden Dukes-Stadien vermehrt Zugewinne von 1q, 7p, 8q, 20q sowie Verluste von 4, 8p und $18 \mathrm{zu}$ finden waren [Diep et al. 2006].

\subsubsection{Diskussion der häufigsten chromosomalen Aberrationen der PT}

Die von uns am häufigsten gefundenen Zugewinne waren Zugewinne von 13q und 20q. Die häufigsten Verluste fanden wir bei 18q. Sowohl die Zugewinne von 13q und 20q, als auch 
der Verlust von 18q waren die nach den onkogenetischen Bäumen berechneten frühsten chromosomalen Aberrationen in der Tumorigenese KRK.

Diese Ergebnisse decken sich mit den Ergebnissen einer Meta-Analyse von Diep et al. [Diep et al. 2006]. In dieser Meta-Analyse werden zusätzlich Verluste von 17p und Zugewinne von $20 p$ als früh auftretende Aberrationen der PT deklariert. Bei der Auswertung unserer Ergebnisse und der Berechnung der onkogenetischen Bäume konnten wir Verluste von 17p und Zugewinne von 20p erst relativ spät in der Tumorigenese KRK finden. Häufige gemeinsam auftretende Aberrationen sind Verluste von 18p und 17p, Zugewinne von $8 q$ gemeinsam mit Verlusten von $8 p$ und gemeinsame Verluste von $4 p$ und $4 q$. Verluste von $4 p$ konnten wir jedoch erst spät beobachten. Dies deckt sich mit den Ergebnissen der MetaAnalyse von Diep et al. [Diep et al. 2006], die den Verlust von 4p mit einem Übergang von einem Dukes A-Stadium zu weiter fortgeschrittenen Dukes -Stadien und der Metastasierung der Leber in Verbindung brachten.

\subsection{Diskussion der chromosomalen Aberrationen der korrespondierenden Met ( $n=29)$ von 25 Patienten mit PT KRK}

Bei den korrespondierenden 29 Met von 25 Patienten mit PT KRK konnten im Median ebenfalls 8 chromosomale Aberrationen gefunden werden.

Viele Arbeitsgruppen konnten eine erhöhte Anzahl an genetischen Aberrationen bei den Met finden [Ried et al. 1996, Al-Mulla et al. 1999, Aragane et al. 2001, Diep et al. 2003, Nakao et al. 2001, Paredes-Zaglul et al. 1998, Knosel et al. 2002, Schlegel et al. 1995, Meijer et al. 1998, Nakao et al. 1998, Aust et al. 2000, Rooney et al. 2001], allerdings stammten bei diesen Untersuchungen PT und Met in der Regel nicht von denselben Patienten. Die Arbeitsgruppen, welche PT und korrespondierende Met von denselben Patienten untersuchten, fanden viele gemeinsame chromosomale Aberrationen bei den PT und ihren korrespondierenden Met, selten jedoch waren diese genetisch identisch [Al-Mulla et al. 1999, Korn et al. 1999, Malkhosyan et al. 1998].

Die Berechnung des onkogenetischen Baumes für die 29 korrespondierenden Met der 25 PT KRK ergab, dass Zugewinne von 13q und 20q, sowie ein Verlust von 18q früh in der Tumorigenese der Met auftreten. Verluste von 1p und 18q, sowie Zugewinne von 17q konnten von uns erst spät in der Tumorigenese der Met gefunden werden. Interessanterweise beschrieben Diep et al. in ihrer Meta-Analyse 2006 Verluste von 17p, 18 und $22 q$ sowie Zugewinne von 8q, 13q und 20 als frühe chromosomale Aberrationen sowohl von PT als auch von Met KRK [Diep et al. 2006]. Zu beachten ist hierbei jedoch, dass es sich in dieser Metaanalyse nicht unbedingt um korrespondierende PT- Met-Paare handelt. 
Bestätigen können wir hierbei den Verlust von 17p, welcher bei uns jedoch vor allem bei den PT auffiel und nicht unbedingt als frühe Veränderung von PT KRK zu sehen war. Verluste von $18 p$ und $18 q$ konnten von uns auch sowohl bei den PT, als auch bei den Met gefunden werden. Exakterweise können wir jedoch nach Berechnung der onkogenetischen Bäume nur den Verlust von $18 q$ als frühe chromosomale Aberration bezeichnen, da Verluste von $18 p$ eher später in der Tumorigenese sowohl der PT als auch der Met auftraten. Verluste von 22q waren bei den von uns untersuchten PT und Met nicht besonders auffällig gewesen. Zugewinne von $8 q$ konnten wir auch sowohl bei den PT als auch den Met finden. Nach Berechnung der onkogenetischen Bäume zeigte sich dieser Zugewinn früh, nicht aber unbedingt als frühstes Ereignis der Tumorigenese der PT und der korrespondierenden Met. Zugewinne von 13q und 20q konnten von uns auch als sehr frühe Ereignisse in der Tumorigenese der PT und der korrespondierenden Met gefunden werden; Zugewinne von $20 p$ zeigten sich nach Berechnung der onkogenetischen Bäume als mittel-frühe Ereignisse. Weiterhin fiel auf, dass Zugewinne von $8 q$ häufig gemeinsam mit Verlusten von $8 p$ auftraten. Weitere häufig gemeinsam auftretende Veränderungen waren Zugewinne von $7 p$ und $7 q$ und Verluste von $18 p$ und $18 q$.

Des Weiteren beschrieben Diep et al. in ihrer Meta-Analyse von 2006 Verluste von 4p und $8 p$, sowie Zugewinne von $7 p$ und $17 q$ und brachten diese mit einer Progression von PT KRK zu metastasierenden Tumoren in Verbindung [Diep et al. 2006]. Wir konnten Verluste von 4p in einem späten Stadium der Tumorigenese der PT bestätigen, Verluste von $8 p$ und Zugewinne von $7 p$ fanden wir mittel- spät in der Tumorigenese der PT und korrespondierenden Met, Zugewinne von 17q fanden wir als späte Aberration der Met. Zusammengefasst sprechen diese Ergebnisse durchaus dafür, dass die oben beschriebenen chromosomalen Aberrationen eine wichtige Rolle in der Metastasierung KRK in die Leber spielen.

Verluste von 14q und 17q, sowie Zugewinne von 1q, 9p, 11, 12p, 19 und X wurden von Diep et al. mit einer Etablierung der Met in Verbindung gebracht [Diep et al. 2006]. Besonders auffallend ist hierbei, dass wir eine Zugewinn von $17 q$ in späten Stadien der Tumorigenese der Met finden konnten.

Die häufigsten gemeinsamen Zugewinne der PT und ihrer korrespondierenden Met sind, in dem von uns untersuchten Kollektiv, Zugewinne von 13q und 20q; die häufigsten zusätzlich zu beobachtenden Zugewinne der Met sind Zugewinne von 6p, 7, 12q und 20q.

Dies lässt vermuten, dass Gene, welche sich auf den Chromosomenarmen 13q und 20q befinden, schon recht früh in die Tumorigenese involviert sind, wohingegen Gene auf den Chromosomenarmen 6p, 7, 12q und 20q eine Rolle bei der Aussaat und Etablierung der Met spielen. 
Der häufigste gemeinsame Verlust der PT und ihrer korrespondierenden Met sind Verluste von 18q, die häufigsten zusätzlich bei den Met zu beobachtenden Verluste sind Verluste von $1 p, 4 q, 5 q, 8 p$ und 18 .

Dies lässt vermuten, dass der Verlust von Tumorsuppressorgenen, welche auf Chromosomenarm 18q lokalisiert sind, bereits in früheren Stadien der Tumorigenese eine wichtige Rolle spielen. Gene auf Chromosomenarm 1p, 4q, 5q, 8p, 18p und weitere Gene auf $18 q$ scheinen eine wichtige Rolle bei der Infiltration der Leber mit Met zu spielen. Die Meta-Analyse von Diep et al. [Diep et al. 2006] beschreibt zusätzlich signifikant mehr Zugewinne von 11q bei korrespondierenden Met KRK. Dies fiel bei der Auswertung unserer untersuchten PT mit ihren korrespondierenden Met nicht in diesem Maße auf.

\subsection{Diskussion der chromosomalen Aberrationen der 34 untersuchten PT KRK}

4.5.1 Diskussion der Anzahl chromosomaler Aberrationen der 34 untersuchten PT $\underline{\mathrm{KRK}}$

Bei den 34 untersuchten PT KRK waren es im Median 7,5 chromosomale Aberrationen. Tendenziell stellten wir mehr Zugewinne (im Median 3,5) als Verluste (im Median 2,5) fest. Auffallend war, dass wir sowohl bei den pT2- als auch bei den pT3-Tumoren im Median 8 chromosomale Aberrationen fanden, bei den pT4- Tumoren waren es im Median 6 chromosomale Aberrationen. Es zeigte sich also keine positive Korrelation zwischen dem pT-Stadium der 34 PT KRK und der Anzahl der chromosomalen Aberrationen. Zu beachten ist hierbei jedoch, dass die Mehrzahl $(n=27)$ der von uns untersuchten 34 PT KRK pT3Tumoren waren und die Anzahl der pT2- $(n=5)$ und pT4- $(n=2)$ Tumoren sehr gering war. Sowohl bei den pN0- $(n=10)$ als auch bei den pN1- $(n=12)$ Tumoren fanden wir im Median 5 chromosomale Aberrationen, wohingegen wir bei den pN2 ( $n=12)$-Tumoren im Median 10 chromosomale Aberrationen fanden $(p=0,08)$. Dies lässt eine vermehrte chromosomale Instabilität bei den pN2-Tumoren vermuten.

\subsubsection{Diskussion der häufigsten chromosomalen Aberrationen der 34 untersuchten PT KRK}

Als häufigste Zugewinne bei den 34 PT KRK traten Zugewinne von Chromosom 7 (38\% der 34 PT), 8q (29\% der 34 PT), 13q (68\% der 34 PT), 20p ( $29 \%$ der 34 PT) und 20q ( $74 \%$ der 34 PT) auf. Die häufigsten Verluste waren Verluste von Chromosomenarm $4 p$ (21\% der 34 PT), 4q (32\% der 34 PT), 8p (32\% der 34 PT), 17p (21\% der 34 PT), 18p (24\% der 34 PT) und $18 \mathrm{q}(74 \%$ der $34 \mathrm{PT})$. 
Auch bei der Auswertung des onkogenetischen Baumes der 34 PT KRK konnte gezeigt werden, dass Zugewinne von 13q und 20q, sowie ein Verlust von 18q bereits sehr früh in der Tumorigenese der 34 PT KRK auftritt. Verluste von $4 p$ und 17p traten erst spät in der Tumorigenese der 34 PT auf.

Unsere Ergebnisse decken sich gut mit den Ergebnissen anderer Arbeitsgruppen [Aragane et al. 2001, Diep et al. 2006, Knosel et al. 2004, Lassmann et al. 2006, Liu et al. 2007, Nakao et al. 2001]. Die Arbeitsgruppe von Liu et al. brachte darüber hinaus Zugewinne von 8q23qter, sowie Verluste von 8p und 18q12qter mit fortgeschrittenen Tumorstadien in Verbindung [Liu et al. 2007]. Die Arbeitsgruppe von Aragane et al. fand zusätzlich bei den PT KRK häufiger Zugewinne von 12p, 14q, 16p und 21q [Aragane et al. 2001].

Die Arbeitsgruppe von Nakao et al. beschrieb 2001 zusätzlich häufige Zugewinne von 6q und 9p, sowie Verluste von 22q bei PT KRK. Zu beachten ist jedoch, dass in dieser Arbeit nur 16 PT KRK mit korrespondierenden Met untersucht wurden. Interessant an dieser Arbeit ist, dass 16 PT KRK, welche in die Leber metastasiert haben mit 19 PT KRK verglichen wurden, welche keine Met aufwiesen. Hierbei zeigte sich, dass PT, welche keine Met aufwiesen auch keine Zugewinne der Chromosomenarme $6 q$ und $7 q$ aufwiesen. Des Weiteren fanden sie einen signifikanten Unterschied in der Häufigkeit der Zugewinne der Chromosomenarme 6q, 7q, 8q, 13q und 20q zwischen den PT ohne Met und den in die Leber metastasierenden PT KRK [Nakao et al. 2001]. Knosel et al. fanden 2004 bei Ihrer Studie mit 30 PT KRK und 22 systemische Metastasen (12 Met, 6 Hirnmetastasen, 4 Bauchwandmetastasen sowie 11 Lymphknotenmetastasen mit Hilfe der CGH zusätzlich bei den PT KRK häufige Zugewinne von 9q, 16p und 19, sowie zusätzlich häufige Verluste von 1p, 3p, 6q, 9p, 11q, 14q und 21q [Knosel et al. 2004].

\subsection{Diskussion der chromosomalen Aberrationen aller Met $(n=102)$}

\subsubsection{Diskussion der Anzahl chromosomaler Aberrationen aller Met}

Bei den 102 untersuchten Met fanden wir im Median 9 chromosomale Aberrationen. Tendenziell stellten wir mehr Verluste (im Median 4) als Zugewinne (im Median 3,5) fest. Somit konnten wir bei den Met im Vergleich zu den PT tendenziell eine höhere Anzahl an chromosomalen Aberrationen feststellen (Median= 9 bei den Met vs. Median =7,5 bei den PT). Dies lässt eine verstärkte genetische Instabilität der Met vermuten. Des Weiteren fiel auf, dass bei den Met die Verluste leicht in der Überzahl waren, wohingegen bei den PT Zugewinne in der Überzahl waren. 


\subsubsection{Diskussion der häufigsten chromosomalen Aberrationen der Met}

Die folgende Tabelle zeigt die in der aktuellen Literatur beschriebenen Veränderungen der Met KRK im Vergleich mit den von uns gefundenen Ergebnissen.

Tabelle 4.6.2/1: in der aktuellen Literatur beschriebene Veränderungen bei Met KRK. In rot ist hinzugefügt, bei wieviel \% der untersuchten Met wir diese Veränderung beschreiben konnten.

\section{Zugewinne Verluste}

\begin{tabular}{|c|c|}
\hline 1q [Knosel et al. 2004](24\%) & 1p [Knosel et al. 2004](16\%) \\
\hline $\begin{array}{l}\text { 6p [Al-Mulla et al. 1999, Diep et al. } \\
2003](26 \%)\end{array}$ & 2q [Knosel et al. 2004](5\%) \\
\hline $\begin{array}{l}\text { 7p [Al-Mulla et al. 1999, Knosel et al .2004, } \\
\text { Nakao et al. 2009](45\%) }\end{array}$ & 3 [Knosel et al. 2004] 3p (5\%) \\
\hline 7q [Paredes-Zaglul et al. 1998](39\%) & $\begin{array}{l}4 \text { [Al-Mulla et al. 1999, Knosel et al. 2004] } \\
4 p(29 \%)\end{array}$ \\
\hline 7 [Diep et al. 2003] 7p (45\%) & 4q [Diep et al. 2003](35\%) \\
\hline 8q23-24 [Aragane et al. 2001] & 5q 12-31 [Knosel et al. 2004](23\%) \\
\hline $\begin{array}{l}\text { 8q [Diep et al. 2003, Paredes-Zaglul et al. } \\
\text { 1998, Nakao et al. 2009, Liu et al. } \\
\text { 2007](49\%) }\end{array}$ & $\begin{array}{l}\text { 8p [Diep et al. 2003, Knosel et al. 2004, } \\
\text { Nakao et al. 2009](49\%) }\end{array}$ \\
\hline 11 [Knosel et al. 2004] 11p (4\%) 11q (3\%) & 9p [Knosel et al. 2004](12\%) \\
\hline 12qter [Knosel et al. 2004](6\%) & 10q [Knosel et al. 2004](10\%) \\
\hline 13q [Diep et al. 2003] $(49 \%)$ & 14q [Diep et al. 2006](26\%) \\
\hline 13 [Knosel et al. 2004, Nakao et al. 2009] & $\begin{array}{l}\text { 17p [Diep et al. } 2003, \text { Nakao et al. } \\
2009](23 \%)\end{array}$ \\
\hline 15q21-26 [Aragane et al. 2001](3\%) & $\begin{array}{l}18 \text { [Al-Mulla et al. 1999, Diep et al. 2003] } \\
18 p(32 \%)\end{array}$ \\
\hline $\begin{array}{l}16 \text { [Knosel et al. 2004] 16p (11\%) 16q } \\
(15 \%)\end{array}$ & $\begin{array}{l}\text { 18q 12-23[Aragane et al. 2001, Nakao et } \\
\text { al. 2009, Liu et al. 2007](70\%) }\end{array}$ \\
\hline 17q12-21 [Knosel et al. 2004] & 21q21 [Knosel et al. 2004](11\%) \\
\hline 17q [Al-Mulla et al. 1999](11\%) & 22 [Al-Mulla et al. 1999] 22q (3\%) \\
\hline 19p [Aragane et al. 2001] (1\%) & \\
\hline 19 [Knosel et al. 2004](1\%) & \\
\hline $\begin{array}{l}\text { 20q [Al-Mulla et al. 1999, Aragane et al. } \\
\text { 2001, Korn et al. 1999, Nakao et al. 2001, } \\
\text { Paredes-Zaglul et al. 1998, Nakao et al. }\end{array}$ & \\
\hline
\end{tabular}




\begin{tabular}{|l|l|}
\hline 2009$](83 \%)$ & \\
\hline $20[$ Diep et al. 2003] 20p (26\%) & \\
\hline $\mathbf{2 2 q}[$ Knosel et al. 2004](2\%) & \\
\hline
\end{tabular}

Am häufigsten fanden wir bei den Met Zugewinne von 1q (24\% aller Met), 6p (26\% aller Met), $7 p$ (45\% aller Met), 7q (39\% aller Met), 8q (49\% aller Met), 13q (49\% aller Met) und $20 q$ ( $83 \%$ aller Met). Die häufigsten Verluste fanden wir bei $4 p$ ( $29 \%$ aller Met), $4 q$ ( $35 \%$ aller Met), $5 q$ (23\% aller Met), 8p (49\% aller Met), 14q (26\% aller Met), 17p (23\% aller Met), 18p (32\% aller Met) und 18q (70\% aller Met).

Bei der Auswertung der onkogenetischen Bäume konnte gesehen werden, dass die frühsten Veränderungen Zugewinne von $13 q$ und $20 q$ sowie Verluste von $18 q$ sind. Recht spät hingegen fanden wir Zugewinne von 20p, sowie Verluste von 17p, 5q und 14q. Häufig gemeinsam auftretende Aberrationen sind Verluste von $8 p$ und $17 p$; Zugewinne von $7 p$ und $7 q$; Verluste von $4 p$ und $4 q$; Verluste von $18 p$ und $18 q$ sowie Zugewinne von $20 p$ gemeinsam mit Zugewinnen von 20q.

Dies deckt sich gut mit den Ergebnissen der Meta-Analyse von Diep et al., welche Verluste von $8 p$ und besonders von Chromosom 4 sowie Zugewinne von $7 p$ mit dem Übergang des PT zu Met zeigen konnte. In dieser Meta-Analyse wird zusätzlich noch der Zugewinn von $17 q$ beim Übergang des PT zum metastasierendem Stadium beschrieben. Wir konnten den Zugewinn von $17 q$ jedoch nur bei $11 \%$ der untersuchten Met finden. Diep et al. beschrieben in ihrer Meta-Analyse Verluste von 14q als spätes Ereignis- dies kann auch durch unsere Ergebnisse bestätigt werden. In der Meta-Analyse als spätes Ereignis hervorgehobene Verluste von 17q konnten lediglich bei $3 \%$ der von uns untersuchten Met festgestellt werden. In der oben genannten Meta-Analyse werden weiterhin Zugewinne von 1q, 9p, 11, 12p, 19 und $X$ als späte Ereignisse hervorgehoben [Diep et al. 2006]. Einen Zugewinn von 1q konnte auch bei $24 \%$ der von uns untersuchten Met gefunden werden. Zugewinne von 9p, 11, 12p, 19 und $X$ konnten wir jedoch nur bei einem kleinen Teil der untersuchten Met beobachten.

\subsection{Diskussion ausgewählter chromosomaler Aberrationen in Bezug der jeweiligen Gene und ihrer Funktion}

\subsubsection{Verluste von 3p}

Wir fanden $3 p$-Verluste bei $11 \%$ aller untersuchten Met.

Lassmann et al. beschreiben den Verlust des auf Chromosomenarm 3p lokalisierten Genes RAF1 bei KRK[Lassmann et al. 2007]. Gene der RAF-Familie kodieren für Serin/Threoninkinasen, welche wichtig für den MAPK (mitogen activated protein kinase)- 
Signalweg sind. Dysregulationen in diesem Signalweg führen zu gesteigerter Proliferation [Rohrbeck et al. 2009].

\subsubsection{Verluste von $5 \mathrm{q}$}

Bei $23 \%$ der untersuchten Met fanden wir Verluste von $5 q$.

Auf Chromosomenarm $5 q$ befindet sich der Genort für das Tumorsupressorgen APC, was erklärt warum es bei Verlusten von $5 q$ zur Progression des Tumors und Metastasierung kommt [Lassmann et al. 2007].

\subsubsection{Zugewinne von $7 p$}

Bei $45 \%$ der untersuchten Metastasen fanden wir einen Zugewinn von 7p.

Die Zugewinne von Chromosom 7 und 13 resultieren häufig aus einer Trisomie dieser Chromosomen. Sie scheinen schon früh in der kolorektalen Tumorigenese aufzutreten, vor allem eine Trisomie des Chromosoms 7 ist häufig die einzige chromosomale Veränderung bei kolorektalen Adenomen. Diese Beobachtungen legen die Vermutung nahe, dass die Chromosomen 13 und vor allem 7 in die initiale Tumorigenese involviert sind [Liu et al. 2007, Al-Mulla et al. 2006].

IGFBP1 scheint das Gen zu sein, das durch den Zugewinn von 7p vermehrt exprimiert wird und eine Rolle in der Tumorigenese und Progression KRK und ihrer Met zu spielen scheint. IGFBP1 ist ein insulin-like growth factor bindendes Protein und ist wichtig bei der Regulation des Zellwachstums. Eine vermehrte Expression dieses Genes wird nicht nur bei KRK, sondern auch bei einer Reihe weiterer Tumoren beobachtet [Hansel et al. 2004, Hill et al. 2003]. Lassmann et al. fanden des Weiteren heraus, dass die Gene IL6, CYLN2 und MET auf Chromosom7 bei KRK amplifiziert sind [Lassmann et al. 2007].

\subsubsection{Verluste von 8p}

Wir fanden Verluste von $8 p$ bei $49 \%$ der untersuchten Met. Verluste von $8 p$ werden in der Literatur mit einer Mikroinvasion und einer verkürzten Überlebenszeit in Verbindung gebracht [Halling et al. 1999]. Auch Knosel et al. konnten zeigen, dass Verluste von 8p vor allem bei Lymphknoten- und Lebermetastasen zu finden sind [Knosel et al. 2004]. Liu et al. beschreiben den Verlust von 8p12pter vor allem bei Tumoren im Stadium III/IV und assoziierten 8p-Verluste mit einer schlechteren Prognose des Patienten [Liu et al. 2007]. Sie bestätigen damit die Resultate von Al-Mulla et al., welche Verluste von $8 p$ und 18q mit einem verkürzten krankheitsfreien Intervall assoziierten [Al-Mulla et al. 2006]. 
Cooke et al. identifizierten 2008 das Tumorsuppressorgen ARHGEF10 auf Chromosomenarm 8p als mögliches Tumorsuppressorgen, dessen Verlust mit einer Progression und Metastasierung diverser Tumoren verbunden ist [Cooke et al. 2008].

\subsubsection{Zugewinne von $8 \mathrm{q}$}

Bei $49 \%$ aller untersuchten Met fanden wir Zugewinne von 8q. In der Literatur ist eine Überexpression des Onkogens RAB2 bei KRK beschrieben [Zahraoui et al. 1989]. RAB2 ist auf dem Chromosomenabschnitt 8q21 lokalisiert. Die Funktion von RAB2 bei KRK ist weiterhin nicht vollständig geklärt, bekannt ist lediglich dessen Zugehörigkeit zur RASFamilie. Proteine der RAS-Familie sind im GTP-gebundenen Zustand aktiv, im GDPgebundenen Zustand sind sie inaktiv. Sie haben eine wichtige Funktion bei der Zellproliferation [González-Pérez et al. 2010].

Weiterhin ist der Chromosomenarm 8q der Genort für das Onkogen c-myc. Diesem Onkogen wird auch eine wichtige Rolle bei der Invasion der Lunge durch das kleinzellige Bronchialkarzinom zugeschrieben. Weitere Gene auf Chromosomenarm 8q, die an der Progression KRK mitwirken, sind EXT1 und E2F5 [Lassmann et al. 2007].

\subsubsection{Verluste von $9 p$}

Wir fanden Verluste von $9 p$ bei $12 \%$ der untersuchten Met. $9 p$ beherbergt den Genort für das Tumorsuppressorgen CDKN2A [Lassmann et al. 2007].

\subsubsection{Zugewinne von $13 \mathrm{q}$}

Bei $49 \%$ aller Met fanden wir einen Zugewinn von 13q. Auf Chromosomenarm 13q sind die Onkogene BRCA2 und D13S25 lokalisiert [Lassmann et al. 2007].

\subsubsection{Verluste von $14 \mathrm{q}$}

Wir fanden $14 q-V e r l u s t e$ bei $26 \%$ der untersuchten Met.

Al-Mulla et al. deklarieren 14q-Verluste bereits in frühen Stadien KRK und heben hervor, dass Patienten mit Verlusten zugleich von 4 und 14q mit einer schlechteren Prognose durch metastasierende Rezidive zu rechnen haben [Al-Mulla et al. 2006]. Die Meta-Analyse von Diep et al.[Diep et al. 2006] zeigt, dass dies vor allem den Verlusten von Chromosom 4 zuzurechnen ist. 
Im Rahmen ihrer Arbeiten über squamöszellige Karzinome detektierten Pehlivan et al. verschiedene Tumorsupressorgene auf Chromosomenarm 14q. Dazu zählen die Gene CHES1, BMP4, SAV und PNN [Pehlivan et al. 2008].

\subsubsection{Verluste von $17 p$}

Wir fanden Verluste von $17 p$ bei $23 \%$ der untersuchten Met.

Al-Mulla et al. brachten Deletionen von 17p mit Lymphknotenmetastasen in Verbindung [AlMulla et al. 1999], Nakao et al. assoziierten 17p-Verluste mit Met KRK [Nakao et al. 2001]. Liu et al. beschrieben Verluste von 17p12pter bereits bei $>50 \%$ ihrer untersuchten Tumoren im Stadium I [Liu et al. 2007].

$17 p$ beherbergt den Genort für das Tumorsuppressorgen p53. P53 ist das klassische Tumorsuppressorgen, dessen Verlust bei vielen Tumoren mit einer Progression bzw. einer Verschlechterung der Prognose verbunden ist [Meek et al. 2009]. Weitere wichtige Tumorsuppressorgene wie HIC1 und LLGL haben ihren Genort auf dem Chromosomenarm 17p [Lassmann et al. 2007].

\subsubsection{Verluste von $18 \mathrm{q}$}

Verluste von $18 q$ fanden wir bei $70 \%$ der untersuchten Met. Liu et al. beschreiben den Verlust von 18q12qter vor allem bei Tumoren im Stadium III/IV und brachten diesen Verlust mit Fernmetastasen und somit einer schlechteren Prognose des Patienten in Verbindung [Liu et al. 2007].

Bei 18q findet sich der Genort für das Tumorsuppressorgen DCC, was erklären könnte, warum es beim Verlust von 18q zur Progression des Tumors kommt.

Das Tumorsuppressorgen DCC kodiert einen Netrin-1 Rezeptor. Es handelt sich hierbei um ein transmembranöses Protein welches zur Ig-Superfamilie der Zelladhäsionsmoleküle gehört. Der zytoplasmatische Teil interagiert mit der Tyrosinkinase Src und PTK2. Bei Abwesenheit seiner Liganden induziert das Protein Apoptose. Ein Verlust von DCC wird in der Literatur auch bei diversen anderen Karzinomen, wie dem Ösophaguskarzinom beschrieben [Gryfe et al. 1997, Park et al. 2008].

Ein weiteres Gen, welches sich auf dem Chromosomenarm 18q befindet und dessen Verlust bei KRK beobachtet wird, ist das Gen LAMA3 [Lassmann et al. 2007]. LAMA3 kodiert die $\alpha 3-U n t e r e i n h e i t$ von Laminin 5, welches durch Integrine die Zellverankerung und Mortalität von Epithelzellen steuert [Ryan et al. 1999]. 


\subsubsection{Zugewinne von $20 \mathrm{q}$}

Zugewinne von 20q beobachteten wir bei $83 \%$ aller untersuchten Met.

Das auf dem Chromosomenabschnitt 20q13.12 lokalisierte Gen MYBL2 scheint in die Progression KRK involviert zu sein. MYBL2 ist direkt durch den CDKN2A/CCND/RB/E2F Signalweg reguliert. Die Überexpression dieses Genes werden auch in diversen anderen Tumoren beobachtet [ Bar-Shira et al. 2002, Skotheim et al. 2002, Amatschek et al. 2004]. Im distalen Abschnitt des Chromosomenarms 20q wurden außerdem weitere mögliche Gene identifiziert, die an der Progression und Metastasierung KRK beteiligt sein könnten. Hierzu zählen das cellular apoptosis susceptibility (CAS-)Gen, das BTAK-Gen (ein mutmaßliches Serin/Threonin-Kinase Gen) und das AIB1-Gen (ein Steroid-Rezeptor Koaktivator Gen) [Anzick et al. 1997]. Lassmann et al. beschrieben 2007 die Gene TOP1, AIB2, MYBL2, CAS, PTPN1, STK15, ZNF217 und CYP24 auf Chromosomenarm 20q bei KRK als amplifiziert [Lassmann et al. 2007].

Nakao et al. fanden 2009 mit Hilfe der array-CGH heraus, dass sich dieser Zugewinn vor allem auf die Region 20q11.21 bezieht [Nakao et al. 2009]. Zugewinne von 20q wurden auch in einer Reihe von weiteren Tumoren gefunden. Hierzu zählen Brustkrebs, Ovarialkrebs, Blasenkrebs und Tumoren des Pankreas [Solinas-Toldo et al. 1996, Kallioniemi A et al. 1999, Iwabuchi et al. 1995, Kallioniemi A et al. 1994].

\subsubsection{Verluste von $21 \mathrm{~g}$}

Verluste von $21 \mathrm{q}$ fanden wir bei $11 \%$ der untersuchten Met. Lassmann et al. beschreiben den Verlust des auf Chromosomenarm 21q lokalisierten Tumorsuppressorgens KEN bei KRK [Lassmann et al. 2007].

\subsection{Ausblick}

Die Prognose der Patienten mit KRK hängt in entscheidendem Maße davon ab, ob Met vorhanden sind oder nicht und in welchem Stadium diese detektiert werden. Nur max. 25\% der Patienten mit Met werden in einem kurativ operablen Stadium entdeckt [Paschos et al. 2008].Selbst 60-80\% der Patienten, welche die Met operativ entfernt bekommen konnten entwickeln Rezidive. Der Großteil der Rezidive (85\%) entsteht in den ersten 30 Monaten nach der Resektion [Gonzalez und Figueras 2007]. Neuere Studien zeigen, dass auch Patienten mit primär nicht resektablen Met nach einer neoadjuvanten Chemotherapie, z.B. mit 5-FU/Leukovorin gegebenenfalls in Kombination mit Oxaliplatin und/oder Irinotecan von einer Resektion der Met profitieren können [Adam et al. 2004]. Zusätzlich kann es nötig sein, 
vor der eigentlichen Resektion der Met die Embolisation eines Portalvenenastes durchzuführen, wenn präoperativ das geschätzte Restlebervolumen auf $<30 \%$ geschätzt wird [Adam et al. 2004]. Weiterhin kann es bei manchen Patienten erforderlich sein, die Leberteilresektion mit ablativen Verfahren wie der Radiofrequenz- oder Kryotherapie zu kombinieren [Adam et al. 2004].

Entscheidend ist daher für die Zukunft, frühzeitig die Patienten mit Met bzw. mit einem hohen Risiko für Met zu detektieren, um die Met in einem frühen Stadium zu entdecken und kurativ angehen zu können bzw. der Metastasierung vorzubeugen. Seit Jahren wird aus diesem Grund mit verschiedenen Methoden und von vielen Arbeitsgruppen versucht prognostische Marker für KRK und ihre Met heraus zu finden. In vielen Kliniken, vor allem Universitätskliniken, wird die CGH und neuerdings auch die array-CGH als RoutineUntersuchung für KRK und ihre Met angeboten. Man weiß, dass ein Verlust vor allem von Chromosom 4 mit einer Progression von dem Dukes-Stadium A zu Dukes-Stadien B-D assoziiert ist und Verluste von $8 p$ sowie Zugewinne von $7 p$ und 17q mit der Entwicklung von Met verbunden ist [Diep et al. 2006]. Patienten, welche diese Aberrationen aufweisen, müssen besonders gründlich und engmaschig überwacht werden. Auch Brosens et al. zeigten 2011, dass Patienten, welche ein Rezidiv ihres Kolonkarzinoms erlitten, signifikant mehr Verluste von Chromosom 5, 5, 15q, 17q und 18q aufwiesen, wobei bei den MSSTumoren (microsatellite stable) nur der Verlust von 4q22.1-4q35.2 signifikant mit einem Tumorrezidiv zu assoziieren war [Brosens et al. 2011].

In unserem Kollektiv fanden wir als häufigste zusätzliche Zugewinne der 29 Met von 25 Patienten mit PT KRK vor allem Zugewinne von 6p, 7, 12q und 20q. Die häufigsten zusätzlichen Verluste der Met im Vergleich zu ihren korrespondierenden PT waren Verluste von $1 p, 4 q, 5 q, 8 p$ und 18p. Interessant für die Zukunft wäre, ob sich diese Aberrationen in einem größeren Kollektiv von Patienten mit PT KRK und korrespondierenden Met bestätigen lassen könnten.

Weiterhin interessant wäre es, ein großes Kollektiv von Patienten mit PT KRK und Met zum einen, sowie Patienten mit PT KRK ohne Met zum anderen zu untersuchen, um genauer zu unterscheiden, welche PT in die Leber metastasieren und welche nicht.

Die beteiligten Gene und ihre Bedeutung für die Metastasierung KRK werden in Zukunft, z.B. mittels der array-CGH, noch genauer untersucht werden müssen, um ihre Rolle bei der Metastasierung KRK besser verstehen zu können. 


\section{Zusammenfassung}

Das KRK ist in Deutschland einer der häufigsten malignen Tumoren. Die meisten betroffenen Patienten sterben auf Grund von Metastasen, wobei das am häufigsten von Metastasen betroffene Organ die Leber ist. Da trotz neuer Therapieoptionen die Prognose für Patienten mit Lebermetastasen (Met) schlecht geblieben ist und bei 5-Jahres-Überlebensraten von 35$40 \%$ liegt, bedient man sich zunehmend molekularzytogenetischer Methoden, wie der $\mathrm{CGH}$, um Gene zu identifizieren, mit deren Hilfe das metastatische Potential des Primärtumores (PT) abgeschätzt werden kann bzw. die Met in frühen Stadien detektiert werden können, um die Prognose des Patienten nachhaltig verbessern zu können.

Da sich die meisten KRK über Adenome entwickeln und dieser Prozess im Mittel 10 Jahre dauert, stellt die wichtigste Methode zur Prävention die Koloskopie dar, welche bei Personen ohne weitere Risikofaktoren, zum Beispiel hereditäre Karzinome, ab dem Alter von 50 Jahren in 10-jährigen Abständen durch die Leitlinien empfohlen wird [Schmiegel et al. 2008]. In der vorliegenden Arbeit wurden 34 PT und 102 Met mit Hilfe der CGH auf chromosomale Aberrationen untersucht und mit dem klinischen Verlauf korreliert.

Im untersuchten Kollektiv befanden sich insgesamt 93 Patienten, bei 25 Patienten wurden sowohl der PT als auch die korrespondierenden Met $(n=29)$ untersucht.

Von den 93 Patienten waren 60 (65\%) männlich, 33 (35\%) waren weiblich.

Das durchschnittliche Alter betrug bei den männlichen Patienten 60,4 Jahre, bei den weiblichen Patienten betrug das durchschnittliche Alter 63,6 Jahre.

Im Median entwickelten die 25 Patienten mit PT KRK und korrespondierenden Met nach 19,6 Monaten Met.

Regelmäßig konnten wir die bereits in der Literatur beschriebenen Veränderungen von KRK und den korrespondierenden Met bestätigen.

Die wichtigsten Ergebnisse dieser Arbeit sind:

- $\quad \mathrm{KRK}$, vor allem metastasierende KRK, zeichnen sich durch eine komplexe Ansammlung von chromosomalen Aberrationen aus. Darunter befinden sich vor allem Zugewinne. Eine hohe Anzahl an chromosomalen Aberrationen scheint einen negativen Effekt für die Prognose des Patienten zu haben.

- Zwischen PT und den dazugehörigen Met konnten wir eine hohen Grad an Übereinstimmung finden, sodass dies auf eine klonale Abstammung hinweisend ist.

- Bei den insgesamt 102 untersuchten Met konnten wir eine größere Anzahl an chromosomalen Aberrationen finden, als bei den insgesamt untersuchten PT ( $n=34)$ was auf die höhere genetische Instabilität der Met zurückzuführen sein könnte. 
- Sowohl bei den 25 PT KRK als auch bei den 29 korrespondierenden Met fanden wir insgesamt im Median 8 chromosomale Aberrationen, darunter insgesamt im Median 3 Zugewinne, 3 Verluste und 0 Amplifikationen.

- Die häufigsten gemeinsamen Zugewinne der 25 PT KRK und ihrer 29 korrespondierenden Met waren Zugewinne von 13q und 20, die häufigsten gemeinsamen Verluste waren Verluste von Chromosomenarm 18q.

- Die häufigsten zusätzlichen Zugewinne der 29 korrespondierenden Met waren Zugewinne von $6 p, 7 p, 12 q$ und $20 q$.

- Die häufigsten zusätzlichen Verluste der 29 korrespondierenden Met waren Verluste von $1 p, 4 q, 5 q, 8 p$ und $18 p$.

- Sowohl der onkogenetische Baum der 25 PT KRK als auch der 29 korrespondierenden Met zeigte als früh in der Tumorigenese auftretende Zugewinne von 13q und 20q, sowie Verluste von 18q. Spät in der Tumorigenese der 25 PT KRK auftretende chromosomale Aberrationen waren Verluste von Chromosomenarm $4 p$, $8 p$ und 17p. Spät in der Tumorigenese der 29 korrespondierenden Met auftretende chromosomale Aberrationen waren Zugewinne von Chromosomenarm 17q, sowie Verluste von Chromosomenarm $1 p$ und 18p.

- Bei Auswertung der insgesamt 34 untersuchten PT KRK konnten insgesamt im Median 7,5 chromosomale Aberrationen gefunden werden, darunter im Median 3,5 Zugewinne, 2,5 Verluste und 0 Amplifikationen. Auffallend waren insgesamt bei den 10 pN0-Tumorenim Median 5 chromosomale Aberrationen, bei den 12 pN1-Tumoren im Median 5 chromosomale Aberrationen und bei den 12 pN2-Tumoren im Median 10 chromosomale Aberrationen $(p=0,08)$. Darunter befanden sich insgesamt bei den pN0-Tumoren im Median 4, bei den pN1-Tumoren im Median 3 und bei den pN2Tumoren im Median 5 Zugewinne $(p=0,48)$. Insgesamt waren es im Median bei den pN0-Tumoren 1 Verlust, bei den pN1-Tumoren 2 Verluste und bei den pN2-Tumoren im Median 5 Verluste $(p<0,01)$

- Die häufigsten Zugewinne der 34 untersuchten PT KRK waren Zugewinne von 7, 8q, 13q und 20. Die häufigsten Verluste der 34 PT KRK waren Verluste von 4, 8p, 17p und 18.

- Der onkogenetische Baum der 34 PT KRK unterschied sich nur in einem früher auftretenden Verlust von Chromosomenarm 8p von dem onkogenetischen Baum der 25 PT KRK mit korrespondierenden Met. Somit waren früh auftretende chromosomale Aberrationen der 34 PT KRK Zugewinne von 13q und 20q, sowie Verluste von 18q. Spät auftretende chromosomale Aberrationen waren Verluste der Chromosomenarme $4 p$ und $17 p$. 
- Bei den 102 untersuchten Met KRK fanden wir insgesamt im Median 9 chromosomale Aberrationen, darunter im Median 3,5 Zugewinne, 4 Verluste und 0 Amplifikationen.

- Die häufigsten Zugewinne der 102 Met waren Zugewinne von 1q, 6p, 7, 8q, 13q und 20q. Die häufigsten Verluste waren Verluste von 4, 5q, 8p, 14q, 17p und 18.

- Bei Berechnung des onkogenetischen Baumes der 102 Met zeigten sich als früh in der Tumorigenese auftretende chromosomale Aberrationen Verluste von 18q und Zugewinne von 20q. Spät in der Tumorigenese der 102 Met auftretende chromosomale Aberrationen waren Verluste von 4p, 5q, 14q und 17p.

Diese Arbeit belegt die Komplexität der chromosomalen Aberrationen bei KRK und den dazugehörigen Met. Es konnten zahlreiche in der Literatur beschriebene Aberrationen bestätigt und bekräftigt werden, darüber hinausgehend konnte der prognostische Wert weiterer Aberrationen untersucht und diskutiert werden. Weiterführend verbleibt die genaue Identifikation von Tumorsuppressor- und Onkogenen mit Hilfe weiterer molekulargenetischer Methoden, wie der array-CGH. Weiterhin interessant wäre es, in einem großen Kollektiv die PT KRK, welche metastasieren den PT KRK gegenüberzustellen, welche über einen längeren Zeitraum keine Met entwickelt haben. 


\section{Literaturverzeichnis}

Aarnio M, Mecklin JP, Aaltonen LA, Nyström-Lahti M, Järvinen HJ (1995): Life-time risk of different cancers in hereditary non-polyposis colorectal cancer (HNPCC) syndrome. Int J Cancer, 64(6): p. 430-3.

Adam R, Pascal G, Castaing D, Azoulay D, Delvart V, Paule B, Levi F, Bismuth H (2004): Tumor progression while on chemotherapy: a contraindication to liver resection for multiple colorectal metastases? Ann surg., 240(6):p.1052-64.

Almendingen K, Hofstad B, Trygg K, Hoff G, Hussain A, Vatn MH (2000): Smoking and colorectal adenomas: a case-control study. Eur J Cancer Prev, 9(3): p. 193-203.

Almendingen K, Hofstad B, Trygg K, Hoff G, Hussain A, Vatn M (2001): Current diet and colorectal adenomas: a case-control study including different sets of traditionally chosen control groups. Eur J Cancer Prev, 10(5): p. 395-406.

Al-Mulla F, Keith WN, Pickford IR, Going JJ, Birnie GD (1999): Comparative genomic hybridization analysis of primary colorectal carcinomas and their synchronous metastases. Genes Chromosomes Cancer, 24(4): p. 306-14.

Al-Mulla F, Behbehani Al, Bitar MS, Varadharaj G, Going JJ (2006): Genetic profiling of stage I and II colorectal cancer may predict metastatic relapse. Mod Pathol, 19(5): $p$. 648-58.

Amatschek S, Koenig U, Auer H, Steinlein P, Pacher M, Gruenfelder A, Dekan G, Vogl S, Kubista E, Heider KH, Stratowa C, Schreiber M, Sommergruber W(2004): Tissuewide expression profiling using $c D N A$ subtraction and microarrays to identify tumorspecific genes. Cancer Res, 64(3): p. 844-56.

Andrieux, J and Sheth F (2009): Comparative genomic hybridization array study and its utility in detection of constitutional and acquired anomalies. Indian J Exp Biol, 47(10): p. 779-91.

Anzick SL, Kononen J, Walker RL, Azorsa DO, Tanner MM, Guan XY, Sauter G, Kallioniemi OP, Trent JM, Meltzer PS (1997): AIB1, a steroid receptor coactivator amplified in breast and ovarian cancer. Science, 277(5328): p. 965-8.

Aragane H, Sakakura C, Nakanishi M, Yasuoka R, Fujita Y, Taniguchi H, Hagiwara A, Yamaguchi T, Abe T, Inazawa J, Yamagishi H (2001): Chromosomal aberrations in colorectal cancers and liver metastases analyzed by comparative genomic hybridization. Int J Cancer, 94(5): p. 623-9.

Atkin WS, Morson BC and Cuzick J (1992):,Long-term risk of colorectal cancer after excision of rectosigmoid adenomas. N Engl J Med, 326(10): p. 658-62.

Aust DE, Willenbucher RF, Terdiman JP, Ferrell LD, Chang CG, Moore DH 2nd, MolinaroClark A, Baretton GB, Loehrs U, Waldman FM (2000): Chromosomal alterations in 
ulcerative colitis-related and sporadic colorectal cancers by comparative genomic hybridization. Hum Pathol, 31(1): p. 109-14.

Bakalakos EA, Kim JA, Young DC, Martin EW Jr (1998): Determinants of survival following hepatic resection for metastatic colorectal cancer. World J Surg, 22(4): 399-405.

Bansal $P$ and Sonnenberg A (1996): Risk factors of colorectal cancer in inflammatory bowel disease. Am J Gastroenterol, 91(1): p. 44-8.

Bar-Shira A, Rashi-Elkeles S, Zlochover L, Moyal L, Smorodinsky NI, Seger R, Shiloh Y (2002): ATM-dependent activation of the gene encoding MAP kinase phosphatase 5 by radiomimetic DNA damage. Oncogene, 21(5): p. 849-55.

Beard SM, Holmes M, Price C, Majeed AW (2000): Hepatic resection for colorectal liver metastases: A cost-effectiveness analysis. Ann Surg, 232(6): p. 763-76.

Bernstein CN, Shanahan F, and Weinstein WM (1994): Are we telling patients the truth about surveillance colonoscopy in ulcerative colitis? Lancet, 343(8889): p. 71-4.

Bingham SA, Day NE, Luben R, Ferrari P, Slimani N, Norat T, Clavel-Chapelon F, Kesse E, Nieters A, Boeing $\mathrm{H}$ et al. (2003): Dietary fibre in food and protection against colorectal cancer in the European Prospective Investigation into Cancer and Nutrition (EPIC): an observational study. Lancet, 361(9368): p. 1496-501.

Bird NC., Mangnall D and Majeed AW (2006):, Biology of colorectal liver metastases: A review. J Surg Oncol, 94(1): p. 68-80.

Brigati DJ, Myerson D, Leary JJ, Spalholz B, Travis SZ, Fong CK, Hsiung GD, Ward DC (1983): Detection of viral genomes in cultured cells and paraffin-embedded tissue sections using biotin-labeled hybridization probes. Virology, 126(1): p. 32-50.

Brooker JC, Saunders BP, Shah SG, Thapar CJ, Thomas HJ, Atkin WS, Cardwell CR, Williams CB (2002): Total colonic dye-spray increases the detection of diminutive adenomas during routine colonoscopy: a randomized controlled trial. Gastrointest Endosc, 56(3): p. 333-8.

Brosens RPM, Belt EJTH, Haan JC, Buffart TE, Carvalho B, Grabsch H, Quirke P, Cuesta MA, Engel AF, Ylstra B, Meijer GA (2011) : Deletion of chromosome 4q predicts outcome in stage II colon cancer Patients. Cell Oncol.; 33 : p. 215-223.

Cammà C, Giunta M, Fiorica F, Pagliaro L, Craxì A, Cottone M(2000): Preoperative radiotherapy for resectable rectal cancer: A meta-analysis. JAMA, 284(8): p. 1008-15.

Chao A, Thun MJ, Jacobs EJ, Henley SJ, Rodriguez C, Calle EE (2000): Cigarette smoking and colorectal cancer mortality in the cancer prevention study II. J Natl Cancer Inst, 92(23): p. 1888-96 
Chapman MA, Buckley D, Henson DB, Armitage NC (1998): Preoperative carcinoembryonic antigen is related to tumour stage and long-term survival in colorectal cancer. $\mathrm{Br} \mathrm{J}$ Cancer, 78(10): p. 1346-49.

Cooke SL, Pole JC, Chin SF, Ellis IO, Caldas C, Edwards PA (2008): High-resolution array CGH clarifies events occurring on 8p in carcinogenesis. BMC Cancer, 8: p. 288.

De Cosse JJ, Bülow S, Neale K, Järvinen H, Alm T, Hultcrantz R, Moesgaard F, Costello C(1992): Rectal cancer risk in patients treated for familial adenomatous polyposis. The Leeds Castle Polyposis Group. Br J Surg, 79(12): p. 1372-5.

Deneo-Pellegrini H, Boffetta P, De Stefani E, Ronco A, Brennan P, Mendilaharsu M (2002): Plant foods and differences between colon and rectal cancers. Eur J Cancer Prev, 11(4): p. 369-75.

Diep CB, Parada LA, Teixeira MR, Eknaes M, Nesland JM, Johansson B, Lothe RA (2003): Genetic profiling of colorectal cancer liver metastases by combined comparative genomic hybridization and G-banding analysis. Genes Chromosomes Cancer, 36(2): p. $189-97$.

Diep CB, Kleivi K, Ribeiro FR, Teixeira MR, Lindgjaerde OC, Lothe RA (2006): The order of genetic events associated with colorectal cancer progression inferred from metaanalysis of copy number changes. Genes Chromosomes Cancer, 45(1): p. 31-41.

Duffy MJ (2001): Carcinoembryonic antigen as a marker for colorectal cancer: is it clinically useful? Clin Chem, 47(4): p. 624-30.

Eaden J, Abrams K, Ekbom A, Jackson E, Mayberry J(2000): Colorectal cancer prevention in ulcerative colitis: a case-control study. Aliment Pharmacol Ther, 14(2): p. 145-53.

Evans RC, Fear S, Ashby D, Hackett A, Williams E, Van Der Vliet M, Dunstan FD, Rhodes $J M$ (2002): Diet and colorectal cancer: an investigation of the lectin/galactose hypothesis. Gastroenterology, 122(7): p. 1784-92.

Fearon ER and Vogelstein B (1990): A genetic model for colorectal tumorigenesis. Cell, 61(5): p. 759-67.

Fidler IJ and Radinsky R (1990): Genetic control of cancer metastasis. J Natl Cancer Inst, 82(3): p. 166-8.

Forozan F, Karhu R, Kononen J, Kallioniemi A, Kallioniemi OP (1997): Genome screening by comparative genomic hybridization. Trends Genet, 13(10): p. 405-9.

Foulkes WD (1995): A tale of four syndromes: familial adenomatous polyposis, Gardner syndrome, attenuated APC and Turcot syndrome. QJM, 88(12): p. 853-63.

Franceschi S. and La Vecchia C (1998): Oral contraceptives and colorectal tumors. A review of epidemiologic studies. Contraception, 58(6): p. 335-43. 
Francini G, Petrioli R, Lorenzini L, Mancini S, Armenio S, Tanzini G, Marsili S, Aquino A, Marzocca G, Civitelli S et al. (1994): Folinic acid and 5-fluorouracil as adjuvant chemotherapy in colon cancer. Gastroenterology, 106(4): p. 899-906.

Friedenreich CM and Orenstein MR (2002): Physical activity and cancer prevention: etiologic evidence and biological mechanisms. J Nutr, 132(11 Suppl): p. 3456S-3464S.

Fung T, Hu FB, Fuchs C, Giovannucci E, Hunter DJ, Stampfer MJ, Colditz GA, Willett WC (2003): Major dietary patterns and the risk of colorectal cancer in women. Arch Intern Med, 163(3): p. 309-14.

Gayowski TJ, Iwatsuki S, Madariaga JR, Selby R, Todo S, Irish W, Starzl TE (1994): Experience in hepatic resection for metastatic colorectal cancer: Analysis of clinical and pathologic risk factors. Surg, 116(4): 703-11.

Ghadirian P, Lacroix A, Maisonneuve P, Perret C, Potvin C, Gravel D, Bernard D, Boyle P (1997): Nutritional factors and colon carcinoma: a case-control study involving French Canadians in Montreal, Quebec, Canada. Cancer, 80(5): p. 858-64.

Giacosa A, Franceschi S, La Vecchia C, Favero A, Andreatta R (1999): Energy intake, overweight, physical exercise and colorectal cancer risk. Eur J Cancer Prev,. 8 Suppl 1: $p$. S53-60.

Giardiello FM, Brensinger JD, Tersmette AC, Goodman SN, Petersen GM, Booker SV, CruzCorrea M, Offerhaus JA (2000): Very high risk of cancer in familial Peutz-Jeghers syndrome. Gastroenterology, 119(6): p. 1447-53.

Giovannucci $E$ (2001): An updated review of the epidemiological evidence that cigarette smoking increases risk of colorectal cancer. Cancer Epidemiol Biomarkers Prev,. 10(7): p. 725-31.

Giovannucci E (2003): Diet, body weight, and colorectal cancer: a summary of the epidemiologic evidence. J Womens Health (Larchmt), 12(2): p. 173-82.

Goldstein NS, Sanford W, Coffey M, Layfield LJ (1996): Lymph node recovery from colorectal resection specimens removed for adenocarcinoma. Trends over time and a recommendation for a minimum number of lymph nodes to be recovered. Am J Clin Pathol, 106(2): p. 209-16.

Gonzalez HD, Figueras J (2007): Practical questions in liver metastases of colorectal cancer: general principles of treatment. HPB, 9: 251-58.

González-Pérez V, Reiner DJ, Alan JK, Mitchell C, Edwards LJ, Khazak V, Der CJ, Cox AD (2010): Genetic and functional characterization of putative Ras/Raf interaction inhibitors in C. elegans and mammalian cells. J Mol Signal, 5(1): p. 2.

Gryfe R, Swallow C, Bapat B, Redston M, Gallinger S, Couture J (1997): Molecular biology of colorectal cancer. Curr Probl Cancer, 21(5): p. 233-300. 
Guillem JG, Bastar AL, Ng J, Huhn JL, Cohen AM (1996): Clustering of colorectal cancer in families of probands under 40 years of age. Dis Colon Rectum, 1996. 39(9): p. 10047.

Guillem JG, Forde KA, Treat MR, Neugut AI, O'Toole KM, Diamond BE (1992): Colonoscopic screening for neoplasms in asymptomatic first-degree relatives of colon cancer patients. A controlled, prospective study. Dis Colon Rectum, 35(6): p. 523-29.

Halling KC, French AJ, McDonnell SK, Burgart LJ, Schaid DJ, Peterson BJ, Moon-Tasson L, Mahoney MR, Sargent DJ, O'Connell MJ, Witzig TE, Farr GH Jr, Goldberg RM, Thibodeau SN (1999): Microsatellite instability and 8p allelic imbalance in stage B2 and C colorectal cancer. J Natl Cancer Inst, 91(15): p. 1295-303.

Hansel DE, Rahman A, House M, Ashfaq R, Berg K, Yeo CJ, Maitra A(2004): Met protooncogene and insulin-like growth factor binding protein 3 overexpression correlates with metastatic ability in well-differentiated pancreatic endocrine neoplasms. Clin Cancer Res, 10(18 Pt 1): p. 6152-8.

Hermsen MA, Meijer GA, Baak JP, Joenje H, Walboomers JJ (1996): Comparative genomic hybridization: a new tool in cancer pathology. Hum Pathol, 27(4): p. 342-9.

Hentze MW, Kulozik AE, Bartram CR(2000): Molekulare Medizin. De Gruyter: S.20.

Hill AS, MacCallum PK, Young BD, Lillington DM(2003): Molecular cloning of a constitutional $t(7 ; 22)$ translocation associated with risk of hematological malignancy. Genes Chromosomes Cancer, 38(3): p. 260-4.

Hurlstone DP, Sanders DS, Lobo AJ, McAlindon ME, Cross SS (2005)a: Indigo carmineassisted high-magnification chromoscopic colonoscopy for the detection and characterisation of intraepithelial neoplasia in ulcerative colitis: a prospective evaluation. Endoscopy, 37(12): p. 1186-92.

Hurlstone DP, Karajeh M, Cross SS, McAlindon ME, Brown S, Hunter MD, Sanders DS (2005)b: The role of high-magnification-chromoscopic colonoscopy in hereditary nonpolyposis colorectal cancer screening: a prospective "back-to-back" endoscopic study. Am J Gastroenterol, 100(10): p. 2167-73.

Iwabuchi H, Sakamoto M, Sakunaga H, Ma YY, Carcangiu ML, Pinkel D, Yang-Feng TL, Gray JW (1995): Genetic analysis of benign, low-grade, and high-grade ovarian tumors. Cancer Res, 55(24): p. 6172-80.

Jemal A, Thomas A, Murray T, Thun M (2002): Cancer statistics, 2002. CA Cancer J Clin, 52(1): p. 23-47.

Johns LE and Houlston RS (2001): A systematic review and meta-analysis of familial colorectal cancer risk. Am J Gastroenterol, 96(10): p. 2992-3003. 
Kallioniemi A, Kallioniemi OP, Sudar D, Rutovitz D, Gray JW, Waldman F, Pinkel D (1992): Comparative genomic hybridization for molecular cytogenetic analysis of solid tumors. Science, 258(5083): p. 818-21.

Kallioniemi A, Kallioniemi OP, Piper J, Tanner M, Stokke T, Chen L, Smith HS, Pinkel D, Gray JW, Waldman FM (1994): Detection and mapping of amplified DNA sequences in breast cancer by comparative genomic hybridization. Proc Natl Acad Sci U S A, 91(6): p. 2156-60.

Kallioniemi A, Kallioniemi OP, Citro G, Sauter G, DeVries S, Kerschmann R, Caroll P, Waldman $F$ (1999): Identification of gains and losses of DNA sequences in primary bladder cancer by comparative genomic hybridization. Genes Chromosomes Cancer, 12(3): p. 213-9

Kallioniemi OP, Kallioniemi A, Piper J, Isola J, Waldman FM, Gray JW, Pinkel D (1994): Optimizing comparative genomic hybridization for analysis of DNA sequence copy number changes in solid tumors. Genes Chromosomes Cancer, 10(4): p. 231-43.

Kelly RB, Cozzarelli NR, Deutscher MP, Lehman IR, Kornberg A (1970): Enzymatic synthesis of deoxyribonucleic acid. XXXII. Replication of duplex deoxyribonucleic acid by polymerase at a single strand break. J Biol Chem, 245(1): p. 39-45.

Kiesslich R, von Bergh M, Hahn M, Hermann G, Jung M (2001): Chromoendoscopy with indigocarmine improves the detection of adenomatous and nonadenomatous lesions in the colon. Endoscopy, 33(12): p. 1001-6

Kiesslich R, Fritsch J, Holtmann M, Koehler HH, Stolte M, Kanzler S, Nafe B, Jung M, Galle $P R$, Neurath MF (2003): Methylene blue-aided chromoendoscopy for the detection of intraepithelial neoplasia and colon cancer in ulcerative colitis. Gastroenterology, 124(4): p. 880-8.

Knosel T, Petersen S, Schwabe H, Schlüns K, Stein U, Schlag PM, Dietel M, Petersen I (2002): Incidence of chromosomal imbalances in advanced colorectal carcinomas and their metastases. Virchows Arch, 440(2): p. 187-94.

Knosel T, Schlüns K, Stein U, Schwabe H, Schlag PM, Dietel M, Petersen I (2004): Chromosomal alterations during lymphatic and liver metastasis formation of colorectal cancer. Neoplasia, 6(1): p. 23-8.

Konings EJ, Goldbohm RA, Brants HA, Saris WH, van den Brandt PA (2002): Intake of dietary folate vitamers and risk of colorectal carcinoma: results from The Netherlands Cohort Study. Cancer, 95(7): p. 1421-33.

Korn WM, Yasutake T, Kuo WL, Warren RS, Collins C, Tomita M, Gray J, Waldman FM (1999): Chromosome arm 20q gains and other genomic alterations in colorectal 
cancer metastatic to liver, as analyzed by comparative genomic hybridization and fluorescence in situ hybridization. Genes Chromosomes Cancer, 25(2): p. 82-90. Krook JE, Moertel CG, Gunderson LL, Wieand HS, Collins RT, Beart RW, Kubista TP, Poon MA, Meyers WC, Mailliard JA (1991): Effective surgical adjuvant therapy for high-risk rectal carcinoma. N Engl J Med, 324(11): p. 709-15.

Kruse R, Rütten A, Lamberti C, Hosseiny-Malayeri HR, Wang Y, Ruelfs C, Jungck M, Mathiak M, Ruzicka T, Hartschuh W, Bisceglia M, FriedI W, Propping P(1998): MuirTorre phenotype has a frequency of DNA mismatch-repair-gene mutations similar to that in hereditary nonpolyposis colorectal cancer families defined by the Amsterdam criteria. Am J Hum Genet, 63(1): p. 63-70.

Kudo S, Kashida H, Tamura T, Kogure E, Imai Y, Yamano H, Hart AR (2000): Colonoscopic diagnosis and management of nonpolypoid early colorectal cancer. World J Surg, 24(9): p. 1081-90.

Kudo S, Rubio CA, Teixeira CR, Kashida H, Kogure E (2001): Pit pattern in colorectal neoplasia: endoscopic magnifying view. Endoscopy, 33(4): p. 367-73.

Kune GA, Kune S and Watson LF (1989): The role of heredity in the etiology of large bowel cancer: data from the Melbourne Colorectal Cancer Study. World J Surg, 13(1): $p$. 124-9; discussion 129-31.

Lashner BA, Provencher KS, Seidner DL, Knesebeck A, Brzezinski A (1997): The effect of folic acid supplementation on the risk for cancer or dysplasia in ulcerative colitis. Gastroenterology, 112(1): p. 29-32.

Lassmann S, Weis R, Makowiec F, Roth J, Danciu M, Hopt U, Werner M (2007): Array CGH identifies distinct DNA copy number profiles of oncogenes and tumor suppressor genes in chromosomal- and microsatellite-unstable sporadic colorectal carcinomas. $J$ Mol Med, 2007. 85(3): p. 293-304.

Lee IM (2003): Physical activity and cancer prevention--data from epidemiologic studies. Med Sci Sports Exerc, 35(11): p. 1823-7.

Lichtenstein P, Holm NV, Verkasalo PK, Iliadou A, Kaprio J, Koskenvuo M, Pukkala E, Skytthe A, Hemminki K (2000): Environmental and heritable factors in the causation of cancer--analyses of cohorts of twins from Sweden, Denmark, and Finland. N Engl J Med, 343(2): p. 78-85.

Little CD, Nau MM, Carney DN, Gazdar AF, Minna JD (1983): Amplification and expression of the c-myc oncogene in human lung cancer cell lines. Nature, 306(5939): p. 194-6.

Liu XP, Kawauchi S, Oga A, Sato T, Ikemoto K, Ikeda E, Sasaki K (2007): Chromosomal aberrations detected by comparative genomic hybridization predict outcome in patients with colorectal carcinoma. Oncol Rep, 17(1): p. 261-7. 
Lubin F, Rozen P, Arieli B, Farbstein M, Knaani Y, Bat L, Farbstein H (1997): Nutritional and lifestyle habits and water-fiber interaction in colorectal adenoma etiology. Cancer Epidemiol Biomarkers Prev, 6(2): p. 79-85.

Majumdar SR, Fletcher RH, and Evans AT (1999): How does colorectal cancer present? Symptoms, duration, and clues to location. Am J Gastroenterol, 94(10): p. 3039-45. Malkhosyan S, Yasuda J, Soto JL, Sekiya T, Yokota J, Perucho M (1998): Molecular karyotype (amplotype) of metastatic colorectal cancer by unbiased arbitrarily primed PCR DNA fingerprinting. Proc Natl Acad Sci U S A, 95(17): p. 10170-5.

Meek DW (2009): Tumour suppression by p53: a role for the DNA damage response? Nat Rev Cancer, 9(10): p. 714-23.

Meijer GA, Hermsen MA, Baak JP, van Diest PJ, Meuwissen SG, Beliën JA, Hoovers JM, Joenje H, Snijders PJ, Walboomers JM (1998): Progression from colorectal adenoma to carcinoma is associated with non-random chromosomal gains as detected by comparative genomic hybridisation. J Clin Pathol, 51(12): p. 901-9.

Melville A (1997): On the evidence. Improving outcomes in colorectal cancer. Health Serv J, 107(5583): p. 34-5.

Mertens F, Johansson B, Höglund M, Mitelman F (1997): Chromosomal imbalance maps of malignant solid tumors: a cytogenetic survey of 3185 neoplasms. Cancer Res, 57(13): p. 2765-80

Meterissian S, Steele GD and Thomas $P$ (1993): Human and murine Kupffer cell function may be altered by both intrahepatic and intrasplenic tumor deposits. Clin Exp Metastasis, 11(2): p. 175-82.

Millikan KW, Staren ED and Doolas A (1997): Invasive therapy of metastatic colorectal cancer to the liver. Surg Clin North Am, 77(1): p. 27-48.

Nakao K, Shibusawa M, Tsunoda A, Yoshizawa H, Murakami M, Kusano M, Uesugi N, Sasaki K (1998): Genetic changes in primary colorectal cancer by comparative genomic hybridization. Surg Today, 28(5): p. 567-9.

Nakao K, Shibusawa M, Ishihara A, Yoshizawa H, Tsunoda A, Kusano M, Kurose A, Makita $T$, Sasaki K (2001): Genetic changes in colorectal carcinoma tumors with liver metastases analyzed by comparative genomic hybridization and DNA ploidy. Cancer, 91(4): p. 721-6.

Nakao M, Kawauchi S, Furuya T, Uchiyama T, Adachi J, Okada T, Ikemoto K, Oga A, Sasaki $K$ (2009): Identification of DNA copy number aberrations associated with metastases of colorectal cancer using array CGH profiles. Cancer Genet Cytogenet, 188(2): $p$. 70-6.

Nanda K, Bastian LA, Hasselblad V, Simel DL (1999): Hormone replacement therapy and the risk of colorectal cancer: a meta-analysis. Obstet Gynecol, 93(5 Pt 2): p. 880-8. 
Nelson HD, Humphrey LL, Nygren P, Teutsch SM, Allan JD (2002): Postmenopausal hormone replacement therapy: scientific review. JAMA, 288(7): p. 872-81.

Norat T, Lukanova A, Ferrari P, Riboli E (2002): Meat consumption and colorectal cancer risk: dose-response meta-analysis of epidemiological studies. Int J Cancer, 98(2): $p$. 241-56.

Normen AL, Brants HA, Voorrips LE, Andersson HA, van den Brandt PA, Goldbohm RA (2001): Plant sterol intakes and colorectal cancer risk in the Netherlands Cohort Study on Diet and Cancer. Am J Clin Nutr, 74(1): p. 141-8.

Paredes-Zaglul A, Kang JJ, Essig YP, Mao W, Irby R, Wloch M, Yeatman TJ (1998): Analysis of colorectal cancer by comparative genomic hybridization: evidence for induction of the metastatic phenotype by loss of tumor suppressor genes. Clin Cancer Res, 4(4): p. 879-86.

Park HL, Kim MS, Yamashita K, Westra W, Carvalho AL, Lee J, Jiang WW, Baek JH, Liu J, Osada M, Moon CS, Califano JA, Mori M, Sidransky D (2008): DCC promoter hypermethylation in esophageal squamous cell carcinoma. Int J Cancer, 122(11): $p$. 2498-502.

Paschos KA, Bird N (2008): Current diagnostic and therapeutic approaches for colorectal cancer liver metastasis. Hippokratia, 12(3):132-38.

Pehlivan D, Gunduz E, Gunduz M, Nagatsuka H, Beder LB, Cengiz B, Rivera RS, Fukushima K, Palanduz S, Ozturk S, Yamanaka N, Shimizu K (2008): Loss of heterozygosity at chromosome $14 q$ is associated with poor prognosis in head and neck squamous cell carcinomas. J Cancer Res Clin Oncol, 134(12): p. 1267-76.

Peters U, Sinha R, Chatterjee N, Subar AF, Ziegler RG, Kulldorff M, Bresalier R, Weissfeld JL, Flood A, Schatzkin A, Hayes RB (2003): Dietary fibre and colorectal adenoma in a colorectal cancer early detection programme. Lancet, 361(9368): p. 1491-5.

Pinczowski D, Ekbom A, Baron J, Yuen J, Adami HO (1994): Risk factors for colorectal cancer in patients with ulcerative colitis: a case-control study. Gastroenterology, 107(1): p. 117-20.

Platzer P, Upender MB, Wilson K, Willis J, Lutterbaugh J, Nosrati A, Willson JK, Mack D, Ried T, Markowitz S (2002): Silence of chromosomal amplifications in colon. Cancer. Cancer Res, 62(4): p. 1134-8.

Poston GJ, Figueras J, Giuliante F, Nuzzo G, Sobrero AF, Gigot JF, Nordlinger B, Adam R, Gruenberger T, Choti MA, Bilchik AJ, Van Cutsem EJ, Chiang JM, D'Angelica MI (2008): Urgent need for a new staging system in advanced colorectal cancer. J Clin Oncol, 26(29): p. 4828-33. 
Prihartono N, Palmer JR, Louik C, Shapiro S, Rosenberg L (2000): A case-control study of use of postmenopausal female hormone supplements in relation to the risk of large bowel cancer. Cancer Epidemiol Biomarkers Prev, 9(4): p. 443-7.

Reid ME, Marshall JR, Roe D, Lebowitz M, Alberts D, Battacharyya AK, Martinez ME (2003): Smoking exposure as a risk factor for prevalent and recurrent colorectal adenomas. Cancer Epidemiol Biomarkers Prev, 12(10): p. 1006-11.

Ried T, Knutzen R, Steinbeck R, Blegen H, Schröck E, Heselmeyer K, du Manoir S, Auer G (1996): Comparative genomic hybridization reveals a specific pattern of chromosomal gains and losses during the genesis of colorectal tumors. Genes Chromosomes Cancer, 15(4): p. 234-45.

Rohrbeck A, Muller VS and Borlak J (2009): Molecular characterization of lung dysplasia induced by c-Raf-1. PLoS One, 4(5): p. e5637.

Rooney PH, Boonsong A, McKay JA, Marsh S, Stevenson DA, Murray GI, Curran S, Haites NE, Cassidy J, McLeod HL (2001): Colorectal cancer genomics: evidence for multiple genotypes which influence survival. Br J Cancer, 85(10): p. 1492-8.

Ryan MC, Lee K, Miyashita Y, Carter WG (1999): Targeted disruption of the LAMA3 gene in mice reveals abnormalities in survival and late stage differentiation of epithelial cells. J Cell Biol, 145(6): p. 1309-23.

Savelieva E, Belair CD, Newton MA, DeVries S, Gray JW, Waldman F, Reznikoff CA (1997): 20q gain associates with immortalization: 20q13.2 amplification correlates with genome instability in human papillomavirus 16 E7 transformed human uroepithelial cells. Oncogene, 14(5): p. 551-60.

Schlegel J, Stumm G, Scherthan H, Bocker T, Zirngibl H, Rüschoff J, Hofstädter F (1995):

Comparative genomic in situ hybridization of colon carcinomas with replication error. Cancer Res, 55(24): p. 6002-5.

Schmiegel W, Reinacher-Schick A, Arnold D, Graeven U, Heinemann V, Porschen R, Riemann J, Rödel C, Sauer R, Wieser M, Schmitt W, Schmoll HJ, Seufferlein T, Kopp I, Pox C (2008): Update S3-guideline "colorectal cancer" 2008. Z Gastroenterol, 46(8): p. 799-840.

Schweizer D (1976)a: DAPI fluorescence of plant chromosomes prestained with actinomycin D. Exp Cell Res, 102(2): p. 408-13.

Schweizer D (1976)b: Reverse fluorescent chromosome banding with chromomycin and DAPI. Chromosoma, 58(4): p. 307-24.

Schweizer D and Nagl W (1976): Heterochromatin diversity in Cymbidium, and its relationship to differential DNA replication. Exp Cell Res, 98(2): p. 411-23.

Shaffer LG and Tommeruo N (2005): ISCN 2005- An International System for Human Cytogenetic Nomenclature. Karger 
Shaffer LG and Bejjani BA (2006): Medical applications of array CGH and the transformation of clinical cytogenetics. Cytogenet Genome Res, 115(3-4): p. 303-9.

Skotheim RI, Monni O, Mousses S, Fosså SD, Kallioniemi OP, Lothe RA, Kallioniemi A (2002): New insights into testicular germ cell tumorigenesis from gene expression profiling. Cancer Res, 62(8): p. 2359-64.

Solinas-Toldo S, Wallrapp C, Müller-Pillasch F, Bentz M, Gress T, Lichter P (1996): Mapping of chromosomal imbalances in pancreatic carcinoma by comparative genomic hybridization. Cancer Res, 56(16): p. 3803-7.

St John DJ, McDermott FT, Hopper JL, Debney EA, Johnson WR, Hughes ES (1993): Cancer risk in relatives of patients with common colorectal cancer. Ann Intern Med, 118(10): p. 785-90.

Swanson RS, Compton CC, Stewart AK, Bland KI (2003): The prognosis of T3NO colon cancer is dependent on the number of lymph nodes examined. Ann Surg Oncol, 10(1): p. $65-71$

Takahashi T, Kato T, Kodaira S, Koyama Y, Sakabe T, Tominaga T, Hamano K, Yasutomi M, Ogawa N (1996): Prognostic factors of colorectal cancer. Results of multivariate analysis of curative resection cases with or without adjuvant chemotherapy. Am J Clin Oncol, 19 (4): p. 408-15.

Terry MB and Neugut Al (1998): Cigarette smoking and the colorectal adenoma-carcinoma sequence: a hypothesis to explain the paradox. Am J Epidemiol, 147(10): p. 903-10.

Terry MB, Neugut Al, Bostick RM, Sandler RS, Haile RW, Jacobson JS, Fenoglio-Preiser CM, Potter JD (2002): Risk factors for advanced colorectal adenomas: a pooled analysis. Cancer Epidemiol Biomarkers Prev, 11(7): p. 622-9.

Terry P, Giovannucci E, Michels KB, Bergkvist L, Hansen H, Holmberg L, Wolk A (2001): Fruit, vegetables, dietary fiber, and risk of colorectal cancer. J Natl Cancer Inst, 93(7): p. 525-33.

Tiemersma EW, Wark PA, Ocké MC, Bunschoten A, Otten MH, Kok FJ, Kampman E (2003): Alcohol consumption, alcohol dehydrogenase 3 polymorphism, and colorectal adenomas. Cancer Epidemiol Biomarkers Prev, 12(5): p. 419-25.

Tsuda S, Veress B, Tóth E, Fork FT (2002): Flat and depressed colorectal tumours in a southern Swedish population: a prospective chromoendoscopic and histopathological study. Gut, 51(4): p. 550-5.

Umar A, Boland CR, Terdiman JP, Syngal S, de la Chapelle A, Rüschoff J, Fishel R, Lindor NM, Burgart LJ, Hamelin R et al. (2004): Revised Bethesda Guidelines for hereditary nonpolyposis colorectal cancer (Lynch syndrome) and microsatellite instability. J Natl Cancer Inst, 96(4): p. 261-8. 
Vasen HF, Mecklin JP, Khan PM, Lynch HT (1991): The International Collaborative Group on Hereditary Non-Polyposis Colorectal Cancer (ICG-HNPCC). Dis Colon Rectum, 34(5): p. 424-5.

Vasen HF, Watson P, Mecklin JP, Lynch HT (1999): New clinical criteria for hereditary nonpolyposis colorectal cancer (HNPCC, Lynch syndrome) proposed by the International Collaborative group on HNPCC. Gastroenterology, 116(6): p. 1453-6.

von Heydenbreck A, Gunawan B, Füzesi L (2004): Maximum likelihood estimation of oncogenetic tree models. Biostatistics, 5(4): 545-56.

Voskuil DW, Kampman E, Grubben MJ, Kok FJ, Nagengast FM, Vasen HF, van 't Veer $P$ (2002): Meat consumption and meat preparation in relation to colorectal adenomas among sporadic and HNPCC family patients in The Netherlands. Eur J Cancer, 38(17): p. 2300-8.

Wei EK, Giovannucci E, Wu K, Rosner B, Fuchs CS, Willett WC, Colditz GA (2004): Comparison of risk factors for colon and rectal cancer. Int J Cancer, 108(3): p. 43342.

Weiss MM, Hermsen MA, Meijer GA, van Grieken NC, Baak JP, Kuipers EJ, van Diest PJ (1999): Comparative genomic hybridisation. Mol Pathol, 52(5): p. 243-51.

Winawer SJ, Zauber AG, Gerdes H, O'Brien MJ, Gottlieb LS, Sternberg SS, Bond JH, Waye JD, Schapiro M, Panish JF et al. (1996): Risk of colorectal cancer in the families of patients with adenomatous polyps. National Polyp Study Workgroup. N Engl J Med, 334(2): p. 82-7.

Wittekind C, Meyer HJ (2010): TNM Klassifikation maligner Tumoren. 7. Auflage. Wiley-VCH, Weinheim.

Wong JH, Severino R, Honnebier MB, Tom P, Namiki TS (1999): Number of nodes examined and staging accuracy in colorectal carcinoma. J Clin Oncol, 17(9): p. 2896900.

Wu K, Willett WC, Fuchs CS, Colditz GA, Giovannucci EL (2002): Calcium intake and risk of colon cancer in women and men. J Natl Cancer Inst, 94(6): p. 437-46.

Yoon H, Benamouzig R, Little J, François-Collange M, Tomé D (2000): Systematic review of epidemiological studies on meat, dairy products and egg consumption and risk of colorectal adenomas. Eur J Cancer Prev, 9(3): p. 151-64.

Zahraoui A, Touchot N, Chardin P, Tavitian A (1989): The human Rab genes encode a family of GTP-binding proteins related to yeast YPT1 and SEC4 products involved in secretion. J Biol Chem, 264(21): p. 12394-401.

Zhang B, Li X, Nakama H, Zhang X, Wei N, Zhang X, Zhang L (2002): A case-control study on risk of changing food consumption for colorectal cancer. Cancer Invest, 20(4): $p$. 458-63. 


\section{Abbildungs (Abb.)- und Tabellen (Tab.)- verzeichnis}

\section{Einleitung}

Tab. 1.1.4/1: Amsterdam- Kriterien S. 8

Tab. 1.1.4/2: Bethesda- Kriterien S. 9

Tab. 1.1.6/1: Stadieneinteilung KRK nach UICC 2010 S. 11/12

Tab. 1.4/1: Adenom- Karzinom- Sequenz S. 19/20

\section{Material und Methoden}

Tab. 2.1.1/1: Darstellung des Kollektivs S. 23

Tab. 2.1.3/1: mTNM-Stadien nach Gayowski S. 24

Tab. 2.3.5.2/1: Inhaltsstoffe 20x SSC S. 32

Tab. 2.3.5.3/1: Denaturierungslösung S. 32

Abb. 2.3.6.2/1: Bild einer Metaphase nach CGH S. 36

Abb. 2.3.6.2/2: Erstellung eines CGH-Profiles S. 37

Abb. 2.3.6.2/3: Summenideogramm S. 38

\section{Ergebnisse}

Tab. 3.1.1/1: Zusammenhang zwischen dem pT- und dem pN-Stadium der PT von 25 Patienten mit PT KRK und korrespondierenden Met $(n=29)$ S. 40

Abb. 3.1.1/1: Kaplan- Meier-Kurve für das Nichtauftreten von Met nach OP des PT ( $n=25)$ von 25 Patienten mit PT KRK und korrespondierenden Met $(n=29)$ S. 41

Tab. 3.1.1/2: Übersicht über die CGH-Ergebnisse der 25 PT von 25 Patienten mit PT KRK und korrespondierenden Met $(n=29)$ S.42

Tab. 3.1.1/3: Anzahl der chromosomalen Aberrationen bezogen auf das pT-Stadium der 25 PT von 25 Patienten mit PT KRK und korrespondierenden Met $(n=29)$ S.42

Tab. 3.1.1/4: Anzahl der chromosomalen Aberrationen bezogen auf das $\mathrm{pN}$ - Stadium der 25 PT von 25 Patienten mit PT KRK und korrespondierenden Met $(n=29)$ S. 43

Tab. 3.1.1/5: Zusammenhang zwischen der Zeitspanne Operation (OP) des PT bis OP der Met und Anzahl der Aberrationen des PT von 25 Patienten mit PT KRK und korrespondierenden Met ( $n=29)$ S.43/44

Abb. 3.1.1/2: Onkogenetischer Baum der 25 PT von 25 Patienten mit PT KRK und korrespondierenden Met ( $n=29)$ S. 45

Tab. 3.1.2/1: Übersicht über die CGH- Ergebnisse der Met $(n=29)$ der 25 PT KRK S. 46 
Abb. 3.1.2/1: Onkogenetischer Baum der korrespondierenden Met $(n=29)$ der 25 PT KRK S. 47

Tab. 3.1.3/1: Übersicht über die CGH-Ergebnisse der 25 PT KRK und ihrer korrespondierenden Met $(n=29) S .48$

Abb. 3.1.3/1: Zugewinne bei PT mit einer korrespondierenden Met $(n=22) S .48$

Abb. 3.1.3/2: Verluste bei PT mit einer korrespondierenden Met $(n=22)$ S. 49

Abb. 3.1.3/3: Zugewinne der PT mit 2-3 korrespondierenden Met $(n=3)$ S.49

Abb. 3.1.3/4: Verluste der PT mit 2-3 korrespondierenden Met $(n=3)$ S.50

Tab. 3.1.3/2: Gemeinsame Zugewinne der 25 PT KRK und ihrer korrespondierenden Met $(n=29) S .51$

Tab. 3.1.3/3: Gemeinsame Verluste der 25 PT KRK und ihrer korrespondierenden Met $(n=29) S .51$

Tab. 3.1.3/4: Zusätzliche Zugewinne der Met $(n=29)$ von 25 PT KRK S.52

Tab. 3.1.3/5: Zusätzliche Verluste der Met $(n=29)$ von 25 PT KRK S.52

Tab. 3.1.3/6: Auswertung der chromosomalen Aberrationen der 25 PT KRK und der korrespondierenden 29 Met S. 53/54

Tab. 3.2.1/1: Lokalisation der PT von 77 der insgesamt 93 Patienten des Kollektivs S.55

Tab. 3.2.1/2: TNM- Klassifikation der PT von 63 der insgesamt 93 Patienten des Kollektivs S. $55 / 56$

Tab. 3.3.1/1: Zusammenhang zwischen dem pT- und dem pN- Stadium der 34 PT KRK S. 56

Tab. 3.3.1/2: Übersicht über die CGH-Ergebnisse der 34 untersuchten PT KRK S. 57

Tab. 3.3.1/3: Anzahl der chromosomalen Aberrationen bezogen auf das pT-Stadium von 34 PT KRK S. 58

Tab. 3.3.1/4: Anzahl der chromosomalen Aberrationen bezogen auf das $\mathrm{pN}$-Stadium von 34 PT KRK S. 59

Abb. 3.3.1/1: Graphische Darstellung der CGH-Ergebnisse der 34 untersuchten PT KRK S. $59 / 60$

Tab. 3.3.1/5: Übersicht über die chromosomalen Aberrationen der 34 untersuchten PT KRK S. $60 / 61$

Abb. 3.3.1/2: Onkogenetischer Baum der 34 untersuchten PT KRK S. 62

Tab. 3.3.2/1: Übersicht über die CGH-Ergebnisse der102 Met KRK S. 63

Abb. 3.3.2/1: CGH-Ergebnisse der 102 untersuchten Met S.63

Tab. 3.3.2/2: Übersicht über die chromosomalen Aberrationen der 102 untersuchten Met S.64/65

Abb. 3.3.2/2: Onkogenetischer Baum von 102 Met S. 66

\section{Diskussion}


Tab. 4.6.2/1: In der aktuellen Literatur beschriebene Veränderungen bei Met KRK S.74/75 


\section{Danksagung}

An dieser Stelle möchte ich zu allererst Christina Enders danken. Sie hat mir die grundlegenden molekularbiologischen Methoden, welche ich für das Anfertigen dieser Arbeit benötigte, beigebracht, mir jederzeit geduldig meine Fragen beantwortet und ist mir immer mit Hilfe und Rat zur Seite gestanden.

Mein besonderer Dank gilt auch Herrn Dr. Jung für seine geduldige Hilfe bei der statistischen Auswertung der Ergebnisse.

Weiterhin danken möchte ich Dr. Bastian Gunawan vor allem für seine Hilfe bei der Auswertung und Interpretation der CGH- Ergebnisse.

Nicht weniger danken möchte ich Judith Wolff-Salgo und der gesamten Abteilung für Gastroenteropathologie für ihre Unterstützung, sowie die allzeit angenehme Arbeitsatmosphäre.

Mein besonderer Dank gilt natürlich Herrn Prof. Füzesi für die umfassenden Arbeitsmöglichkeiten in seiner Abteilung und die aufmerksam kritische Beurteilung von Fragestellungen, welche die experimentelle und schriftliche Ausarbeitung voran brachte und mir half, Fehlern vorzubeugen oder diese zu korrigieren. 


\section{Lebenslauf}

Am 07. November 1984 bin ich als erste Tochter der Anästhesistin Frau Dr. Hizar Richter und des Lehrers Herrn Norbert Richter in Bad Hersfeld zur Welt gekommen. Ich habe eine Schwester, Nadja Richter, welche am 04. Juni 1986 geboren ist und Jura/Rechtswissenschaften in Konstanz studiert hat.

Die schulische Ausbildung schloss ich am 18. Juni 2004 an der Modellschule Obersberg in Bad Hersfeld mit der „Allgemeinen Hochschulreife“ und der Note 1,5 ab.

Unmittelbar nach dem Abitur verbrachte ich drei Monate in St. Raphael, Südfrankreich. Ich arbeitete dort an der Rezeption von Pierre et Vacances, Cap Esterel, um meine Französischkenntnisse zu vertiefen.

Im Oktober 2004 begann ich das Studium der Humanmedizin an der Ludwigs- MaximilliansUniversität München.

Den 1.Abschnitt der Ärztlichen Prüfung bestand ich im September 2006 mit der Note 3 in München.

Den klinischen Studienabschnitt begann ich im Oktober 2006 am Klinikum Rechts der Isar der Technischen Universität München. Seit April 2007 führte ich das Medizinstudium an der Georg-August-Universität Göttingen fort. Den 2. Abschnitt der Ärztlichen Prüfung und die Approbation erlangte ich im November 2010 mit der Note 1,5 an der Georg- AugustUniversität Göttingen.

Als Famulantin war ich vier Wochen in der Klinik für Anästhesie und Intensivmedizin im Klinikum Bad Hersfeld unter Leitung von Herrn Prof. Fahle tätig. Es folgten 8 Wochen Chirurgie im Rotkreuzklinikum München unter Leitung von Herrn Prof. Schönberg, sowie 2 Wochen Viszeralchirurgie im Klinikum Rechts der Isar, München unter Leitung von Herrn Prof. Friess und 4 Wochen Innere Medizin/Kardiologie im Rotkreuzklinikum München unter Leitung von Herrn Prof. von Arnim.

Ich begann die Dissertationsabeit über „Molekularzytogenetische Veränderungen bei kolorektalen Karzinomen und Lebermetastasen kolorektaler Karzinome“ im Februar 2008 in der Abteilung für Gastroenteropathologie des Universitätsklinikums Göttingen unter Leitung von Herrn Prof. Füzesi. 
Das Praktische Jahr habe ich im August 2009 mit dem Fach Chirurgie begonnen. Ich verbrachte zwei Monate in der Klinik für Thoraxchirurgie unter Leitung von Herrn Prof. Schmid und zwei Monate in der Klinik für Viszerale Chirurgie unter Leitung von Herrn Prof. Candinas am Inselspital Bern. Im Anschluss an das erste Tertial nahm ich am „Basic Science Writing Course" der Schweizerischen Gesellschaft für Chirurgie in Ütliberg teil. Im zweiten Tertial belegte ich Innere Medizin am Universitätsklinikum Göttingen. In dieser Zeit war ich in den Kliniken für Kardiologie/Pneumologie unter Leitung von Herrn Prof. Hasenfuß und Hämatologie/Onkologie unter Leitung von Herrn Prof. Trümper tätig.

Als Wahlfach belegte ich im dritten Tertial Anästhesie unter Leitung von Herrn Prof. Stüber am Inselspital Bern.

Am 01.01.11 begann ich die Facharztausbildung für Viszeralchirurgie an der Universitätsklinik Freiburg unter Leitung von Herrn Prof. Hopt.

Da mein Interesse vor allem der Leber- und Transplantationschirurgie gilt, arbeite ich seit dem 01.01.12 an der Medizinischen Hochschule Hannover in der Abteilung für Viszeral- und Transplantationschirurgie unter Leitung von Herrn Prof. Klempnauer.

Neben dem Studium vertiefte ich meine Sprachkenntnisse in Englisch und Französisch an der Zentralen Einrichtung für Sprachen und Schlüsselqualifikationen in Göttingen. Ich erwarb das UNIcert-Zertifikat Französisch mit der Note "gut“, sowie einen Leistungsnachweis im Fach Englisch, M-II mit der Note 1,8.

In meiner Freizeit mache ich viel Sport und unternehme gerne Reisen. 